\title{
norden
}

Selected Plasticisers and Additional Sweeteners in the Nordic Environment

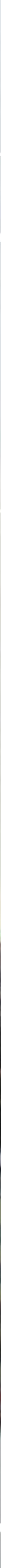



4 norden 



\section{Selected Plasticisers and Additional Sweeteners in the Nordic Environment}

Mikael Remberger, Lennart Kaj, Katarina Hansson, Hanna Andersson and Eva Brorström-Lundén, IVL Swedish Environmental Research Institute, Helene Lunder and Martin Schlabach, NILU, Norwegian Institute for Air Research 
Selected Plasticisers and Additional Sweeteners in the Nordic Environment

Mikael Remberger, Lennart Kaj, Katarina Hansson, Hanna Andersson and Eva Brorström-Lundén IVL Swedish Environmental Research Institute, Helene Lunder and Martin Schlabach, NILU, Norwegian Institute for Air Research

ISBN 978-92-893-2464-9

http://dx.doi.org/10.6027/TN2013-505

TemaNord 2013:505

(C) Nordic Council of Ministers 2013

Layout: Hanne Lebech/NMR

Cover photo: Image Select

Print: Rosendahls-Schultz Grafisk

Copies: 150

Printed in Denmark

This publication has been published with financial support by the Nordic Council of Ministers. However, the contents of this publication do not necessarily reflect the views, policies or recommendations of the Nordic Council of Ministers.

www.norden.org/en/publications

\section{Nordic co-operation}

Nordic co-operation is one of the world's most extensive forms of regional collaboration, involving Denmark, Finland, Iceland, Norway, Sweden, and the Faroe Islands, Greenland, and Åland.

Nordic co-operation has firm traditions in politics, the economy, and culture. It plays an important role in European and international collaboration, and aims at creating a strong Nordic community in a strong Europe.

Nordic co-operation seeks to safeguard Nordic and regional interests and principles in the global community. Common Nordic values help the region solidify its position as one of the world's most innovative and competitive.

Nordic Council of Ministers

Ved Stranden 18

DK-1061 Copenhagen K

Phone (+45) 33960200

www.norden.org 


\section{Content}

Preface

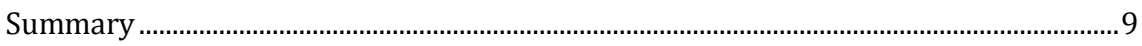

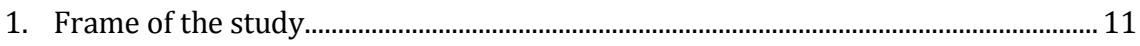

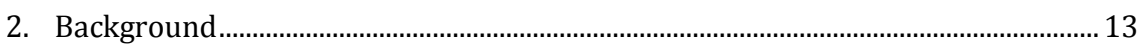

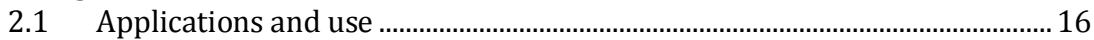

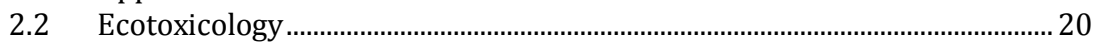

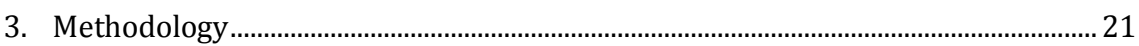

3.1 Sampling sites and sample selection ........................................................... 21

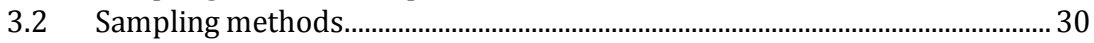

3.3 Analysis methods, plasticisers.............................................................................. 30

3.4 Analysis methods, sweeteners...................................................................... 37

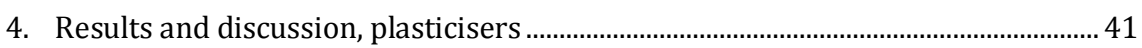

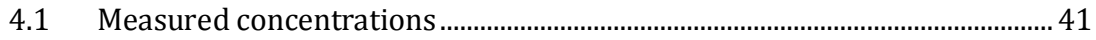

4.2 Initial ecotoxicological assessment................................................................. 51

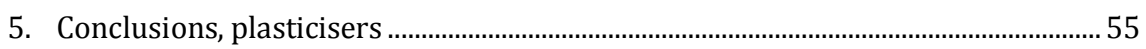

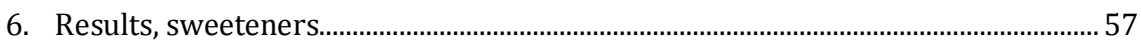

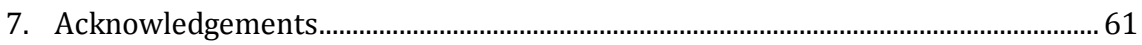

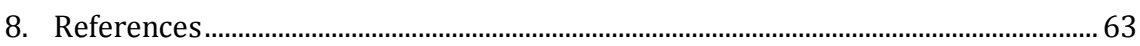

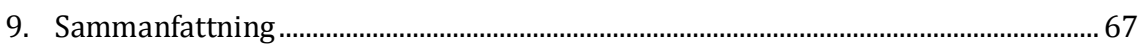

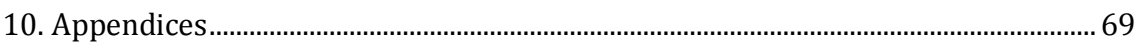

10.1 Analysis of selected plasticizers and additional sweeteners in a

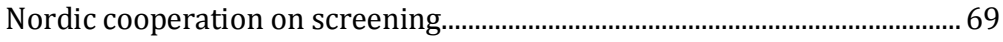

10.2 Appendix 2 Sample list, plasticisers.................................................................. 73

10.3 Appendix 3 Individual results, plasticisers ...................................................... 75

10.4 Appendix 4 Individual results, optional plasticisers........................................ 77

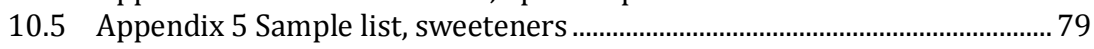

10.6 Appendix 6 Individual results, sweeteners..................................................... 80 



\section{Preface}

The aim of the Nordic environmental screening is to obtain a snapshot of the occurrence of potentially hazardous substances, both in regions most likely to be polluted as well as in some very pristine environments. The focus is on less known, anthropogenic substances and their derivatives, which are either used in high volumes or are likely to be persistent and hazardous to humans and other organisms. In this study the occurrence of selected plasticisers in environmental samples from the Nordic countries has been investigated. This was done to gain experience in environmental screening of this kind of substances and provide a better knowledge of plasticisers in the environment. If the substances subjected to screening are found in significant amounts this may result in further investigations or monitoring on national level and measures to reduce contamination.

Some of the samples were also analyzed for selected sweeteners (aspartam, cyclamate, sucralose). These reults are only briefly presented.

The Nordic screening project is run by a steering group with representatives from the Danish Centre for Environment and Energy, Aarhus University, Denmark, the Finnish Environment Institute, the Icelandic Food and Biotech R\&D, the Environment Agency of the Faroe Islands, the Climate and Pollution agency in Norway and the Swedish Environmental Protection Agency.

The project is financed and supported by the Nordic Council of Ministers through the Nordic Chemicals Group and the Aquatic Ecosystems Group as well as the participating institutions. The chemical analyses have been carried out jointly by IVL Swedish Environmental Research Institute (plasticisers) and NILU Norwegian Institute for Air Research (sweeteners).

The respective participating Nordic countries organised sample selection, collection and transport of samples based on a sample protocol and manuals provided by the analytical laboratories. 



\section{Summary}

The overall aim of this screening study was to investigate the occurrence of selected plasticisers in environmentally related samples from the Nordic countries. Eight phthalates, four adipates and one azelate were analysed for. Measurements were carried out in effluents and sludges from waste water treatment plants, sediments and fish. Usually the participating countries (Denmark, Finland, Faroe Islands, Island, Norway and Sweden) contributed three samples from each sample type. A smaller number of bird eggs were also included. The relatively few samples and sample types are intended to give a "snap shot" of the situation.

For all sample types the phthalates DEHP, DINP and DIDP were most frequently detected and found in the higest concentrations. DBP and BBP were also found frequently but in lower concentrations. The remaining phthalates L79P, DOP and DUP were found occasionally at low concentrations. This can also be said for the adipates DEHA and BOA, while DINA and DBEEQ was not found at all. The azelate DEHZ was found only once in sludge.

In sludge DINP, DEHP and DIDP taken together made up 96-99.7\% of the summed concentration of all measured plasticisers. The highest summed concentration was $260,000 \mu \mathrm{g} / \mathrm{kg} \mathrm{dw}$. As opposed to effluents where DEHP nearly always showed the highest concentration, all sludges were dominated by DINP.

A general observation regarding sediments is that sites in direct vicinity of waste water treatment plants showed increased concentrations of plasticisers.

Concentrations in fish muscle were generally low and quite close to LOQ.

The plasticisers included in the screening may be harmful to the environment. The fact that the concentrations found in effluents and sediments were close to or exceeded PNEC in several cases indicate the need for further studies to assess potential risks. Furthermore, some of the substances were also found in biota.

The effluents and some of the sludges were also analyzed for sweeteners. The results showed that there is a widespread occurrence of the sweeteners cyclamate and sucralose in effluent from WWTPs in all the Nordic countries and that these substances are not profoundly accumulated in sludge. 



\section{Frame of the study}

The occurrence and the environmental risk of chemicals are prioritized issues in several international legislative acts (e.g. the EUs Water framework directive, Registration Evaluation Authorisation of Chemicals (REACH), Stockholm Convention on Persistent Organic Pollutants (POPs) and the Convention on long-range trans-boundary air pollutionLRTAP) and there is a focus on "emerging" chemicals in different research and monitoring programs.

In this screening study the concentrations of the chemicals were determined in a variety of media, collected at different locations and representing different source characteristics, e.g. point sources and dispersed use related to many activities and products. Background samples were also taken. In addition to finding out current levels of the selected chemicals in different matrices the aim was to highlight important transport pathways and to identify current emissions. The results of this screening project may be used to estimate the environmental risk posed by these chemicals to vulnerable Nordic ecosystems.

However, there are limitations and uncertainties in screening studies; measurements of a chemical are carried out in several media at several sites but only a few samples at each site which gives only a "snap shot" of the situation.

The plasticisers included in the screening study are listed in Table 1.1. Abbreviations and CAS number are given for each compound.

The selection of compounds was based on a literature study of plasticisers by Lambert et al. (2010).

\begin{tabular}{lll} 
Table 1.1: Name, abbreviation and CAS-number for the plasticisers included in this study \\
\hline Compound name & Abbreviation & CAS \# \\
\hline Di butyl phthalate & DBP & $84-74-2$ \\
Butyl benzyl phthalate & BBP & $85-68-7$ \\
Di(2-ethylhexyl) phthalate (reference compound) & DEHP & $117-81-7$ \\
Dialkyl(C7-C9) phthalate & L79P & $68,515-41-3$ \\
Di-n-octyl phthalate & DOP & $117-84-0$ \\
Diisononyl phthalate & DINP & $28,553-12-0$ \\
Diisodecyl-phthalate & DIDP & $26,761-40-0$ \\
Diundecyl phthalate & DUP & $3,648-20-2$ \\
Di(2-ethylhexyl) adipate & DEHA & $103-23-1$ \\
Diisononyl adipate & DINA & $33,703-08-1$ \\
Benzyl octyl adipate & BOA & $3,089-55-2$ \\
Di(2-(2-butoxyethoxy)ethyl) adipate & DBEEA & $141-17-3$ \\
Di(2-etylhexyl) azelate & DEHZ & $103-24-2$ \\
\hline
\end{tabular}





\section{Background}

Plasticisers are used to increase the plasticity of a material, especially plastics. The chemical structure of the plasticisers selected for this study are presented in Table 2.1.

Table 2.1: Structure of the substances selected for the study

Compound nam

Structure

CAS \#

Abbreviation

Dibutyl phthalate

84-74-2

DBP

Butyl benzyl phthalate

85-68-7

BBP
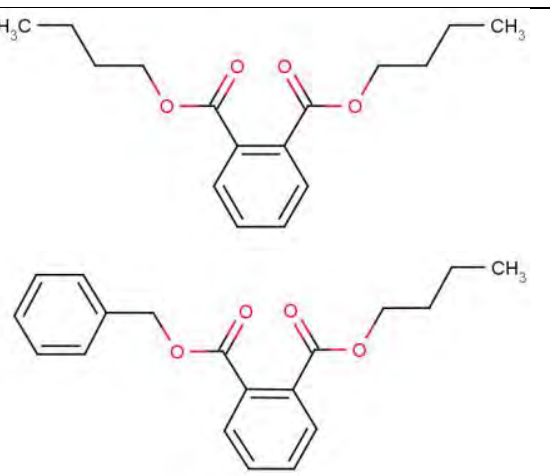

Di(2-ethylhexyl) phthalate

117-81-7

DEHP

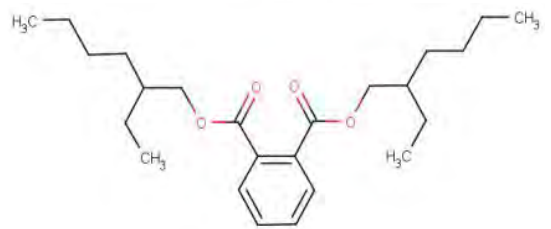

1,2-Benzenedicarboxylic acid, di-

C7-9-branched and linear alkyl

esters

68515-41-3

L79P

Di-n-octyl phthalate

$117-84-0$

DOP

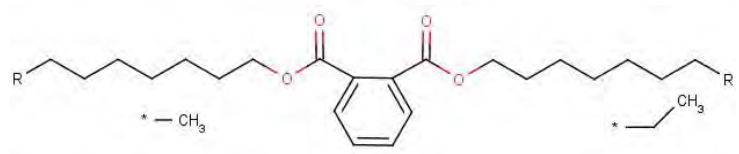

Diisononyl phthalate 28553-12-0

DINP

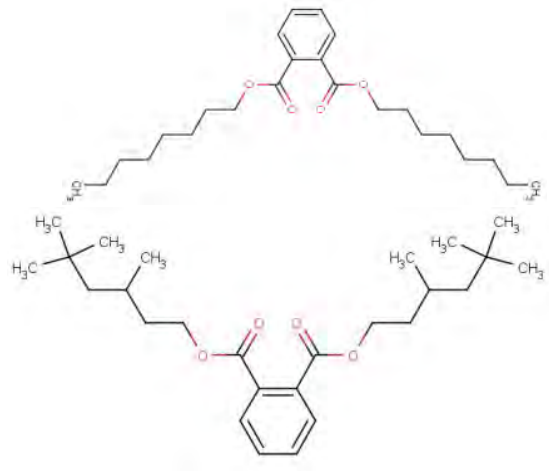




\section{Compound name \\ CAS \#}

Abbreviation

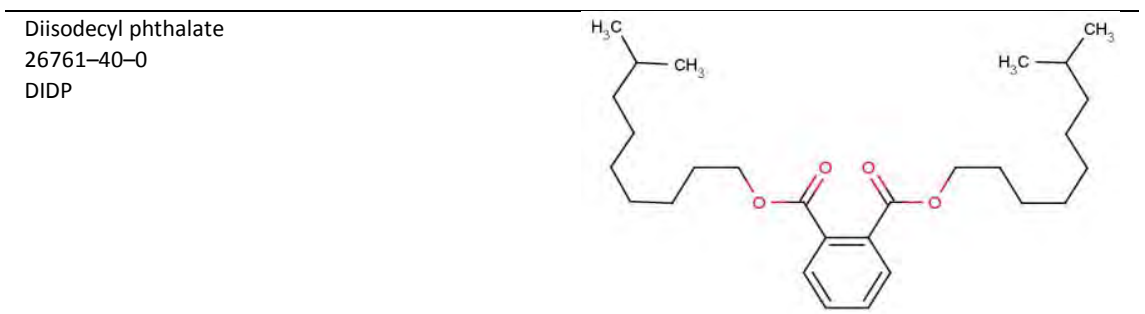

Diundecyl phthalate

3648-20-2

DUP

Di(2-ethylhexyl) adipate

103-23-1

DEHA
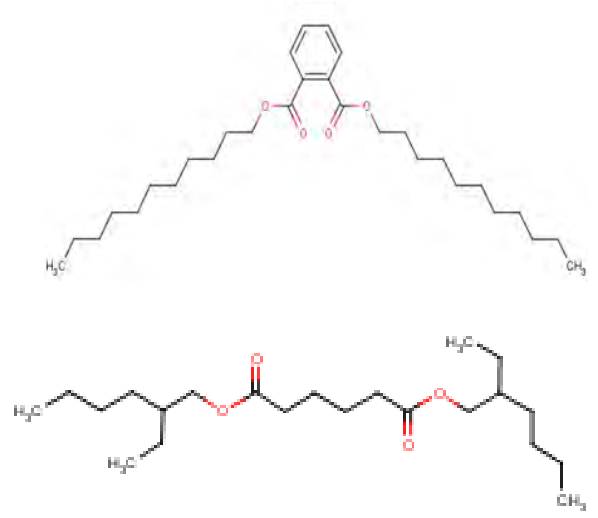

Diisononyl adipate

33703-08-1

DINA

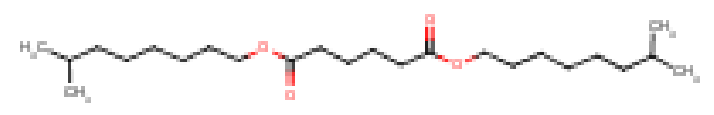

Benzyl octyl adipate

3089-55-2

BOA

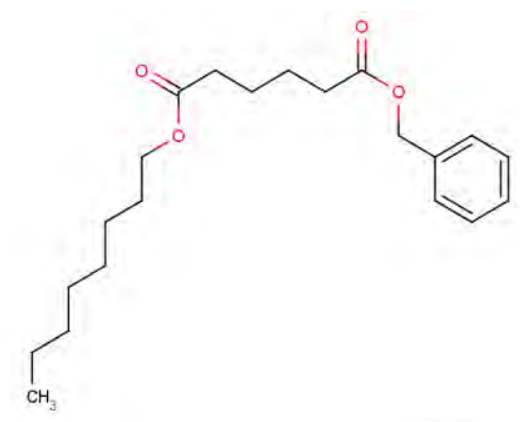

Di(2-(2-butoxyethoxy)ethyl) adipate 141-17-3

DBEEA

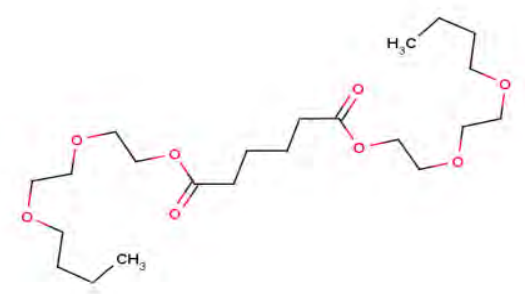

Di(2-ethylhexyl) azelate

103-24-2

DEHZ

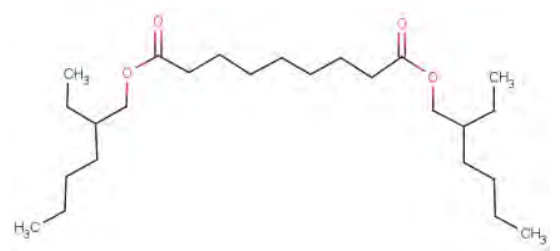


All of the screened plasticisers are hydrophobic with log $\mathrm{K}_{\mathrm{ow}}$ values larger than three and most of the substances have relatively low water solubility (Table 2.2, and more on water solubility below). They may thus be bioaccumulative, Lambert et al. (2010) did also conclude that all but DBEEA were bioaccumulative. Furthermore the vapour pressure of these substances are also relatively low, indicating that losses from water to air is expected to be low.

Table 2.2: Physical-chemical properties of the selected substances. Vapour pressure and water solubility was recalculated to uniform units. Est = estimated, calc=calculated

\begin{tabular}{|c|c|c|c|}
\hline Abbre-viation & logKow & Water solubility & Vapour pressure Ref 1 \\
\hline DBP & $4.57^{\operatorname{Ref} 1}$ & $10 \mathrm{mg} / \mathrm{l}\left(20^{\circ} \mathrm{C}\right)^{\text {Ref } 1}$ & $0.0097+/-0.0033 \mathrm{~Pa}\left(25^{\circ} \mathrm{C}\right)$ \\
\hline BBP & $4.84^{\text {Ref } 1}$ & $2.69 \mathrm{mg} / \mathrm{l}\left(25^{\circ} \mathrm{C}\right)^{\operatorname{Ref} 2}$ & $0.00112 \mathrm{~Pa}\left(20^{\circ} \mathrm{C}\right)$ \\
\hline DEHP & $7.5^{\text {Ref } 1}$ & $\begin{array}{l}0.27 \mathrm{mg} / \mathrm{l}\left(25^{\circ} \mathrm{C}\right)^{\text {Ref } 2} \\
0.003 \mathrm{mg} / \mathrm{I}^{\text {Ref } 5} \\
0.00249 \mathrm{mg} / \mathrm{l}(\text { calc })^{\text {Ref } 6}\end{array}$ & $0.0000189 \mathrm{~Pa}\left(25^{\circ} \mathrm{C}\right)$ \\
\hline L79P & $6.9-8.6^{\text {Ref } 7}$ & $<1 \mathrm{mg} / \mathrm{l}^{\text {Ref } 1}$ & $0.1 \mathrm{~Pa}\left(100^{\circ} \mathrm{C}\right)$ \\
\hline DOP & $8.1^{\text {Ref } 1}$ & $\begin{array}{l}0.022 \mathrm{mg} / \mathrm{l}\left(25^{\circ} \mathrm{C}\right)^{\operatorname{Ref} 1} \\
0.0004-0.0005 \mathrm{mg} / \mathrm{I}^{\text {Ref } 3,4} \\
0.00249 \mathrm{mg} / \mathrm{l}(\text { calc })^{\text {Ref } 6}\end{array}$ & $0.0000133 \mathrm{~Pa}\left(25^{\circ} \mathrm{C}\right)$ \\
\hline DINP & $8.6^{\operatorname{Ref} 6}$ & $\begin{array}{l}0.2 \mathrm{mg} / \mathrm{l}\left(20^{\circ} \mathrm{C}\right)^{\text {Ref } 2} \\
0.00011 \mathrm{mg} / /^{\text {Ref } 3} \\
0.000308(\text { calc })^{\text {Ref } 6}\end{array}$ & $0.000072 \mathrm{~Pa}\left(25^{\circ} \mathrm{C}\right)$ \\
\hline DIDP & $9.46^{\operatorname{Ref} 6}$ & $\begin{array}{l}0.00002 \mathrm{mg} / \mathrm{l}\left(20^{\circ} \mathrm{C}\right)^{\text {Ref } 1} \\
0.00017 \mathrm{mg} / \mathrm{I}^{\text {Ref } 3} \\
0.0000381{\text { (calc })^{\text {Ref } 6}}\end{array}$ & $0.000051 \mathrm{~Pa}\left(25^{\circ} \mathrm{C}\right)$ \\
\hline DUP & $10.33^{\operatorname{Ref} 6}$ & $\begin{array}{l}0.83-1.39 \mathrm{mg} / \mathrm{l}\left(25^{\circ} \mathrm{C}\right)^{\text {Ref } 1} \\
0.00000441 \mathrm{mg} / \mathrm{l}(\text { calc })^{\text {Ref } 6}\end{array}$ & $0.015 \mathrm{~Pa}\left(25^{\circ} \mathrm{C}\right)$ \\
\hline DEHA & $8.1(\text { Est) })^{\text {Ref } 1}$ & $0.78 \mathrm{mg} / \mathrm{l}\left(22^{\circ} \mathrm{C}\right)^{\operatorname{Ref} 1}$ & $0.000113 \mathrm{~Pa}\left(20^{\circ} \mathrm{C}\right)$ \\
\hline DINA & $9.56-10.4^{\text {Ref } 1}$ & $<1 \mathrm{mg} / \mathrm{l}\left(20^{\circ} \mathrm{C}\right)^{\mathrm{Ref}} 1$ & $<10 \mathrm{~Pa}\left(20^{\circ} \mathrm{C}\right)$ \\
\hline BOA & nd & nd & nd \\
\hline DBEEA & $3.24^{\operatorname{Ref} 1}$ & nd & $0.0000131 \mathrm{~Pa}\left(25^{\circ} \mathrm{C}\right)$ \\
\hline DEHZ & $9.6^{\operatorname{Ref} 1}$ & Insoluble in water ${ }^{\text {Ref } 1}$ & $0.000507 \mathrm{~Pa}\left(25^{\circ} \mathrm{C}\right)$ \\
\hline
\end{tabular}

Ref 1: Lambert et al. (2010), in which the orginal references are listed

Ref 2: ChemIDplus Advanced

Ref 3: Letinksi et al. 1999

Ref 4: Ellington 1999

Ref 5: Stales et al. 1997

Ref 6: Cousins and Mackay 2000

Ref 7: CPSC 2010

Precise water solubility measurements for compounds with water solubility $>1 \mathrm{mg} / \mathrm{l}$ can easily be obtained with classic shake-flask experiments. For more hydrophobic plasticisers (e.g. DEHP, DOP, DINP, DIDP, DUP) this technique can generate unreliable results (Stales et al. 1997). The measurement problems are caused by emulsion or micelle for- 
mation leading to overestimation of the true water solubility. Accurate direct measurements can be performed with "slow-stir" or "generatorcolumn" techniques since it avoids the emulsion formation (De Bruijn et al. 1989, Ref 3,4,5 in Table 2.2). The water solubility may also be calculated by the "three-solubility" approach (Cousins and Mackay 2000, ref 6 in Table 2.2). Thus water solubilities cited from different sources can vary considerably. In this case lower values are probably more reliable.

\subsection{Applications and use}

Phthalates (esters of phthalic acid) are the most commonly used plasticisers. The main use is as additive to polyvinyl chloride (PVC). Of the amount produced in Europe $93 \%$ is used for that purpose. Another area of use is in cosmetics (dibutyl phthalate, DBP). In the last ten years there has been a pronounced change in use from lower molecular weight (mainly di(2-ethylhexyl) phthalate, DEHP) to higher molecular weight (diisononyl phthalate DINP, diisodecyl phthalate, DIDP and others) phthalates. The high molecular weight phthalates now represent more than $80 \%$ of the amount beeing produced in Europe (ECPI, 2012). The change in use during the last decade is also evident from data on use of phthalates in the Nordic countries extracted from the SPIN database (SPIN, 2012). Data for DBP, butylbenzyl phthalate (BBP) and DEHP are illustrated in Figure 2.2, for DINP, DIDP, diundecyl phthalate (DUP) and dioctyl phthalate (DOP) in Figure 2.3. For dialkyl(C7-C9) phthalate (L79P) the only data according to SPIN are 753 tonnes for 2000, 454 tonnes for 2001 and 105 tonnes for 2009, all for Sweden. The latest avalible figures (2009), also for adipates and azelates, are illustrated in Table 2.3. The reporting to the SPIN database could vary between countries, and therefore uncertainties could be in the numbers, especially when comparisons are made between countries. It should also be remembered that SPIN lists ingredients in chemical preparations, not in finished consumer articles.

Figure 2.1 Use of plasticisers in the Nordic countries according to SPIN for the year 2009

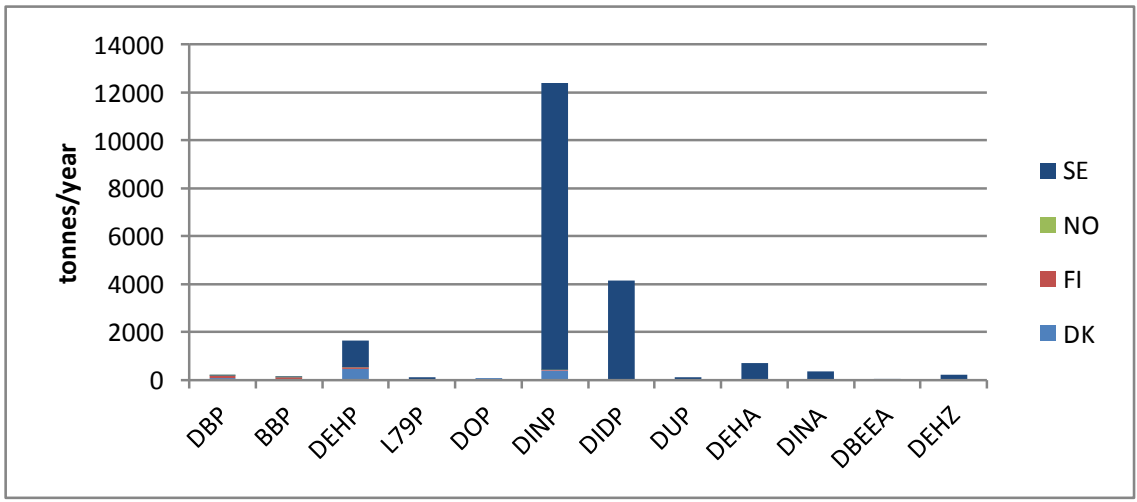


Adipates (esters of adipic acid) are used as specialty plasticisers. In PVC applications, adipates offer enhanced low temperature properties compared to phthalates. It is not uncommon to use adipates in blends with high molecular weight phthalates to attain a desired combination of properties (ECPI, 2012). The use of di(2-ethylhexyl) adipate (DEHA) and diisononyl adipate (DINA) in the Nordic countries extracted from the SPIN database is illustrated in Figure 2.4. There were no data for benzyl octyl adipate (BOA) in the SPIN database.

Figure 2.2 Use in the Nordic countries according to SPIN for DBP, BBP and DEHP for the years 1999-2009. Please note the different $y$-axis scales
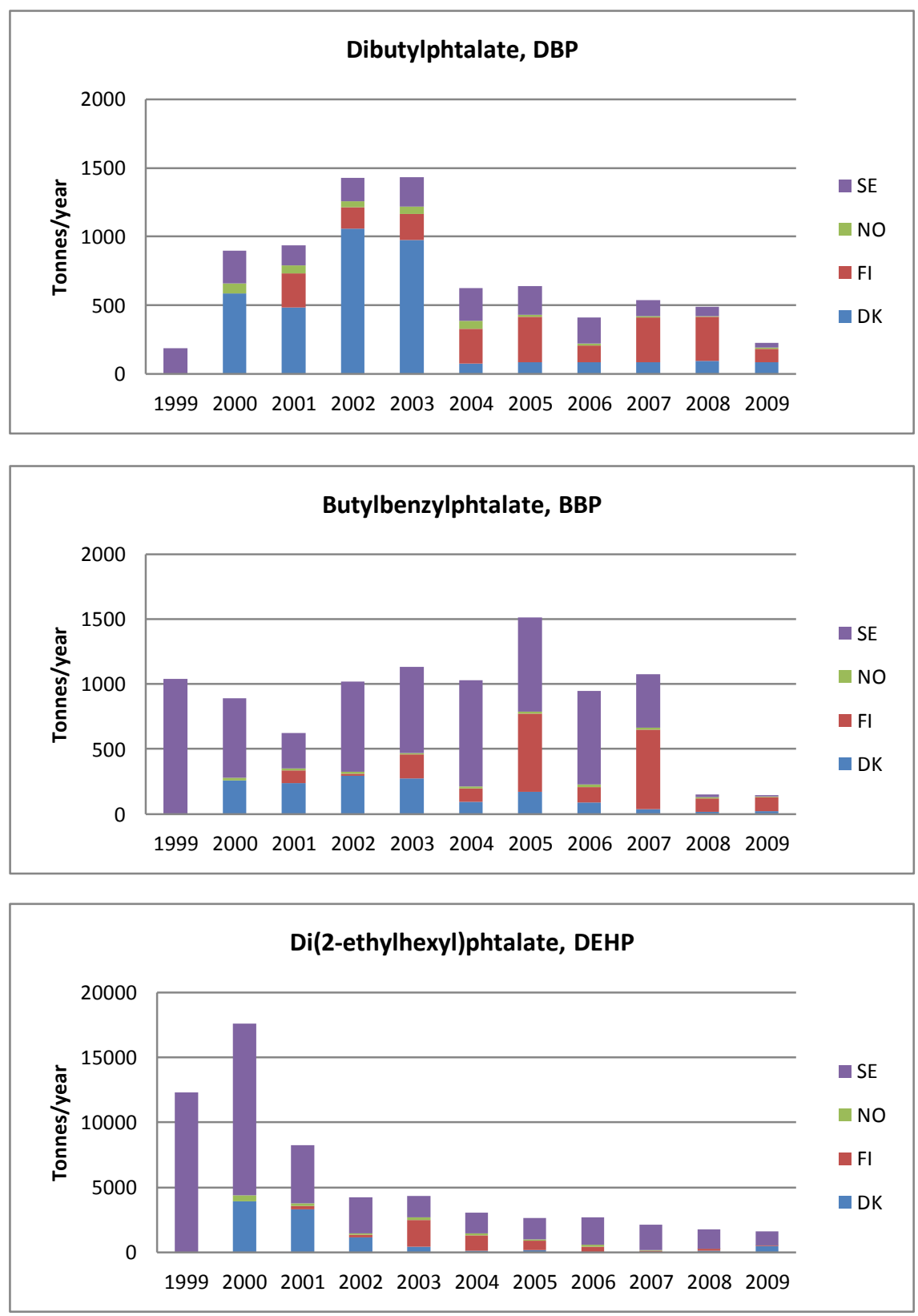
Figure 2.3 Use in the Nordic countries according to SPIN for DINP, DIDP, DUP and DUP for the years 1999-2009. Please note the different y-axis scales
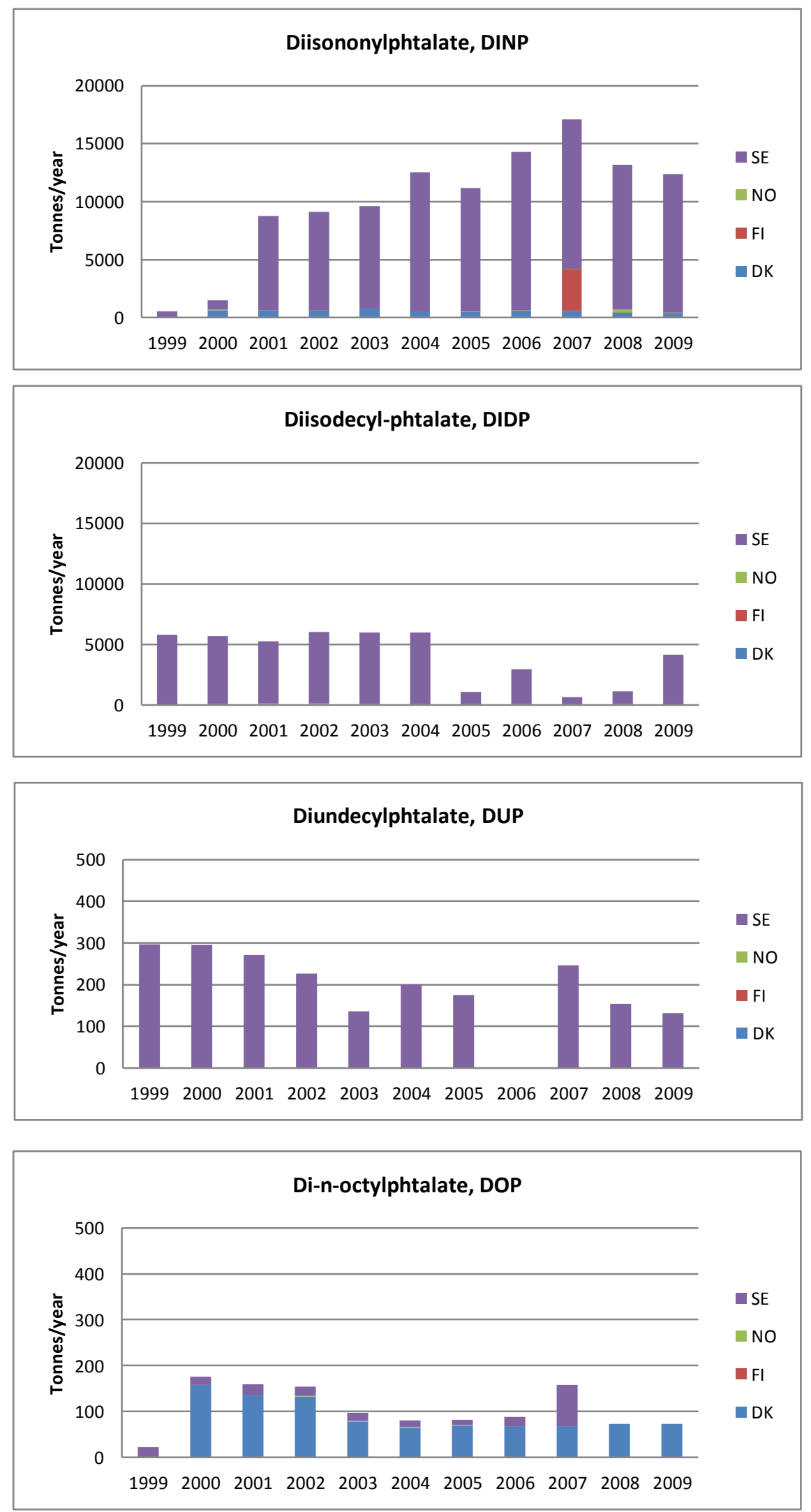
Azelates (esters of azelaic acid) impart low temperature performanc-es superior to adipates. Their use is generally limited to extremely demanding low temperature flexibility specifications (e.g. underground cable sheathing in arctic environments) (ECPI, 2012). The use of di(2ethylhexyl) azalate (DEHZ) in the Nordic countries extracted from the SPIN database is illustrated in Figure 2.4 .

Figure 2.4 Use in the Nordic countries according to SPIN for DOP, DEHA, DINA and DEHZ for the years 1999-2009. Please note the different $y$-axis scales
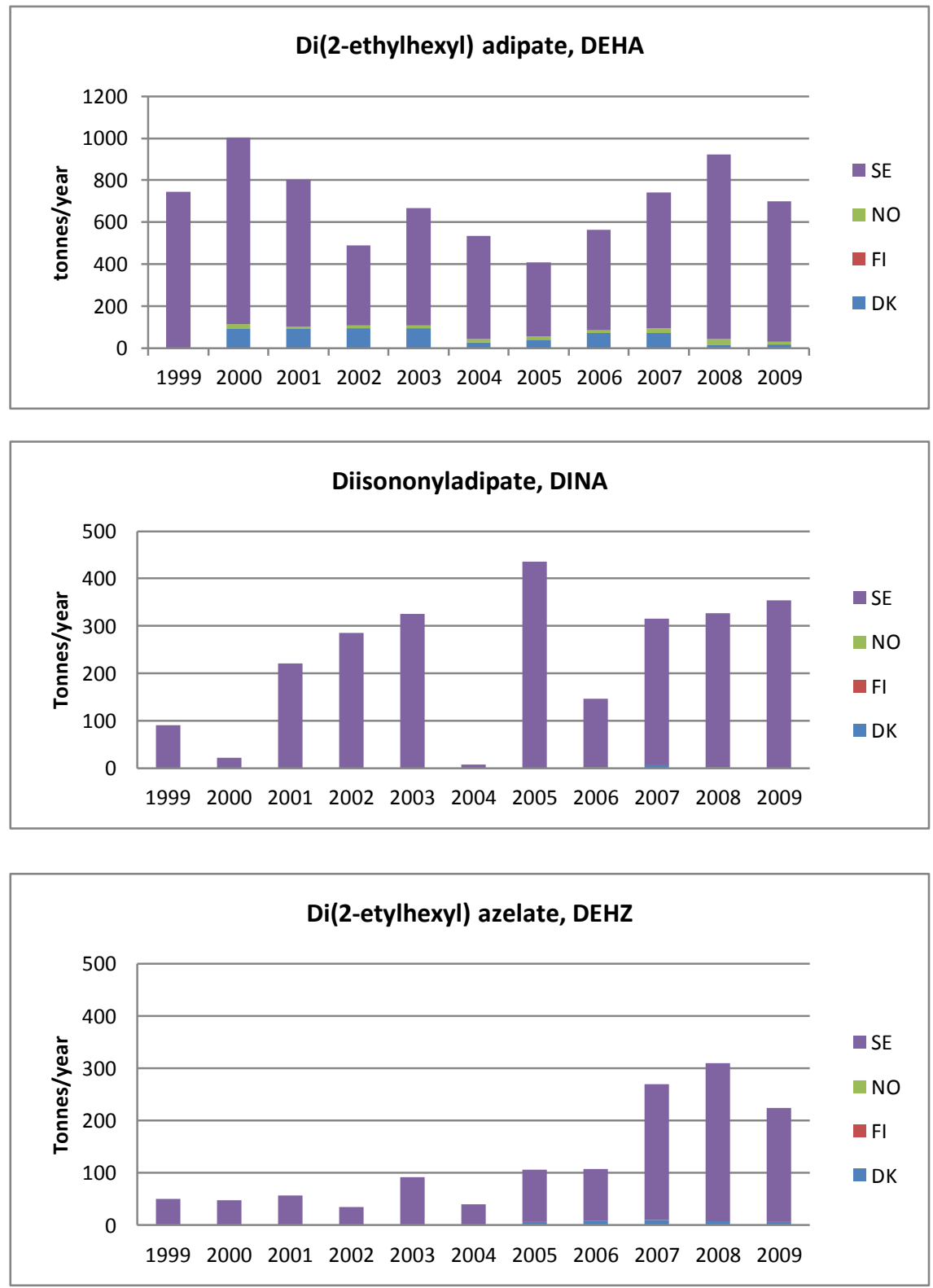


\subsection{Ecotoxicology}

In the substance descriptions in the report by Lambert et al. (2010) it is clear that the characteristics of the screened plasticisers are varying; some of the substances have been shown to be toxic to aquatic organisms and other substances have been shown not to be. Also the toxicity to mammals varies among the screened substances; effects seen for some substance in chronic toxicity tests were for example reprotoxic effects. Furthermore, suspicion of endocrine disruptive effects were mentioned for some substances, this will however not be further discussed here.

PNEC for the water and sediment compartments, as reported in EU risk assessments, are listed Table 2.3. For DEHP the PNEC water $_{\text {could not }}$ be specified as there were no reliable long-term studies below the water solubility of the compound (ECB 2008). However, DEHP has shown to induce effects in fish exposed via the food (ECB 2008). The $\mathrm{PNEC}_{\text {sediment }}$ of DEHP was based on a study on frog. In the risk assessment it is also mentioned that effects on microbially mediated processes may occur at concentrations around $1 \mathrm{mg} / \mathrm{kg} \mathrm{dw}$ (ECB 2008). In the EU risk assessments of DINP and DIDP PNEC ${ }_{\text {water }}$ could not be specified as no toxic effects were seen in any of the performed long-term tests, nor were effects seen in studies of orally exposed fish (ECB 2003 a; ECB 2003 b). $\mathrm{PNEC}_{\text {sediment }}$ could not be specified either, as no effects were seen in the tests conducted and as the equilibrium partitioning method was not applicable as PNEC $_{\text {water }}$ were lacking (ECB 2003 a).

\begin{tabular}{|c|c|c|}
\hline Substance(reference) & PNEC $_{\text {water }}$ & PNEC $_{\text {sediment }}$ \\
\hline DBP (ECB 2004) & $10 \mu \mathrm{g} / \mathrm{l}$ & $3.1^{*} \mathrm{mg} / \mathrm{kg} \mathrm{dw}$ \\
\hline \multirow[t]{2}{*}{ BBP (ECB 2007) } & 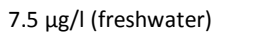 & $1.72 * \mathrm{mg} / \mathrm{kg}$ ww (freshwater) \\
\hline & $0.75 \mu \mathrm{g} / \mathrm{l}$ (marine waters) & $0.17^{*} \mathrm{mg} / \mathrm{kg}$ ww (marine waters) \\
\hline DEHP (ECB 2008) & na & $>100 \mathrm{mg} / \mathrm{kg} \mathrm{dw}^{\mathrm{a}}$ \\
\hline L79P & - & - \\
\hline DOP & - & - \\
\hline DINP (ECB 2003a) & $\mathrm{Na}$ & na \\
\hline DIDP (ECB 2003b) & $\mathrm{Na}$ & na \\
\hline DUP & - & - \\
\hline DEHA & - & - \\
\hline DINA & - & - \\
\hline BOA & - & - \\
\hline DBEEA & - & - \\
\hline $\mathrm{DEHZ}$ & - & - \\
\hline
\end{tabular}

$\mathrm{a}=$ effects on microbially mediated processes might occur at concentrations around $1 \mathrm{mg} / \mathrm{kg} \mathrm{dw}$ (ECB 2008). 


\section{Methodology}

\subsection{Sampling sites and sample selection}

The purpose of this screening was to sample several environmental matrices with a wide geographical distribution at locations where it's expected to find the compounds investigated.

Each country made their own selection of sample sites according to the strategy previously agreed upon in the steering group. Samples were chosen to represent areas directly influenced by human activities but also background areas. When possible, samples were chosen so as to facilitate comparisons between areas/regions. The goal was to cover the matrices effluent and sludge from waste water treatment plants (WWTPs), sediment and biota (fish and egg).

Sampling was done according to a sampling manual provided by the analysing laboratories (Appendix 1).

All samples collected are listed in Appendix 2, where also the sampling characteristics are given in detail. Below the different sampling sites from each country are presented and their locations are shown in maps, Figure 3. to Figure 3.

\subsubsection{Denmark}

\section{WWTP effluent and sludge}

Effluent and sludge were sampled at Esbjerg central WWTP and Ejby Mølle WWTP, Odense. Effluent was sampled at Råbylille strand WWTP, Vordingborg.

The WWTPs in Esbjerg and Odense had in 2010 loads on 115,000 and 275,000 pe respectively, while the load on Råbylille Strand was much smaller, 1,100 pe. Råbylille Strand only receives wastewater from households while the others receive from both household and industry.

\section{Sediment}

Sediment samples were collected at Vedbæk, Øresund, from Kolding Fjord and from Limfjorden.

\section{Fish}

Fish (Flounder) were sampled at Ho bugt (vicinity of Esbjerg), Hjelm bugt (vicinity of Vordingborg) and Agersö, Great Belt. 


\subsubsection{Faroe Islands}

\section{WWTP effluent and sludge}

Effluent was sampled at Sersjantvikin WWTP, Torshavn and Klaksvik Hospital WWTP, Klaksvik. Sludge was sampled at Sersjantvikin WWTP, Torshavn and Main Hospital WWTP, Torshavn. (Influent was sampled at Main Hospital WWTP, Torshavn). The Sersjantvikin WWTP, Torshavn receives domestic wastewater only and from approx. 1,000 pe. The WWTP may be described as consisting of a primary purification step. The sampling site denoted Klaksvík Hospital WWTP in this report is best described as a sewage line. Klaksvík hospital is a small hospital with 36 hospital beds, and performes clinical chemical analyses and x-ray diagnostic analyses.

\section{Sediment}

Sediment was sampled in Torshavn harbour, near the marina and near the shipyard (station BA). Sediment was also sampled in Klaksvik harbour and in Kollafjord.

\section{Fish}

One fish sample (Arctic charr) was from Lake á Mýrunum, a background freshwater lake. Five samples (Cod, liver) came from Mýlingsgrunnur approximately $30 \mathrm{~km} \mathrm{NW}$ on Faroe shelf.

\section{Egg}

Black guillemot eggs were sampled from two locations; island Skúvoy (6 eggs), and island Koltur (5 eggs). The eggs were analysed as one pooled sample from each sampling site. These locations are background areas, and will typically represent possible long-range transported contaminants.

\subsubsection{Finland}

\section{WWTP effluent and sludge}

Effluent and sludge samples (single, dewatered) were collected at three municipal WWTPs: Kakolanmäki, Turku (population equivalent 890,000), Viikki, Helsinki (pe 1,220,000), and Viinikanlahti, Tampere (pe 300,000). All these plants collect small or medium enterprise (SME) industrial wastewaters as well.

\section{Sediments}

Sediment was sampled at urban locations in the same cities as was used for WWTP sampling; Turku, Helsinki and Tampere.

\section{Fish}

Fish (Perch) were sampled at Pyhäjärvi in the vicinity of Tampere, at Kuhmoinen from the large lake Päijänne and in the Turku archipelago. 


\subsubsection{Iceland}

\section{WWTP effluent and sludge}

Sludge was sampled at the WWTPs Hveragerði, Borg-Grímsnesi and Klettagarðar, Reykjavik. Effluent was not sampled.

\section{Sediment}

Two sediment samples were collected in central Reykjavik and one in the fresh water lake pingvallavatn.

\section{Fish}

Two fish samples (Arctic charr and Brown trout) were from lake pingvallavatn while one sample (Cod) was from the Island Seas, about $200 \mathrm{~km} \mathrm{NW}$ off the coast.

\subsubsection{Norway}

\section{WWTP effluent and sludge}

Effluent and sludge were sampled at Rambekk WWTP, Gjøvik having lake Mjøsa as its receiving water. Rambekk WWTP treats waste water from residential buildings and industry in the municipality of Gjøvik. The treatment plant is a mechanical / chemical system with a capacity of ca. 45,000 pe (population equivalents). The plant treats 4.5-7 mill $\mathrm{m}^{3}$ waste water each year. The plant treats sludge from Gjøvik, but also accept sludge from seven municipalities in the region. The plant produces 2,100 tonns of sludge granulat each year.

\section{Sediment}

Sediment was taken in Puddefjorden near central Bergen and in Kviturspollen approximately $30 \mathrm{~km}$ from Bergen towards the open sea.

Fish

Fish (Brown trout) were sampled at Vingrom, lake Mjøsa.

\subsubsection{Sweden}

\section{WWTP effluent and sludge}

Effluent and digested dewaterised sludge were sampled at Öhn WWTP, Umeå (129,000 pe), Ryaverken WWTP, Göteborg (640,000 pe), and Gässlösa WWTP, Borås (73,000 pe),

\section{Sediment}

Two sediment samples were collected from the vicinity of Göteborg (Björkö and Stockholmen) and one representing a more remote area in Kosterfjorden West of Strömstad. The samples from Björkö and Stockholmen were 
collected with a grab sampler of Panar type. The sample from Kosterfjorden was received from the Geological Survey of Sweden (SGU).

\section{Fish}

Fish were collected at Hakefjorden at the mouth of Göta älv, Göteborg (Mackerel), at Kullen, Øresund (Herring) and at Holmöarna, Bothnian bay (Perch)

\section{Egg}

Eggs (Guillemot) were collected at Stora Karlsö. Samples (mixture of 5 eggs) were received from the Swedish Environmental Specimen Bank.

Figure 3.1 Sampling sites Denmark. Sample identification codes according to Appendix 2

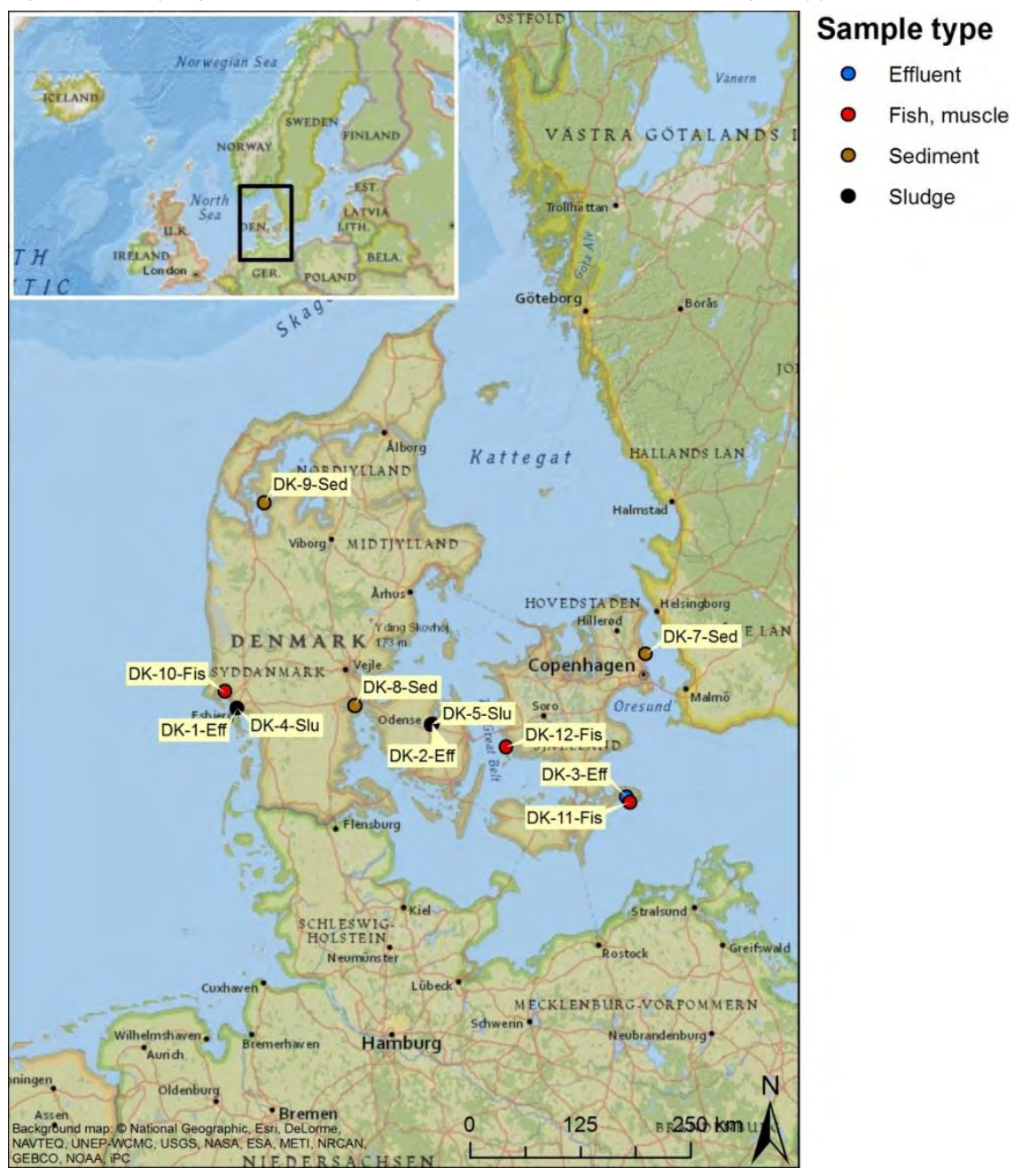


Figure 3.2 Sampling sites Finland. Sample identification codes according to Appendix 2

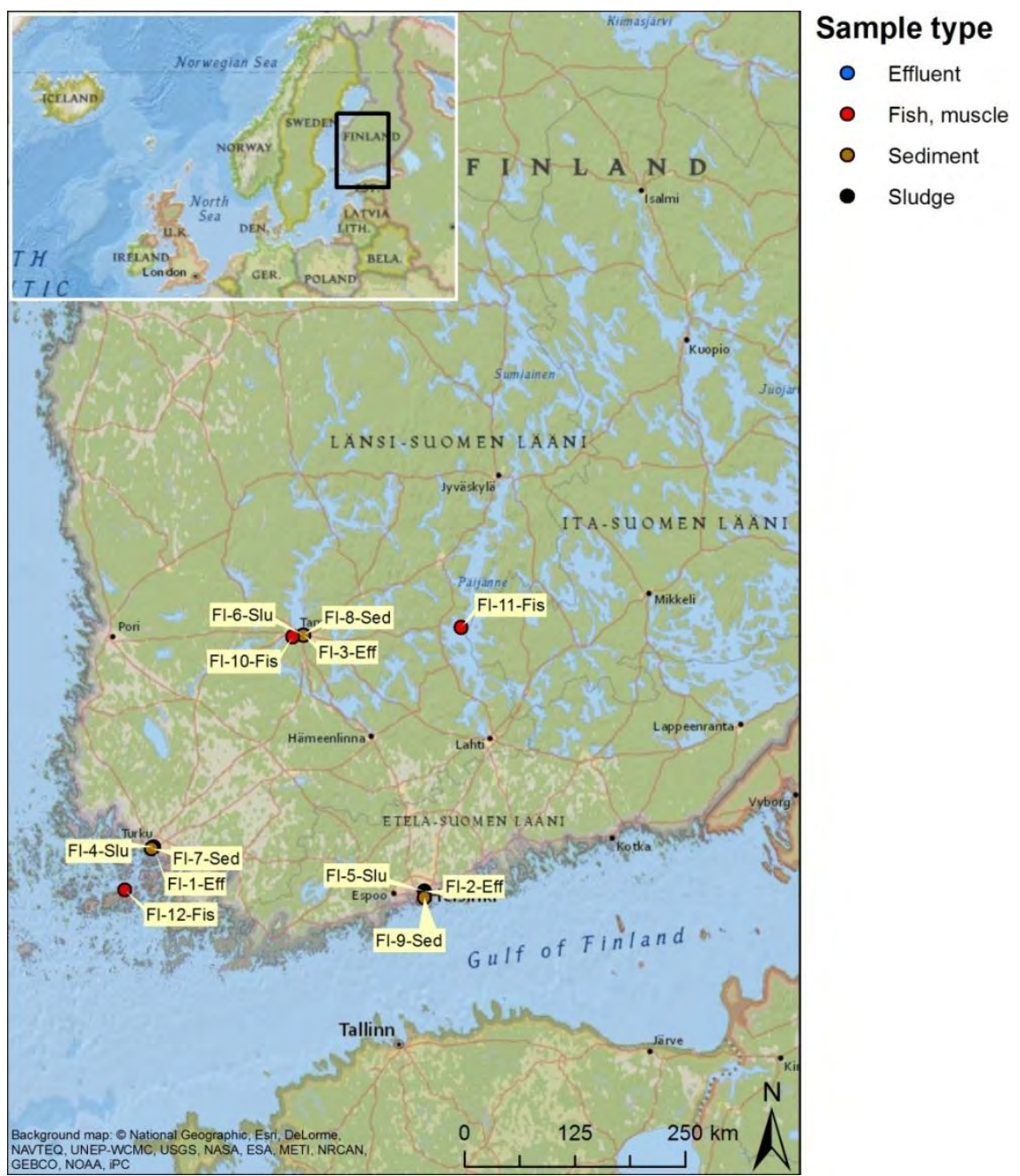


Figure 3.3 Sampling sites Faroe Islands. Sample identification codes according to Appendix 2

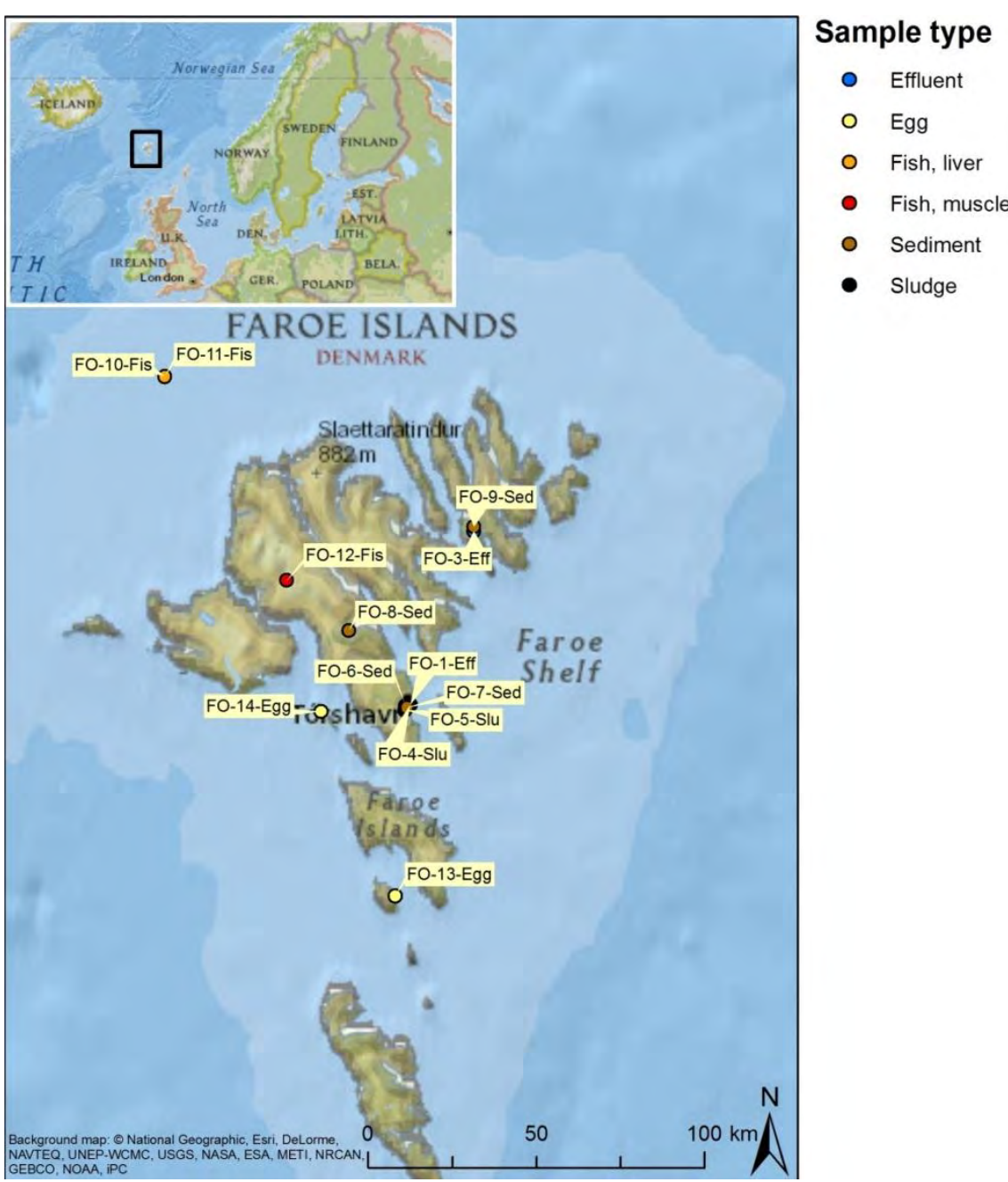


Figure 3.4 Sampling sites Iceland. Sample identification codes according to Appendix 2

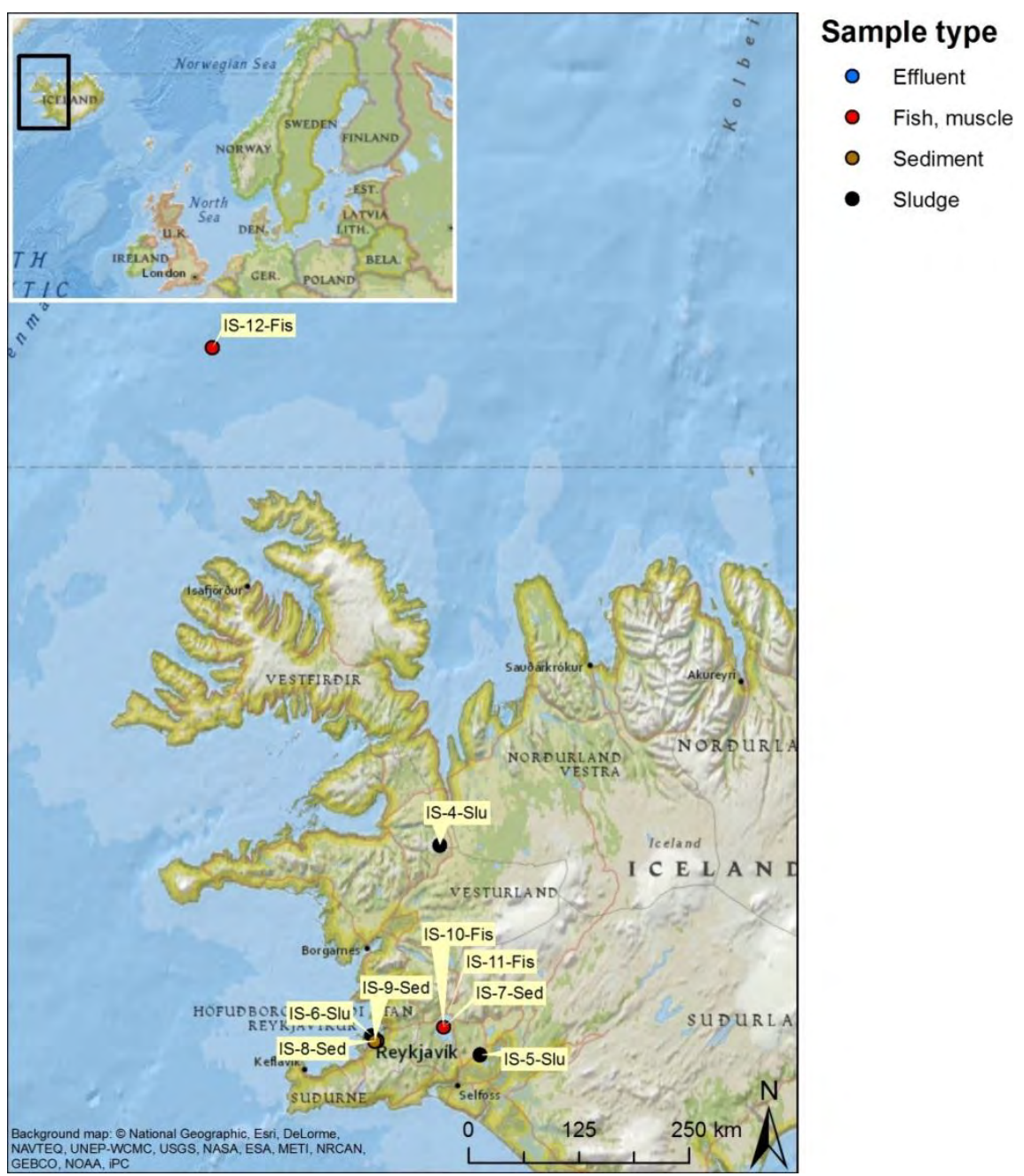


Figure 3.5 Sampling sites Norway. Sample identification codes according to Appendix 2

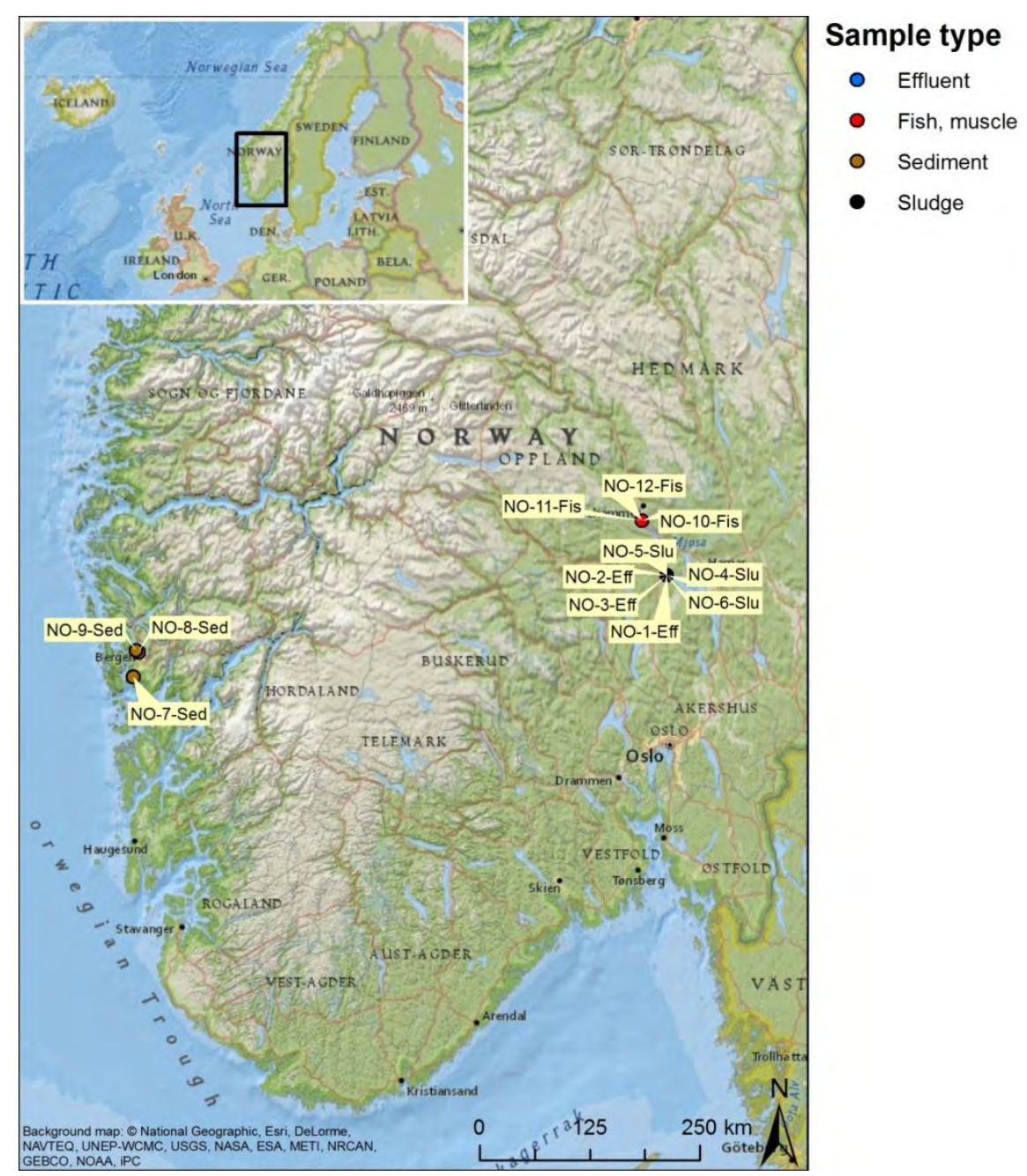


Figure 3.6 Sampling sites Sweden. Sample identification codes according to Appendix 2

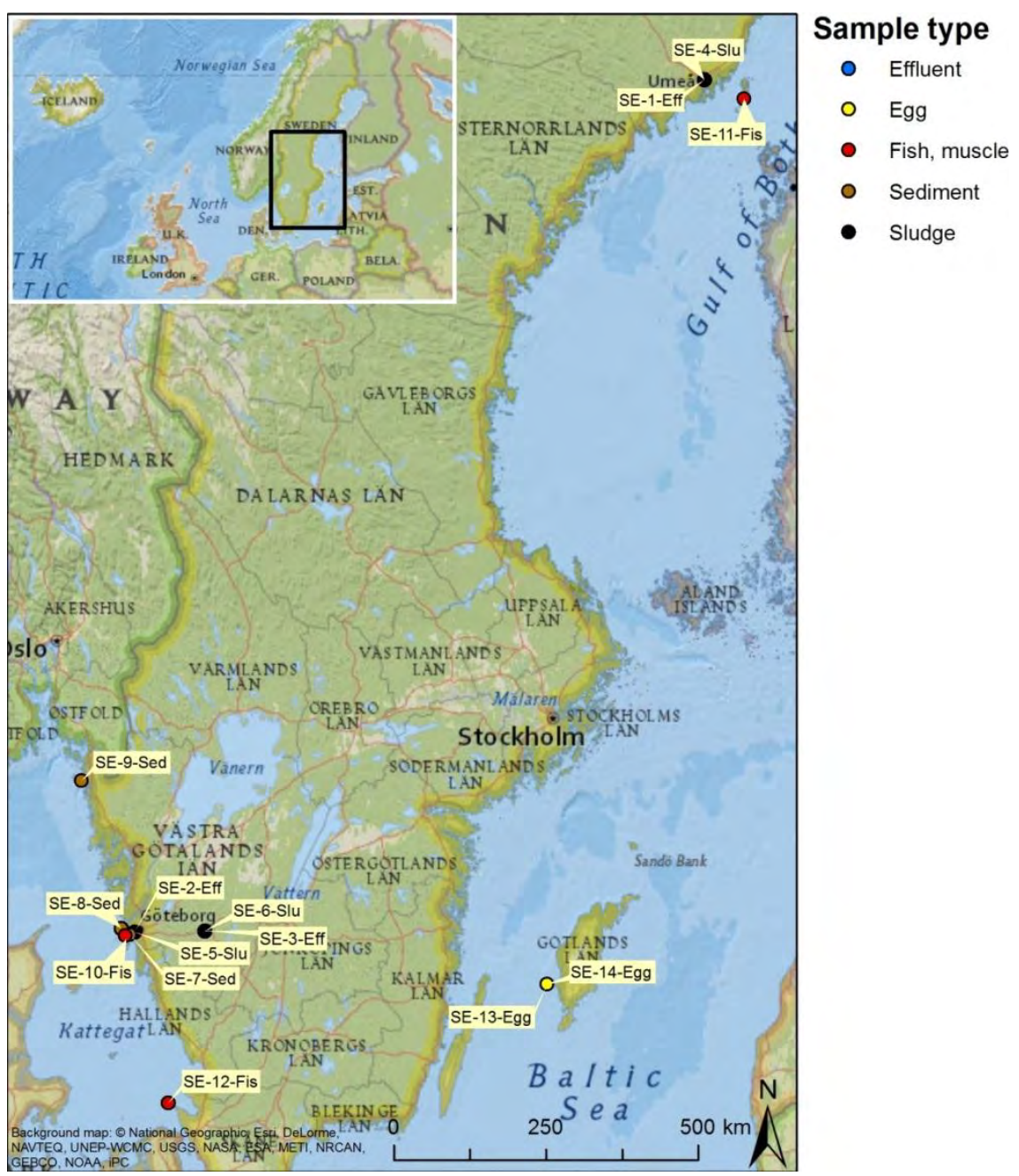




\subsection{Sampling methods}

\subsubsection{Effluent}

Effluents were sampled as grab samples. For analysis of plasticisers sampling was done in glass bottles with PTFE seals and the samples were stored cool. For analysis of sweeteners $1 \mathrm{~L} \mathrm{PE-bottles} \mathrm{with} \mathrm{PP} \mathrm{seals}$ were used and samples were stored frozen $\left(-18^{\circ} \mathrm{C}\right)$ until analysis.

\subsubsection{Sludge}

The sewage treatment plants sludge samples were collected by trained personnel or the staff at the different plants. For analysis of plasticisers the sludge was transferred into previously preheated $\left(400{ }^{\circ} \mathrm{C}\right)$ glass jars with the lid protected with $\mathrm{Al}$-foil. For analysis of sweeteners $100 \mathrm{~mL}$ PP jars with PP lid were used. All samples were stored frozen $\left(-18^{\circ} \mathrm{C}\right)$ until analysis.

\subsubsection{Sediment}

Surface sediment $(0-2 \mathrm{~cm})$ samples were collected by means of a sampler. The sediment was transferred into glass jars as described for sludge and stored in a freezer $\left(-18^{\circ} \mathrm{C}\right)$ until analysed.

\subsubsection{Biota}

Fish were collected by means of suitable fishing-gear. The fish were stored in a freezer $\left(-18^{\circ} \mathrm{C}\right)$ until dissected. Fish samples were deliverd as whole fish or dissected in the respective countries. Fish muscle or liver was dissected for analysis by means of solvent cleaned scalpels.

A homogenised mixture of 5-10 eggs were stored in pre-cleaned glass jars at $\left(-18^{\circ} \mathrm{C}\right)$.

\subsection{Analysis methods, plasticisers}

\subsubsection{Analytical standards}

DINP and DIDP were donated by ECPI (European Council for Plasticisers \& Intermediates, a sector group of CEFIC, March 26, 2000). The recovery (surrogate) standard deuterium labeled DEHP ( $\mathrm{d}_{4}$-DEHP) was purchased from CIL (Cambridge Isotope Laboratories,Andover, MA, USA), dipropylphthalate (DPP) from TCI (Tokyo Kasei, Organic Chemicals, Tokyo, Japan) and deuterium labeled DEHA ( $\mathrm{d}_{8}$-DEHA) from Chiron (Chiron As Trondheim Norway). Di(2-(2-butoxyethoxy)ethyl) adipate 
(DBEEA) was purchased from Sigma-Aldrich, di(2-ethylhexyl) adipate (DEHA) and DEHZ from TCI, DBP, BBP, DEHP and DOP from Ultra Scientific and DUP, diisononyl adipate (DINA) and benzyl oktyl adipate (BOA) from Chiron. The phthalate mixture di-C7-9-branched and linear alkylester with the trade name Bisoflex L79P (L79P) was produced by Emery Oleochemicals GmbH.

DPP was used as recovery standard for the lower molecular weight phthalates (DBP, BBP), $d_{4}$-DEHP for the heavier molecular weight phthalates (DEHP, L79P, DOP, DINP, DIDP, DUP) and $d_{8}$-DEHA for the adipates and DEHZ.

\subsubsection{Materials}

Phthalates are recognised as ubiquitous pollutants in indoor as well as outdoor environments (Furtmann 1995). Therefore, it is not surprising that phthalates are generally detected even in high purity chemicals, ultra-pure water, organic solvents used for extraction and laboratory equipment (Tienpont, David et al. 2005). The contamination from laboratory equipment and environment limits the analysis of plasticisers, especially phthalates. Special routines are therefore essential in order to guarantee the integrity of the samples. The routines used at the laboratory in order to minimise the risk for contamination of the samples are briefly described below.

All glass equipment were wrapped in aluminium foil and heated to $400{ }^{\circ} \mathrm{C}$ for 8 hours. The aluminium foil prevents re-contamination of the equipment until used. All equipment made of Teflon and metal was washed with solvent before use. During the whole analytical procedure samples, extracts, solvents and chemicals were carefully protected from air precipitation and dust that has been proved to be a source of phthalates (Tienpont, David et al. 2005). This was accomplished by covering test tubes, jars and other equipment with clean aluminium foil (Parkman and Remberger 1994). Solvents used for extraction were delivered from Rathburn Chemical Ltd. (Peeblesshire, Scotland) and were checked before used. Ultra-pure water was produced by Milli- $Q$ equipment. Batches of water from this equipment were stored in glass containers and were checked prior to use. The checked batches of solvents and water were exclusively applied for this project. Chemicals and equipment such as $\mathrm{Na}_{2} \mathrm{SO}_{4}$, were thermally treated at $400{ }^{\circ} \mathrm{C}$ before use.

SPE (solid phase extraction) columns containing ethylenediamine- $\mathrm{N}$ propyl modified silica (PSA) were prepared in glass columns immediately before use. Pre-cleaned GF/C-filters were used as frits. The columns were pre-cleaned carefully and activated prior to use by passing hexane, MTBE, methanol and ultra-pure water through the columns.

SPE columns containing C18 used to concentrate water samples were carefully cleaned before used with MTBE, acetone, methanol and ultrapure water. Low and consistent blank samples were difficult to achieve 
even after such careful cleaning. The problem seems to be the frits placed on both sides of the SPE-phase. Soxhlet extraction of the frits before used decreased blank values.

\subsubsection{Sample preparation}

\section{WWTP effluent}

The effluent water samples (200-400 mL) were subjected to solid phase extraction (SPE; C18). The sample was spiked with recovery standards $\left(\mathrm{d}_{8^{-}}\right.$ DEHA, DPP and $d_{4}$-DEHP). To avoid clogging of the SPE-column filter aid (diatomaceous earth or Empore filter aid 400) was used. Following the sample the SPE-column was rinsed with ultra-pure water and dried under full vacuum suction on the vacuum manifold. The analytes were eluted with methanol, MTBE and finally hexane. The extracts were combined and methanol was washed away by shaking the extract with ultra-pure water. The extract was dried over sodium sulphate and cleaned up (see below).

\section{Sludge and sediment}

The pore water in the sediment samples was separated by centrifugation before extraction. Centrifugation of the sludge was not necessary because the analysed sludges were dewatered. Sludge samples were acidified with phosphorous acid prior to extraction. The sample was fortified with recovery standards ( $\mathrm{d}_{8}$-DEHA, DPP and $\mathrm{d}_{4}$-DEHP), mixed carefully and subsequently extracted twice with acetone. The first extraction lasted for $16 \mathrm{~h}$ and the second $30 \mathrm{~min}$ including $5 \mathrm{~min}$ in ultrasonic bath. The acetone in the pooled extract was washed away by dilution with ultra-pure water and subsequent extraction with hexane:MTBE. The organic extract was safeguarded after phase separation. The water phase was extracted one more time with a mixture of hexane and MTBE. The combined extract was subjected to clean-up (see below).

\section{Fish, Egg and liver}

Samples (muscle, $5 \mathrm{~g}$; liver $4 \mathrm{~g}$, egg $2 \mathrm{~g}$ ) were spiked with recovery standard ( $\mathrm{d}_{8}$-DEHA, DPP and $\mathrm{d}_{4}$-DEHP) and homogenised in acetonitrile. Sodium sulphate was added to facilitate the phase separation. The sample was shaken vigorously for one minute. The extract was safeguarded after centrifugation and the samples were extracted once more with acetonitrile. The extracts were combined and the acetonitrile removed by shaking with water and heane:MTBE. The extracts were dried, concentrated and the solvent changed to hexane followed by clean-up.

\section{Clean-up of extracts}

The raw extracts contain high amounts of "matrix related compounds" that may interfere with the target analytes leading to inaccurate quantification. It may also lead to damage of the chromatographic system leading to poor separation and sensitivity. 
PSA-columns were used for the clean-up of extracts from effluents, and biota. Phthalate contamination from these columns was a serious problem. This was solved by replacing the PP-frits with small GF/Cfilters. The columns were carefully solvent cleaned before running the samples. The analytes were eluted with hexane: MTBE.

Clean-up of sludge and sediment-extracts were performed on a dual SPE-column containing graphitised carbon black (GCB) and PSA. This column has the advantage to retain the dark brown material and polar compounds that is co-extracted with the plasticisers. The sample, dissolved in hexane, was applied on the column and the analytes were eluted with toluen: MTBE.

The eluates were concentrated using a clean stream of $\mathrm{N}_{2}$ gas, spiked with injection standard and stored in a freezer $\left(-18^{\circ} \mathrm{C}\right)$ prior to GC-MS/ MS analysis.

\subsubsection{Instrumental analysis}

The extracts were analyzed on a 7890A gas chromatograph coupled to a 7000A Triple Quad MS (Agilent Technologies Inc., Santa Clara, CA, USA). The injection was made pulsed splitless at $250^{\circ} \mathrm{C}$. The fused silica capillary column (VF-5MS $30 \mathrm{~m} \times 0.25 \mathrm{~mm}$ i.d. x $0.25 \mu \mathrm{m}$ film thickness, Varian) was held at $45^{\circ} \mathrm{C}$ for $1 \mathrm{~min}$, ramped $15^{\circ} \mathrm{C} / \mathrm{min}$ to $300^{\circ} \mathrm{C}$, and held isothermal for $10 \mathrm{~min}$. The transfer line was held at $280^{\circ} \mathrm{C}$. Helium was used as carrier gas. The detector was used in MRM mode with electron ionisation at energy $70 \mathrm{eV}$. The analytes were identified by their characteristic retention times and two characteristic precursor/product ion pairs (MRMs). The instrument was calibrated with a six point calibration curve. Quantification was based on comparison of peak abundance to the known response of the internal standard (biphenyl). The reported analyte concentrations were calculated according to the determined recovery of surrogate standard.

\subsubsection{Quality control}

When performing environmental screening all steps in the study such as selection of sampling site, sampling frequency, time of sampling, performing of sampling, transport and storage of samples, chemical analysis and data treatment are generating some degree of uncertainty. To quantitatively estimate the contribution of all steps is an extremely difficult task or not possible at all. However, we will discuss the relevance of the different contributors in a qualitative way.

One important question is whether a sample is representative for a given time period or a given region. Many of the selected compounds are intermittently emitted to the environment and a constant concentration of these compounds in the environment is not expected. In this screening, the samples were collected within a narrow time frame and at dif- 
ferent geographical locations. The results obtained here are therefore only a snapshot of the reality at those places at the given time.

Factors with influence on sampling uncertainty are analyte loss due to adsorption to sample containers, wastewater flow and particle content, tidal water current, contamination and degradation during transport and storage. The uncertainty due to loss of analyte is minimised (especially for water samples) by the laboratory's selection of sample containers.

The uncertainty of the chemical analysis is governed by loss during extraction and clean-up, interference from other compounds, trueness of analytical standards, instrumental parameters, and contamination.

The following quality criteria were used to ensure correct identification and quantification of the target compounds: (a) the retention times should match those of the standard compounds within $\pm 0.05 \mathrm{~min}$., (b) the intensity ratios of the selected MRMs should be within $\pm 15 \%$ of that observed for the standard compounds (c) the signal-to-noise ratios should be greater than 3:1.

Field blanks were collected at several sampling stations. An analytical method blank was included for each sample batch analysed to assess background interferences and possible contamination of the samples. Concentrations below field blank levels were treated as not detected. Possible background levels of analytes were subtracted from measured sample values.

Limit of quantification (LOQ) was defined as a signal 10 times the standard deviation of the blank values. Internal standard was added to the sample at the start of the working-up procedure. The internal standard has similar chemical and physical properties as the compounds to be analyzed. If available, isotopically labelled internal standards were used.

In this investigation four plasticisers consisting of isomeric mixtures were determined (L79P, DINP, DIDP, DINA). In this case the analytes were determined from the sum of a cluster of chromatographically unresolved peaks in a quite broad retention window (about $4 \mathrm{~min}$ ). Substances with similar retention times which produce masses similar to the analytes can interfere with the analyte. This may lead to incompletely resolved signals and to additional signals in the chromatographic pattern. This can affect accuracy and precision of the analytical results.

The extraction efficiency for the different matrixes based on recovery standards are summarized in Table 3.1.

Table 3.1: Extraction efficiency (\%) of recovery standards for different matrices

\begin{tabular}{lcccc}
\hline & Effluent & Sediment & Sludge & Biota \\
\hline$d_{8}$-DEHA & 90 & 86 & 77 & 55 \\
DPP & 99 & 78 & 75 & 51 \\
$d_{4}$-DEHP & 97 & 78 & 76 & 42 \\
\hline
\end{tabular}


The performance of the analytical metods used was examined in spiking experiments. The authentic samples used were collected from lakes with known low antropogenic influence and are included in the national monitoring programme of contaminants (A. Bignert; The Environmental speciment bank at Museum of Natural History (NRM)). The added amount of analytes were close to specified LOQ. The spiked samples were treated according the the same analytical protocol as the samples.

The recovery that was obtained for the matrices effluent, sediment and biota of the detected analytes are presented in Table 3.2. The results are adjusted according to the respective recovery standards and the background subtracted (se 3.3.1).

Table 3.2: Extraction recovery (\%) of the analytes for different matrices

\begin{tabular}{lrrr}
\hline & Effluent & Sediment & Biota \\
\hline DBP & 111 & 115 & 101 \\
BBP & 104 & 125 & 111 \\
DEHP & 120 & 107 & 62 \\
L79P & 99 & 77 & 44 \\
DOP & 78 & 96 & 39 \\
DINP & 76 & 98 & 42 \\
DIDP & 68 & 96 & 39 \\
DUP & 74 & 85 & 29 \\
DEHA & 90 & 90 & nd \\
\hline
\end{tabular}

The results are adjusted according to the respective recovery standards

The uncertainty of the analytical method used was estimated by analysis of parallel samples of authentic matrices. From these results average concentration, standard deviation, and relative standard deviation, RSD (Table 3.3) were calculated. Due to low concentrations, RSD could not be evaluated in this way for all analytes. In these cases spiked samples were used (results indicated in italics). An approximate $95 \%$ confidence interval for the analytical results could be obtained by multiplying RSD from Table 3.3 with a "coverage factor" of 2 (ISO, 1993).

Table 3.3: RSD (\%) evaluated from analysis of authentic parallel samples

\begin{tabular}{lrrrr}
\hline & Effluent & Sludge & Sediment & Fish \\
\hline DBP & 7 & 7 & 6 & 3 \\
BBP & 5 & 3 & 27 & 10 \\
DEHP & 13 & 6 & 9 & 7 \\
L79P & 10 & 23 & 17 & 17 \\
DOP & 12 & 16 & 33 & 26 \\
DINP & 5 & 7 & 11 & 9 \\
DIDP & 7 & 13 & 13 & 15 \\
DUP & 14 & 6 & 11 & 6 \\
\hline
\end{tabular}

Figures in italalics ar data obtained through spiking experiments.

LOQs were based on variation of blank samples (10 x SD) or (when data were not available) were estimated from the calibration curve (in italics), Table 3.4. 
Table 3.4: Summary of LOQs for the matrices included in the investigation

\begin{tabular}{lrrrr}
\hline & $\begin{array}{r}\text { Effluent } \\
\mathbf{n g} / \mathbf{l}\end{array}$ & $\begin{array}{r}\text { Sludge } \\
\boldsymbol{\mu g} / \mathbf{k g ~ d w}\end{array}$ & $\begin{array}{r}\text { Sediment } \\
\boldsymbol{\mu g} / \mathbf{k g ~ d w}\end{array}$ & $\begin{array}{r}\text { Biota } \\
\boldsymbol{\mu g} / \mathbf{k g ~ w w}\end{array}$ \\
\hline DBP & 50 & 8 & 8 & 4 \\
BBP & 20 & 11 & 4 & 2 \\
DEHP & 200 & 80 & 20 & 4 \\
L79P & 50 & 8 & 8 & 2 \\
DOP & 20 & 10 & 5 & 1 \\
DINP & 80 & 100 & 30 & 40 \\
DIDP & 80 & 100 & 20 & 40 \\
DUP & 20 & 10 & 6 \\
DEHA & 25 & 8 & 1 & 30 \\
BOA & 20 & 200 & 10 & 8 \\
DINA & 100 & 5 & 40 \\
DEHZ & 150 & 100 & 50 & 2 \\
DBEEA & 150 & $1 \mathrm{~g}$ dw & $4 \mathrm{~g} \mathrm{dw}$ & $10 \mathrm{~g} \mathrm{ww}$ \\
Sample amount & 11 & & & 10 \\
\hline
\end{tabular}

The LOQs are based on variation of blank samples or (when data were not available) were estimated from the calibration curve (in italalics).

Those LOQs were used in the calculation of the results. In addition LOQs were also determined from variation of the results $(10 \mathrm{x}$ SD) for spiked samples (see above), Table 3.5.

Table 3.5: Summary of LOQ retrived in spiking experiments

\begin{tabular}{lrrr}
\hline & $\begin{array}{r}\text { Effluent } \\
\mathbf{n g} / \mathbf{l}\end{array}$ & $\begin{array}{r}\text { Sediment } \\
\mathbf{n g} / \mathbf{g} \text { dw }\end{array}$ & $\begin{array}{r}\text { Biota } \\
\mathbf{n g} / \mathbf{g} \text { ww }\end{array}$ \\
\hline DBP & 38 & 9 & 3 \\
BBP & 15 & 11 & 9 \\
DEHP & 30 & 42 & 6 \\
L79P & 22 & 5 & 4 \\
DOP & 3 & 8 & 4 \\
DINP & 108 & 60 & 44 \\
DIDP & 71 & 63 & 77 \\
DUP & 17 & 23 & 4 \\
DEHA & 8 & 8 & $\mathrm{nd}$ \\
Sample amount & $1 \mathrm{~L}$ & $4 \mathrm{~g} \mathrm{dw}$ & $10 \mathrm{~g} \mathrm{ww}$ \\
\hline
\end{tabular}

Sampling blanks (see Appendix 1 Sampling manual) for water were sent to Denmark, Norway and Finland. After being returned to the laboratory they were analysed together with the effluent samples. All plasticisers showed concentrations below LOQ.

Sampling blanks used for solid samples (sediments and biota) were sent to Faroe Islands, Island and Sweden. The results are summerised in the leftmost columns in Table 3.6. The concentrations were all below LOQ exept for a low concentration of DEHP in one of the blanks. 
Table 3.6: Sampling blanks for solids. Results calculated as for biota samples

\begin{tabular}{|c|c|c|c|c|c|}
\hline & $\begin{array}{l}\text { FO-15-BLS } \\
\mu g / k g ~ w w\end{array}$ & $\begin{array}{l}\text { IS-15-BLS } \\
\mu \mathrm{g} / \mathrm{kg} \mathrm{ww}\end{array}$ & $\begin{array}{l}\text { SE-15-BLS } \\
\mu \mathrm{g} / \mathrm{kg} w w\end{array}$ & $\begin{array}{l}\text { IS-16-BLS Jar } \\
\mu \mathrm{g} / \mathrm{kg} \mathrm{ww}\end{array}$ & $\begin{array}{l}\text { IS-16-BLS Lid } \\
\mu \mathrm{g} / \mathrm{kg} \mathrm{ww}\end{array}$ \\
\hline DBP & $<\mathrm{LOQ}$ & $<\mathrm{LOQ}$ & $<\mathrm{LOQ}$ & $<\mathrm{LOQ}$ & 7.9 \\
\hline BBP & $<L O Q$ & $<L O Q$ & $<\mathrm{LOQ}$ & $<L O Q$ & $<\mathrm{LOQ}$ \\
\hline DEHP & $<\mathrm{LOQ}$ & 15 & $<\mathrm{LOQ}$ & $<\mathrm{LOQ}$ & 14 \\
\hline L79P & $<\mathrm{LOQ}$ & $<\mathrm{LOQ}$ & $<\mathrm{LOQ}$ & $<\mathrm{LOQ}$ & $<\mathrm{LOQ}$ \\
\hline DOP & $<\mathrm{LOQ}$ & $<\mathrm{LOQ}$ & $<\mathrm{LOQ}$ & $<\mathrm{LOQ}$ & $<\mathrm{LOQ}$ \\
\hline DINP & $<\angle O Q$ & $<\mathrm{LOQ}$ & $<\mathrm{LOQ}$ & 620 & 8500 \\
\hline DIDP & $<\mathrm{LOQ}$ & $<\mathrm{LOQ}$ & $<\mathrm{LOQ}$ & 7800 & 21000 \\
\hline DUP & $<\mathrm{LOQ}$ & $<\mathrm{LOQ}$ & $<\mathrm{LOQ}$ & $<\mathrm{LOQ}$ & $<L O Q$ \\
\hline
\end{tabular}

For LOQ values see Table 3.4.

For a few samples (FO-13-Egg, FO-14-Egg and IS-11-Fis) a different type of sampling jar than that sent out from the laboratory was used. This glass jar had a metall lid with a gasket made from a polymer material. An empty jar of this type (labeled IS-16-BLS) was analysed as a blank. Results for the jar and the lid are presented separately in Table 3.6, rightmost columns. DINP and DIDP was found predominantly on the lid, probably originating from the gasket. The jars were also fitted with a clean aluminium foil under the lid. This should protect the sample but problems with contamination cannot be fully ruled out e.g. due to damaged aluminium foil.

Originally two fish liver samples were delivered in the probably contaminating type of sample jars. The livers contained high concentrations of DINP and DIDP (data not shown). When additional fish from the same area were delivered as whole fish and the livers (FO-15Fis-FO-19-Fis) analysed, DINP and DIDP concentrations were $<$ LOQ.

\subsection{Analysis methods, sweeteners}

\subsubsection{Sample preparation}

Effluent water $(50 \mathrm{~mL})$ was acidified to $\mathrm{pH} 3$ with $\mathrm{HCl}$ and internal standards (d6-sucralose, d3-aspartame and d11-cyclamate, all from Toronto Research Chemicals Inc.) were added.

Sludge ( $3 \mathrm{~g}$ ) was shaken in $100 \mathrm{~mL}$ diluted $\mathrm{HCl}$ for $30 \mathrm{~min}$ and internal standards were added. The $\mathrm{pH}$ should be 3 in the suspension and was adjusted if necessary. The suspension was centrifuged at 1,000 rpm for 5 min and the liquid phase collected.

The aqueous samples, prepared in this way were solid phase extracted differently depending on the analyte.

\section{Sucralose}

The sample was solid phase extracted on a column (Oasis HLB plus, Waters Corp.) installed with a pre-filter (nylon), both preconditioned with methanol. The column was washed with $0.01 \mathrm{M} \mathrm{HCl}$, deionized water (MilliQ-plus), $1 \mathrm{v} / \mathrm{v} \%$ methanol in $0.01 \mathrm{M} \mathrm{HCl}, 20 \mathrm{v} / \mathrm{v} \%$ methanol in de- 
ionized water and ammoniumhydroxide. The column was dried by suction and sucralose was eluted with $3 \times 3 \mathrm{~mL}$ acetone : methanol $(5: 1, \mathrm{v} / \mathrm{v})$. To remove additional matrix compounds the extract was passed through a mixed-mode ion exchange SPE-cartridge (Isolute-MM, Biotage), preconditioned with methanol. Any sucralose remaining in the SPE-resin was washed out with additional acetone:methanol, which was pooled with the extract. The extract volume was reduced to $1 \mathrm{~mL}$ by evaporation under nitrogen (Zymark TurboVap II Concentration Workstation, Caliper Life Sciences). Further clean up was performed by passing the extract through another mixed-mode ion exchange SPE cartridge (Oasis MAX, Waters Corp.) with subsequent extract volume reduction.

The method was based on NILU's already established method (Brorström-Lundén et al, 2008). The performance and quality of this method was tested in an international interlaboratory comparison (Kaj, 2009).

\section{Cyclamate}

The sample was solid phase extracted on a column (Oasis HLB plus, Waters Corp.) installed with a pre-filter (nylon), both preconditioned with methanol. The column was washed subsequently with $0.01 \mathrm{M} \mathrm{HCl}$, and 1 $\mathrm{v} / \mathrm{v} \%$ methanol in $0.01 \mathrm{M} \mathrm{HCl}$. The column was dried by suction and cyclamate was eluted with $3 \times 2 \mathrm{~mL}$ deionized water:methanol (5:1, $\mathrm{v} / \mathrm{v}$ ). The extract volume was reduced by evaporation under nitrogen (Zymark TurboVap II Concentration Workstation, Caliper Life Sciences). Several tests were done to optimize the SPE-procedure and to try to find a suitable method for further clean up. The method was based on a paper by Scheurer (Scheurer, M et al. 2009). A more polar elution solvent seemed to be more efficient than methanol, that was suggested in the paper. The SDB-1 columns (Bakerbond SDB-1, $200 \mathrm{mg} / 6 \mathrm{~mL}$ from J.T Baker) refered to in the paper were tested and were shown to have the same properties as the HLB column used for sucralose.

\section{Aspartame}

The sample preparation method described by Scheurer (Scheurer, M et al. 2009) could not be adopted directly for the current samples, as the matrix effects were significant. Several tests were done to optimize the SPE-procedure and to try to find a suitable method for further clean up. Effluent water samples were analysed with the method described below, without giving a reasonable LOQ. The matrix effects in sludge are assumed to be even greater. There were no significant amounts in any of the effluent water samples. As the amounts of sweeteners in general are assumed to be lower in sludge, it is not expected to find significant amounts and the LOQ was therefore only estimated.

The sample was solid phase extracted on a column (Oasis HLB plus from Waters Corp.) installed with a pre-filter (nylon), both preconditioned with methanol. The column was washed subsequently with $0.01 \mathrm{M} \mathrm{HCl}$ and 1 $\mathrm{v} / \mathrm{v} \%$ methanol in $0.01 \mathrm{M} \mathrm{HCl}$. The column was dried by suction and aspar- 
tame was eluted with $3 \times 3 \mathrm{~mL}$ of acetone: methanol $(5: 1, \mathrm{v} / \mathrm{v})$. The extract volume was reduced by evaporation under nitrogen (Zymark TurboVap II Concentration Workstation, Caliper Life Sciences).

\subsubsection{Instrumental analysis}

The extracts were analyzed on an Acquity ultra performance liquid chromatograph coupled to a Time-of-flight Mass Spectrometer (Waters LCT Premier XE). Compound separation was performed with a reversed phase column (Acquity UPLC HSS T3, $2.1 \mathrm{~mm}$ ID x $100 \mathrm{~mm}$ length, particle size $1.8 \mu \mathrm{m}$, Waters). The injection volume was $5 \mu \mathrm{L}$. Deionized water was used as solvent $A$ and methanol as solvent $B$. The flow rate was 0.4 $\mathrm{mL} / \mathrm{min}$.-The binary gradient started with $95 \%$ A. Solvent B was introduced at a linear rate up to $90 \% \mathrm{~B}$ at $5 \mathrm{~min}$ and kept isocratic until 5.5 min. At 6 min solvent B was set to $5 \%$ and the column was equilibrated up to a total runtime of $7 \mathrm{~min}$.

The analytical detector was equipped with a Z-spray electrospray ion source, which was optimized to the following values: Negative $\mathrm{W}$ mode, sample cone $30 \mathrm{~V}$, capillary voltage $2,800 \mathrm{~V}$, source temperature $100{ }^{\circ} \mathrm{C}$, cone gas flow $4 \mathrm{~L} / \mathrm{h}$, desolvation temperature $350^{\circ} \mathrm{C}$ and gas flow $767 \mathrm{~L} / \mathrm{h}$. The scan mass area was $50-500 \mathrm{~m} / \mathrm{z}$ with $0.3 \mathrm{~s}$ frequency. Data processing and instrument control were performed by the Masslynx software, and the quantification was performed with signal extraction of a peak width of 100 ppm (sucralose/cyclamate) and $50 \mathrm{mDa}$ (aspartame).

Table 3.7: Quantifier and qualifier ions used for mass spectrometric detection

\begin{tabular}{lccc}
\hline Component & Mw & $\begin{array}{r}\text { Quantifier } \\
\mathbf{M - 1}\end{array}$ & $\begin{array}{r}\text { Qualifier } \\
\mathbf{2}^{\circ} \mathbf{M}-\mathbf{1}\end{array}$ \\
\hline d11-cyclamate & 190 & 189 & \\
Cyclamate & 179 & 178 & 403 \\
d6-sucralose & 402 & 401 & 395 \\
Sucralose & 398 & 397 & \\
d3-aspartame & 297 & 296 & \\
Aspartame & 294 & 293 & \\
\hline
\end{tabular}

The instrumental method was based on NILU's already established method for sucralose (Brorström-Lundén, E. et al. 2008) with adaption to an UPLC column.

\subsubsection{Quality control}

For each analyte laboratory blanks followed the sample preparation. Recovery for the added internal standard was determined. Since there were no measurable signal for either method blank nor field blank samples, a slightly different approach for determination of the Limits of quantification (LOQ) was applied. LOQ, defined as 10 times the signal to noise ratio $(\mathrm{S} / \mathrm{N})$, was determined manually by examining the $\mathrm{S} / \mathrm{N}$-level in the sample or in the quantification standard, with the recovery and 
sample extraction volumes taken into account. The accuracy of the method was determined by spiking authentic samples and processing them according to the complete analytical process, while the repeatability was investigated by analyzing duplicate samples. Based on these data the measuring uncertainty is estimated to be lower than $40 \%$ for all three analytes. This uncertainty is in accordance with results of an international interlaboratory comparison on sucralose (Kaj, 2009).

Table 3.8: Results of quality assurance for effluent water

\begin{tabular}{lcr}
\hline & Average recovery & Average lab blank \\
\hline Sucralose & $31 \%$ & $<0.01 \mu \mathrm{g} / \mathrm{L}$ \\
Cyclamate & $43 \%$ & $<0.01 \mu \mathrm{g} / \mathrm{L}$ \\
Aspartame & $25 \%$ & $<0.01 \mu \mathrm{g} / \mathrm{L}$ \\
\hline
\end{tabular}

Table 3.9: Results of quality assurance for sludge

\begin{tabular}{lr}
\hline & Average recovery \\
\hline Sucralose & $46 \%$ \\
Cyclamate & $56 \%$ \\
Aspartame & $25 \%{ }^{*}$ \\
\hline
\end{tabular}

* Estimated from effluent water

After the study was finalised, two papers were published showing the difficulties in Aspartame analysis and the rapid degradation of Aspartame under environmental conditions (Berset and Ochsenbein 2012; Scheurer et al. 2012). 


\section{Results and discussion, plasticisers}

\subsection{Measured concentrations}

All measured concentrations of individual substances are tabulated in Appendix 3 and 4. An overview of the detection frequencies, i.e. the fraction of samples where a substance was found in a concentration above the limit of quantification (LOQ) for the different sample matrices, is given inTable 4.1.

Table 4.1: Percentage of samples with a concentration above LOQ for the individual substances in the different sample matrices

\begin{tabular}{lrrrrr}
\hline & Effluent & Sludge & Sediment & Fish & Egg \\
\hline \# of samples & 14 & 15 & 18 & 21 & 4 \\
DBP & $79 \%$ & $100 \%$ & $84 \%$ & $48 \%$ & $50 \%$ \\
BBP & $100 \%$ & $100 \%$ & $63 \%$ & $0 \%$ & $0 \%$ \\
DEHP & $93 \%$ & $100 \%$ & $84 \%$ & $81 \%$ & $0 \%$ \\
L79P & $7 \%$ & $31 \%$ & $16 \%$ & $0 \%$ & $0 \%$ \\
DOP & $64 \%$ & $88 \%$ & $26 \%$ & $0 \%$ & $0 \%$ \\
DINP & $86 \%$ & $100 \%$ & $95 \%$ & $19 \%$ & $50 \%$ \\
DIDP & $64 \%$ & $100 \%$ & $84 \%$ & $10 \%$ & $0 \%$ \\
DUP & $0 \%$ & $31 \%$ & $11 \%$ & $0 \%$ & $0 \%$ \\
DEHA & $71 \%$ & $94 \%$ & $68 \%$ & $0 \%$ & $0 \%$ \\
BOA & $14 \%$ & $25 \%$ & $0 \%$ & $0 \%$ & $0 \%$ \\
DINA & $0 \%$ & $0 \%$ & $0 \%$ & $0 \%$ & $0 \%$ \\
DBEEA & $0 \%$ & $0 \%$ & $0 \%$ & $0 \%$ & $0 \%$ \\
DEHZ & $0 \%$ & $6 \%$ & $0 \%$ & $0 \%$ & $0 \%$ \\
\hline
\end{tabular}

Generally, the phthalates and the adipate DEHA were most frequently found. The adipates DINA and DBEEA were not found at all. The azelate DEHZ was found only once in sludge.

In the following, the concentrations found are presented in more detail.

\subsubsection{WWTP effluent and sludge}

\section{Effluent}

Seven of the plasticisers were frequently detected in effluents, two only occasionally. The dominating plasticisers were in declining order of their median concentration DEHP, DINP, DIDP, DBP, BBP, DEHA and DOP. The median concentration of DINP was approximately one third of the value for DEHP. The concentration of DIDP was significantly lower and at the same level as DBP and BBP (Table 4.2, Figure 4.1). The concentrations often ranged 2-3 orders of magnitude. 
Table 4.2: Effluents ( $n=14)$. Percentage of samples with a concentration above LOQ (DF), minimum, median and maximum concentration ( $\mathrm{ng} / \mathrm{l}$ ). Substances with $\mathrm{DF}=0$ are not shown

\begin{tabular}{lllll}
\hline & DF & Conc, $\min$ & Conc, median & Conc, $\max$ \\
\hline DBP & $79 \%$ & $<50$ & 130 & 510 \\
BBP & $100 \%$ & 20 & 120 & 610 \\
DEHP & $93 \%$ & $<200$ & 1,600 & 15,000 \\
L79P & $7 \%$ & $<50$ & $<50$ & 270 \\
DOP & $64 \%$ & $<20$ & 22 & 59 \\
DINP & $86 \%$ & $<80$ & 470 & 27,000 \\
DIDP & $64 \%$ & $<100$ & 180 & 4,000 \\
DEHA & $71 \%$ & $<25$ & 47 & 1,300 \\
BOA & $14 \%$ & $<20$ & $<20$ & 270 \\
\hline
\end{tabular}

\section{Figure 4.1 Effluents. Median concentration (ng/l)}

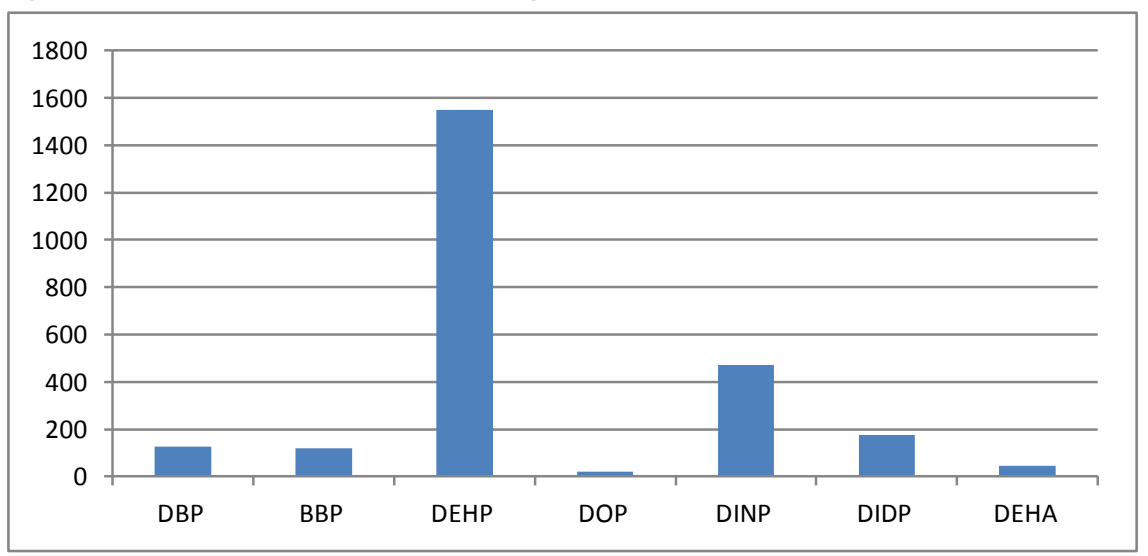

Figure 4.2 Concentration (ng/l) of plasticisers in individual effluents. Above: DEHP, DINP, DIDP, below: remaining substances, note the different $y$-axis scales.
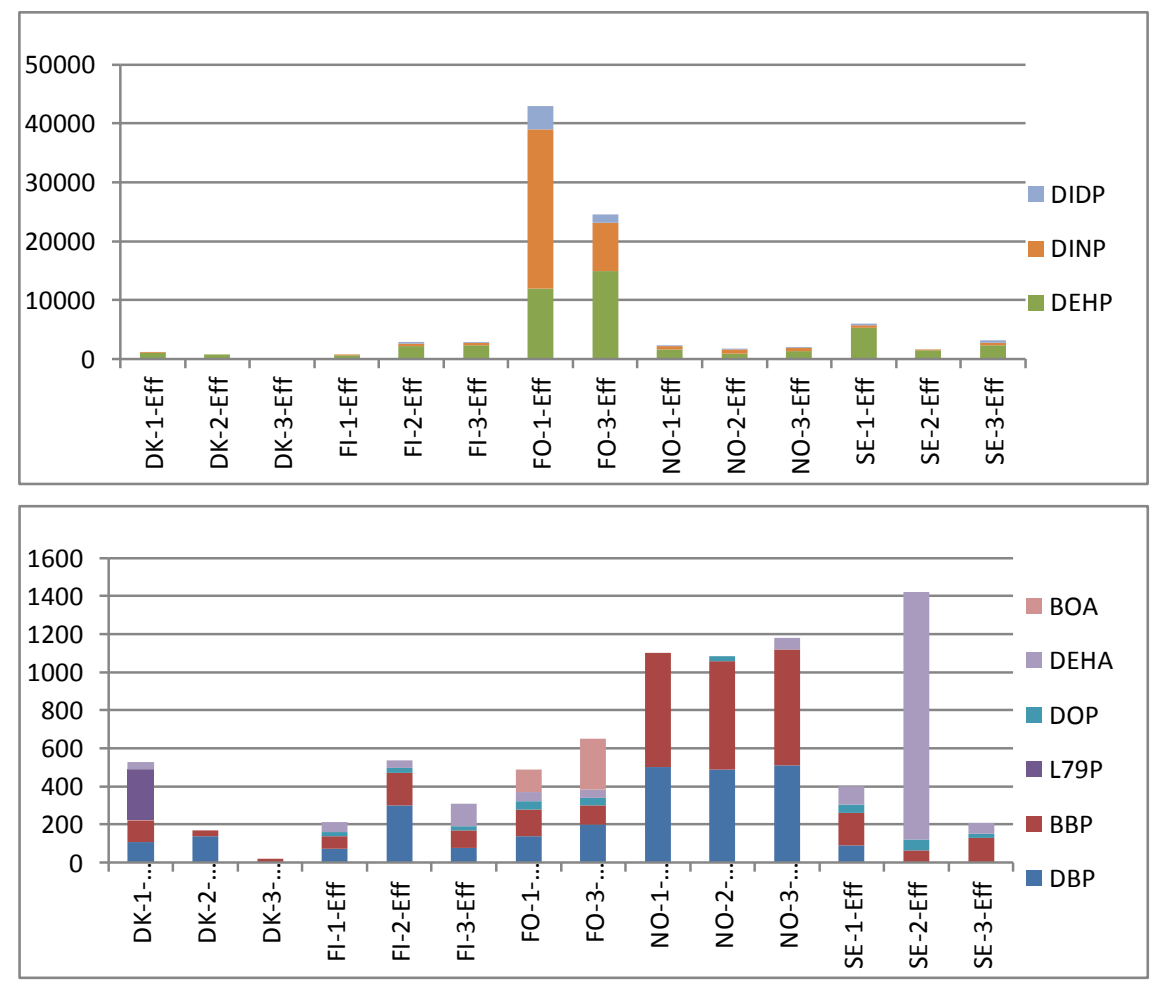
The concentrations of plasticisers in the individual effluents are presented in Figure 4.2. The effluents from Faroe Islands clearly showed the highest summed concentrations.

DEHP was the dominating plasticiser in all effluents with two exceptions: FO-1-Eff (Torshavn) where DINP dominated and DK-3-Eff (Vordingborg) where only a low concentration of BBP was detected. DINP was in most cases the second compound of importance. DINP, DBP and BBP competed for third place. Again, with DK-3-Eff as an exception, DEHP, DINP and DIDP taken together made up 54-99\% of the total amount.

The relative concentrations of DIDP to DEHP in effluents from different countries were quite similar, the ratio DINP to DEHP somewhat more varying influnced by one of the effluents from Faroe Islands (FO-1Eff) (Table 4.3). It should be observed that all Norwegian effluents are from the same WWTP. There is no data on effluents from Iceland since no samples were delivered.

Table 4.3: Relative concentrations of selected phthalates in effluents

\begin{tabular}{lrrr}
\hline Country & DINP / DEHP & DIDP / DEHP & DIDP / DINP \\
\hline DK & 0.15 & - & - \\
FI & $0.15-0.20$ & $0.05-0.10$ & $0.31-0.49$ \\
FO & $0.54-2.3$ & $0.09-0.33$ & $0.15-0.17$ \\
NO & $0.38-0.64$ & $0.11-0.21$ & $0.27-0.32$ \\
SE & $0.09-0.23$ & $0.04-0.16$ & $0.41-0.70$ \\
\hline
\end{tabular}

The domination of DEHP is somewhat puzzling since the relative amounts of DEHP, DINP and DIDP in the effluents do not mirror the use of plasticisers according to the SPIN database (Figur 2.1). The use of DEHP has successively been replaced by DINP. One possible explanation to the discrepancy between the current consumption and what is detected in WWTP effluents may be that the total amount of DEHP accumulated in the technosphere under decades still is the dominating pool of phthalates and therefore also occurs in high concentrations in WWTP effluents. For example, phthalate-containing materials in buildings constitute a large reservoir of DEHP, and in-use release from this reservoir may be a significant environmental source (Batterman et al. 2009). Another contributing factor may be that DEHP have a higher water solubility than DINP and DIDP (see Table 2.2).

When DIDP was found the concentration was always lower than that for DINP and the ratio DIDP / DINP was fairly constant (Table 4.3).

The Norwegian effluents showed the highest concentrations of DBP and BBP.

Two of the adipates were detected in the effluents, DEHA and BOA. Of these, DEHA was most frequently found (71\%) and it also has the highest usage of the adipates according to the SPIN database (Figure 2.4). DEHA was measured in concentrations $<25-1,300 \mathrm{ng} / \mathrm{l}$, with the highest concentration in an effluent from Sweden, SE-2-Eff (Ryaverken WWTP, Göteborg). In SE-2-Eff, DEHA occured in similar levels as DEHP. 
In a previous Swedish screening (Remberger et al. (2005), DEHA was not detected in any effluent water. This discrepancy may be a result of the lower LOQ in the present study ( $25 \mathrm{ng} / \mathrm{l}$ ) compared to $200 \mathrm{ng} / \mathrm{l} \mathrm{in}$ the previous.

\section{Sludge}

DINP, DEHP and DIDP were the dominating plasticisers in sludge and were found in all samples. DBP, BBP, DOP and DEHA were always or nearly always found but at much lower concentrations. L79P, DUP, BOA and DEHZ was occasionally found (Table 4.4, Figure 4.3).

Table 4.4: Sludge ( $n=15)$. Percentage of samples with a concentration above LOQ (DF), minimum, median and maximum concentration $(\mu \mathrm{g} / \mathrm{kg} \mathrm{dw})$. Substances with $\mathrm{DF}=0$ are not shown

\begin{tabular}{lrrrr}
\hline & DF & Conc, $\min$ & Conc, median & Conc, max \\
\hline DBP & $100 \%$ & 27 & 85 & 610 \\
BBP & $100 \%$ & 81 & 200 & 1,100 \\
DEHP & $100 \%$ & 12,000 & 24,000 & 67,000 \\
L79P & $31 \%$ & $<8$ & $<8$ & 390 \\
DOP & $88 \%$ & $<10$ & 68 & 220 \\
DINP & $100 \%$ & 17,000 & 73,000 & 160,000 \\
DIDP & $100 \%$ & 1,800 & 14,000 & 42,000 \\
DUP & $31 \%$ & $<20$ & $<20$ & 1,400 \\
DEHA & $94 \%$ & $<8$ & 29 & 970 \\
BOA & $25 \%$ & $<10$ & $<8$ & 1,100 \\
DEHZ & $6 \%$ & $<10$ & 32 \\
\hline
\end{tabular}

Figure 4.3 Sludge. Median concentrations $(\mu \mathrm{g} / \mathrm{kg} \mathrm{dw})$.

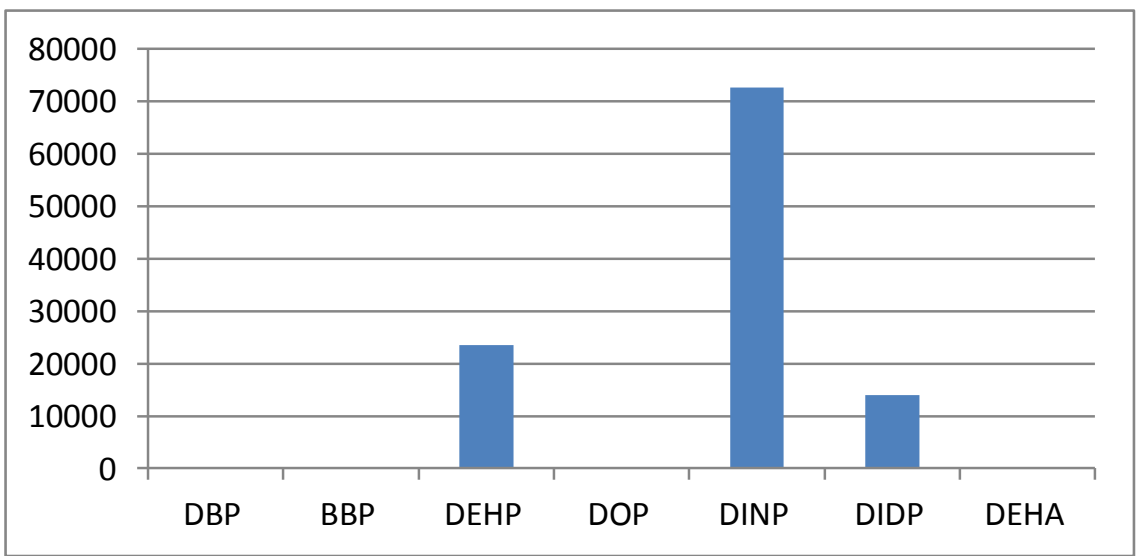

The concentrations of the individual plasticisers ranged about one order of magnitude which is quite small compared to the case for effluents.

The concentrations in sludge in idividual samples are presented in Figure 4.4 . 
Figure 4.4 Concentration $(\mu \mathrm{g} / \mathrm{kg} \mathrm{dw})$ of plasticisers in individual sludge samples. Above: DEHP, DINP, DIDP, below: remaining substances, note the different $y$-axis scales
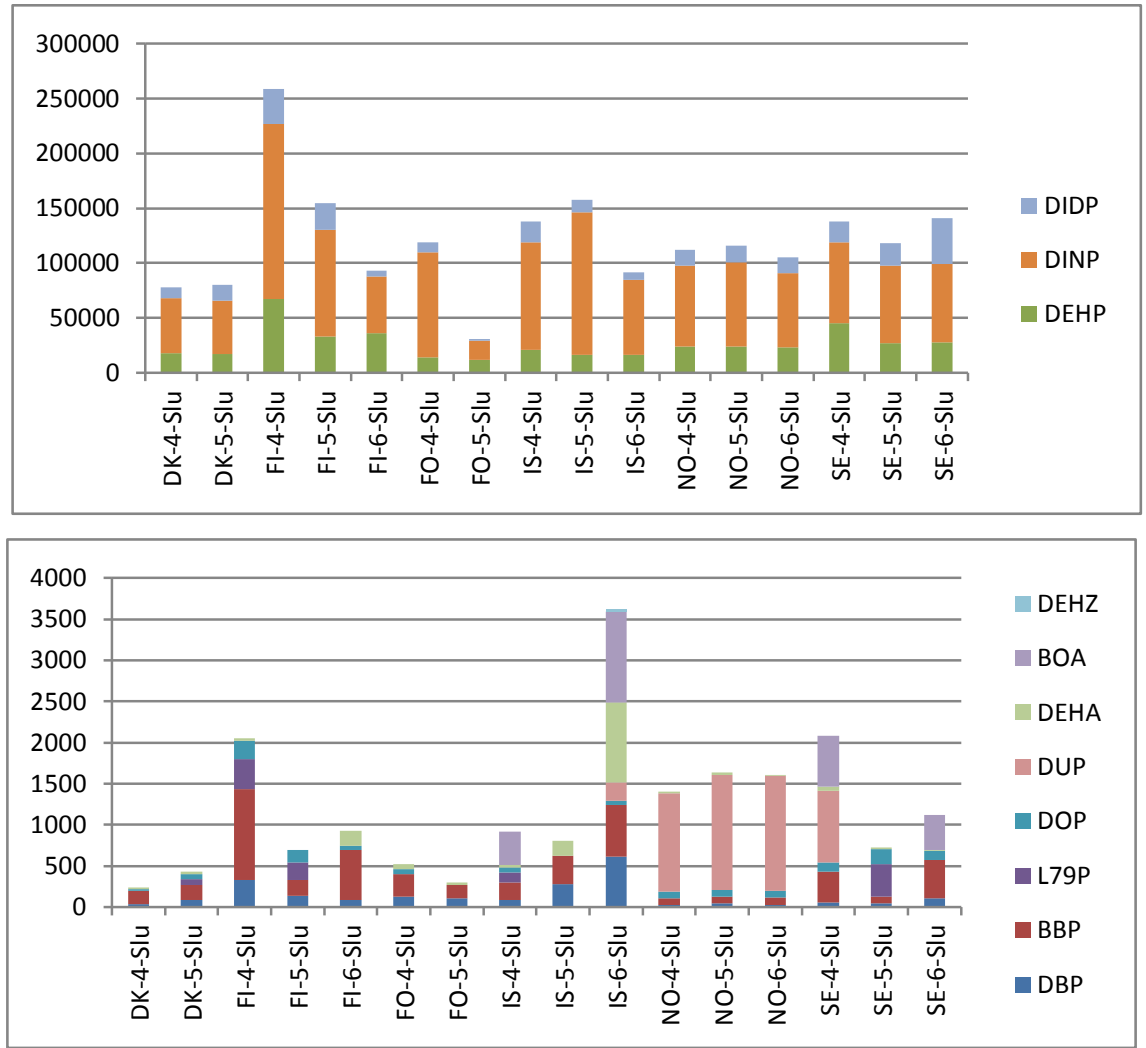

DINP, DEHP and DIDP taken together made up $96-99.7 \%$ of the summed concentration of all measured plasticisers.

Relative concentrations of DEHP, DINP and DIDP are illustrated in Figure 4.5

Figure 4.5 Relative concentration of DEHP, DINP and DIDP in individual sludge samples

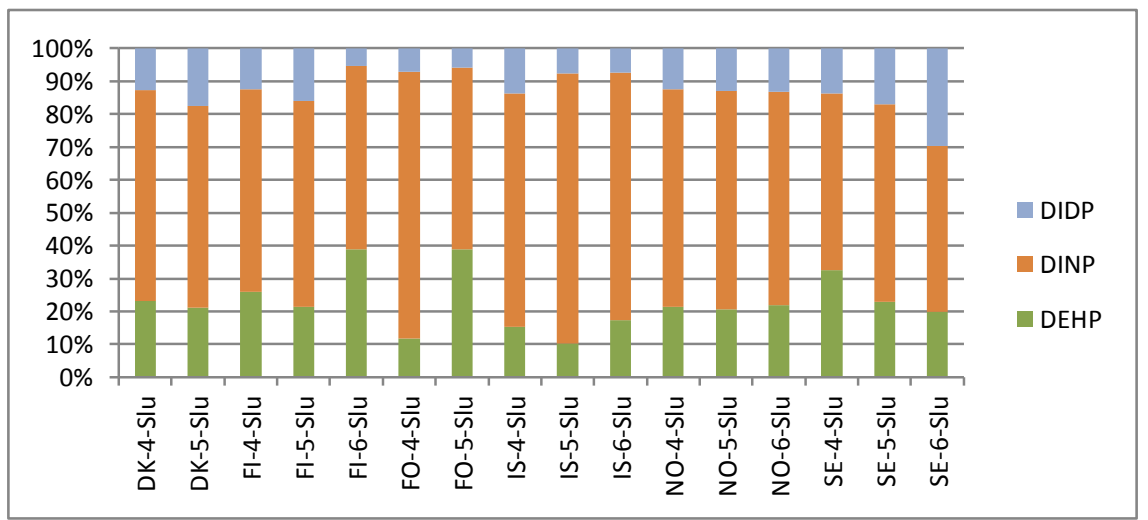

There were no great differences in the composition of the plasticisers in the sludge among the Nordic countries. The highest summed concentration, 
$260,000 \mu \mathrm{g} / \mathrm{kg} \mathrm{dw}$, was found in a FI-4-Slu (Turku). This concentration can also be stated as $0.026 \% \mathrm{dw}$.

The concentrations of DINP, DEHP and DIDP were in the same range as detected in a Swedish survey 2006: DINP 37,000-65,000 $\mu \mathrm{g} / \mathrm{kg} \mathrm{dw}$, DEHP 36,000-80,000 $\mu \mathrm{g} / \mathrm{kg} \mathrm{dw}$, DIDP 15,000-51,000 $\mu \mathrm{g} / \mathrm{kg} \mathrm{dw}$ (PalmCousins et al. 2007).

The composition of phthalates in sludge (Figure 4.3) mirrors quite well the consumption of phthalates in the Nordic countries (Figure 2.1).

The median concentrations in effluent water and sludge were used to calculate the concentration ratios DINP / DEHP and DIDP / DEHP. The result (Table 4.5) of this calculation clearly shows that the heavier phthalates, DINP and DIDP, are enriched relative to DEHP in the solid phase (sludge). This is expected given their high $\mathrm{K}_{\mathrm{ow}}$ and low water solubility.

Table 4.5: Relative concentrations (median for all samples) of DINP and DIDP to DEHP in effluent and sludge

\begin{tabular}{lrr}
\hline Matrix & DINP / DEHP & DIDP / DEHP \\
\hline Effluent & 0.2 & 0.1 \\
Sludge & 3 & 0.6 \\
\hline
\end{tabular}

The two adipates DEHA and BOA were, as was the case for the effluents, also detected in the sludge. The detection frequencies were $94 \%$ and $25 \%$, respectively. BOA was only detected in sludge collected from Iceland and Sweden. The highest concentrations of both BOA (1 $100 \mu \mathrm{g} / \mathrm{kg} \mathrm{dw})$ and DEHA $(970 \mu \mathrm{g} / \mathrm{kg} \mathrm{dw}$ ) occurred in a sample from Island IS-6-Slu (Borg-Grimness).

\subsubsection{Sediment}

Six out of 13 plasticisers were frequently detected and three less frequently. The quantitatively dominating phatlates were in declining order DINP, DEHP and DIDP (Table 4.6, Figure 4.). Their concentrations ranged 1-2 orders of magnitude. The adipate, DEHA, was also frequently detected but in lower concentrations. Four plasticisers were not detected in any of the sediments: BOA, DEHZ, DINA, and DBEEA.

Table 4.6: Sediments ( $n=18$ ). Percentage of samples with a concentration above LOQ (DF), minimum, median and maximum concentration $(\mu \mathrm{g} / \mathrm{kg} \mathrm{dw})$. Substances with $\mathrm{DF}=0$ are not shown

\begin{tabular}{lrrrr}
\hline & Det freq & Conc, $\min$ & Conc, median & Conc, max \\
\hline DBP & $84 \%$ & $<8$ & 45 & 410 \\
BBP & $63 \%$ & $<4$ & 16 & 3,000 \\
DEHP & $84 \%$ & $<80$ & 1,000 & 9,500 \\
L79P & $16 \%$ & $<8$ & $<8$ & 29 \\
DOP & $26 \%$ & $<5$ & $<5$ & 12 \\
DINP & $95 \%$ & $<30$ & 1,900 & 17,000 \\
DIDP & $84 \%$ & $<10$ & 510 & 36,000 \\
DUP & $11 \%$ & $<1$ & 3 & 58 \\
DEHA & $68 \%$ & & & 27 \\
\hline
\end{tabular}


Figure 4.6 Median concentrations $(\mu \mathrm{g} / \mathrm{kg} \mathrm{dw})$ of selected plasticisers in all sediment samples

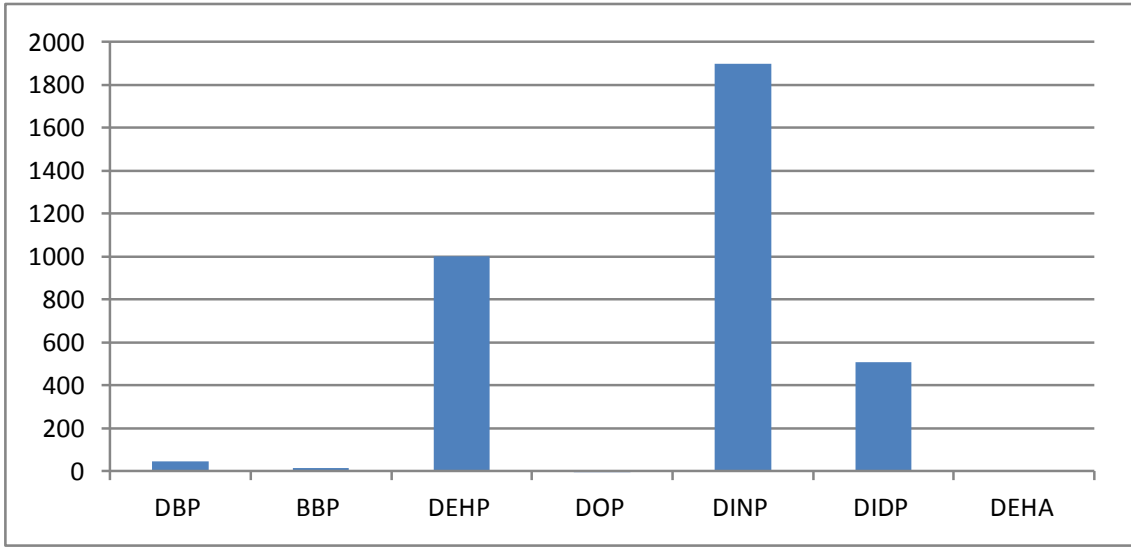

Figure 4.7 Concentration $(\mu \mathrm{g} / \mathrm{kg} \mathrm{dw}$ ) of plasticisers in individual sediment samples. Above: DEHP, DINP, DIDP, below: remaining substances, note the different $y$-axis scales
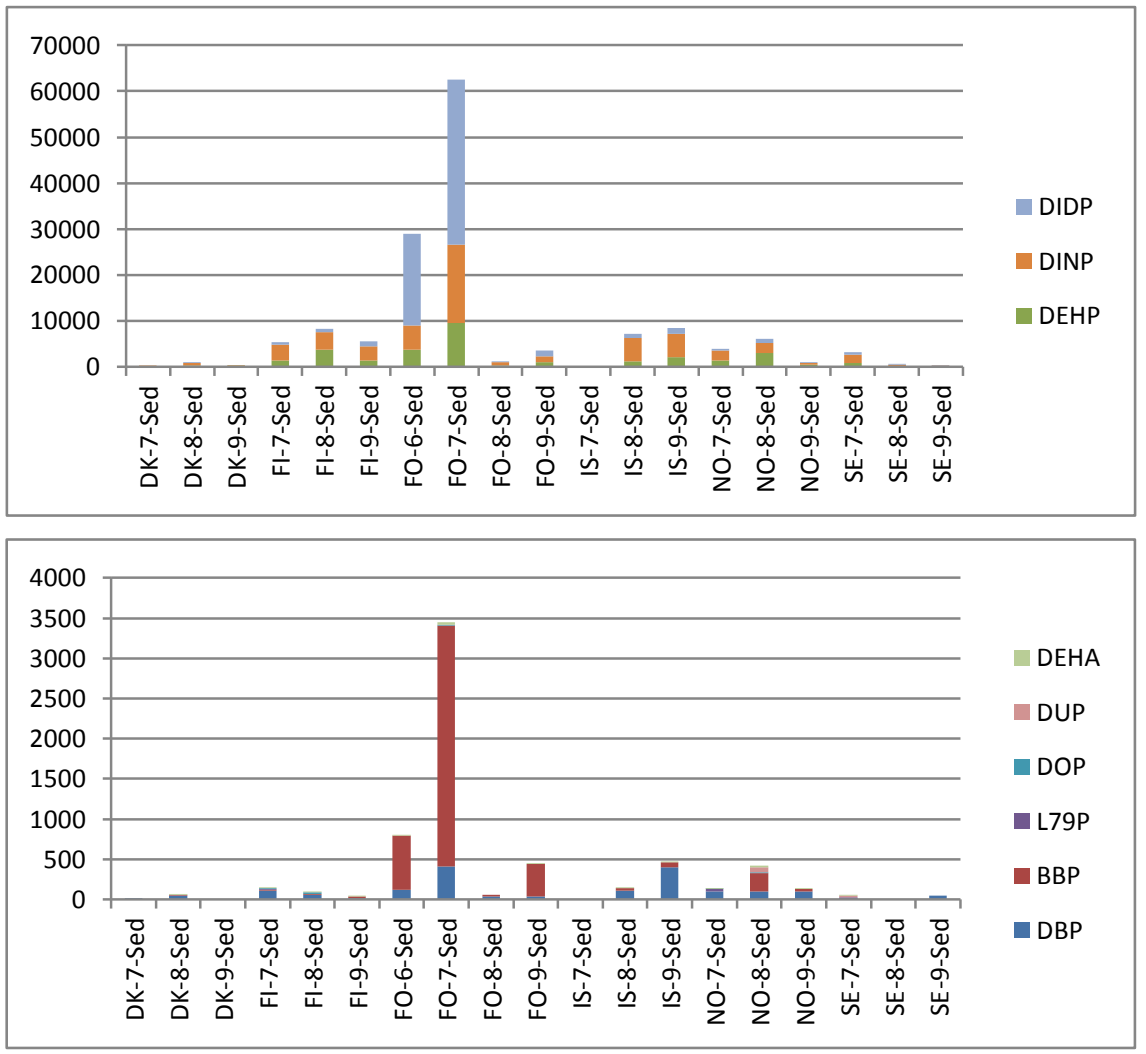

The concentration of plasticisers in individual sediments are presented in Figure 4.7. Two samples from Faroe Islands (Torshavn harbour) showed the highest total concentrations dominated by DIDP. In general the sediments were dominated by DINP or DEHP (Figure 4.8). 
Figure 4.8 Sediment. Relative concentrations of individual plasticisers. For the sample IS-7-Sed all concentrations were $<\mathrm{LOQ}$

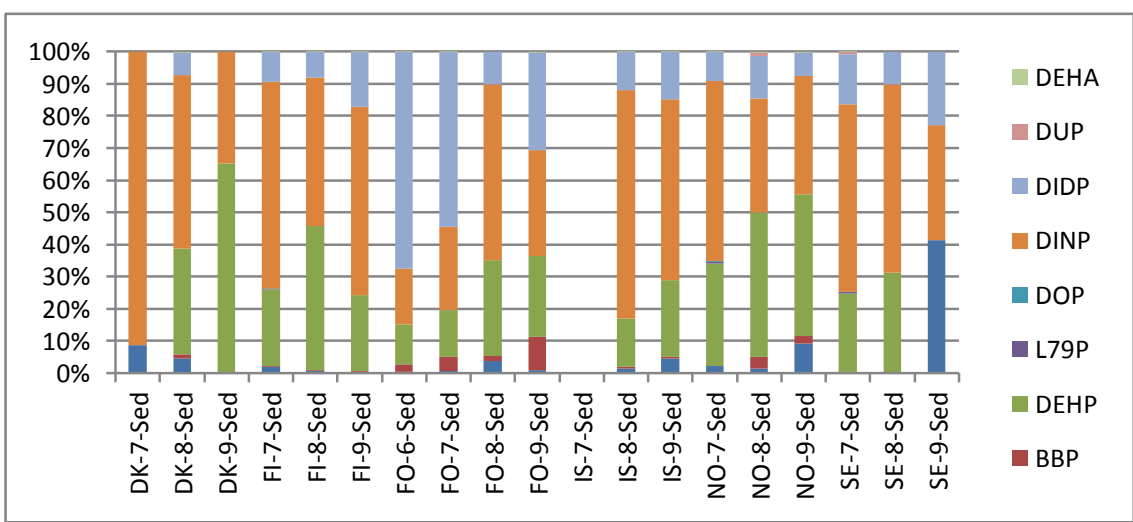

The Danish sediments are from locations not directly influenced by WWTPs while the opposite is true for the sediments from Finland. The Finnish sediments all show higher concentrations than the Danish.

The sediments showing the highest concentrations, FO-6-sed and FO7-sed, are directly influenced by a WWTP.

NO-8-Sed and NO-9-Sed are from the harbor in Bergen (depth 26 and $79 \mathrm{~m}$ respectively), NO-7-Sed are $30 \mathrm{~km}$ away from Bergen and in a vicinity of a marina (depth $13 \mathrm{~m}$ ). The sediment from the greatest depth showed the lowest concentrations which may reflect a higher degree of degradation in the older (deeper) sediments.

The sediments SE-7-Sed and SE-8-Sed are on increasing distance from the mouth of Göta River, the sediment SE-9-Sed is from a background location on the Swedish West Coast. This series of sediments showed clearly decreasing plasticiser concentrations when moving from urban to background areas.

\subsubsection{Biota}

\section{Fish muscle}

Four out of 13 plasticisers, all phthalates, were detected in fish muscle. The concentrations were close to LOQ making the quantification uncertain (Table 4.7).

Table 4.7: Fish muscle ( $n=16)$. Percentage of samples with a concentration above LOQ (DF), minimum, median and maximum concentration $(\mu \mathrm{g} / \mathrm{kg} \mathrm{ww})$. Substances with $\mathrm{DF}=0$ are not shown

\begin{tabular}{lrrrr}
\hline & Det freq & Conc, min & Conc, median & Conc, max \\
\hline DBP & $50 \%$ & $<4$ & 0.1 & 30 \\
DEHP & $75 \%$ & $<4$ & 7.7 & 53 \\
DINP & $<40$ & $<40$ & 290 \\
DIDP & $25 \%$ & $<40$ & $<40$ & 410 \\
\hline
\end{tabular}

Concentrations in individual fish muscle samples are illustrated in Figure 4.9 and Figure 4.10. 
Figure 4.9 Concentration ( $\mu \mathrm{g} / \mathrm{kg} \mathrm{ww}$ ) of plasticisers in individual samples of fish muscle. IS-11-FIS may be contaminated, see text

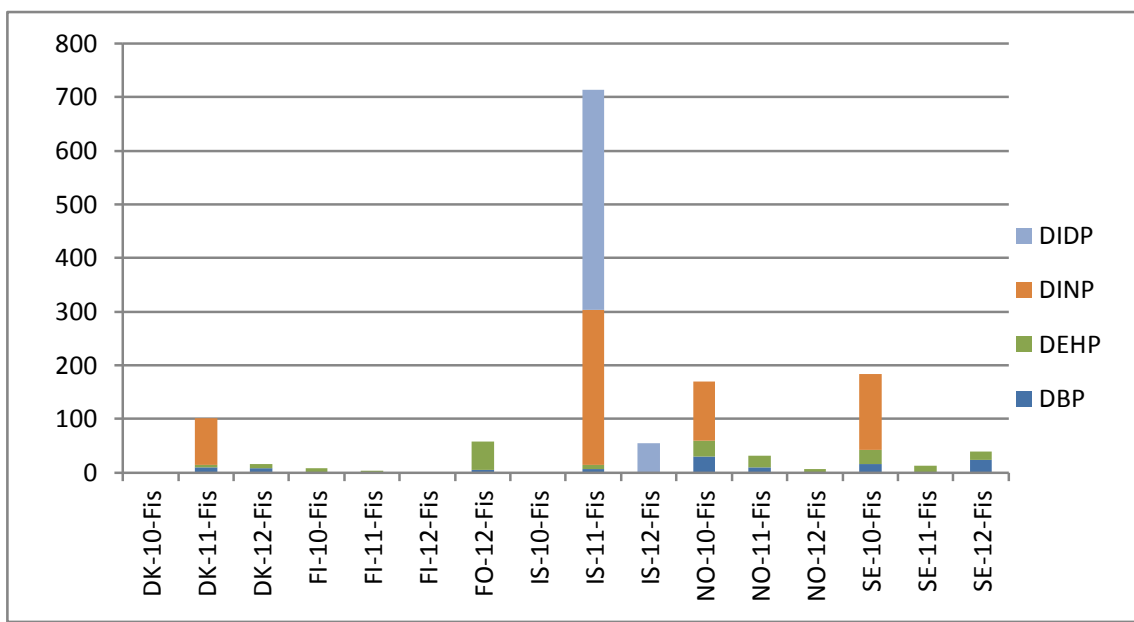

Figure 4.10 Concentration ( $\mu \mathrm{g} / \mathrm{kg} \mathrm{ww}$ ) of plasticisers in individual samples of fish muscle sorted according to species. IS-11-FIS may be contaminated, see text

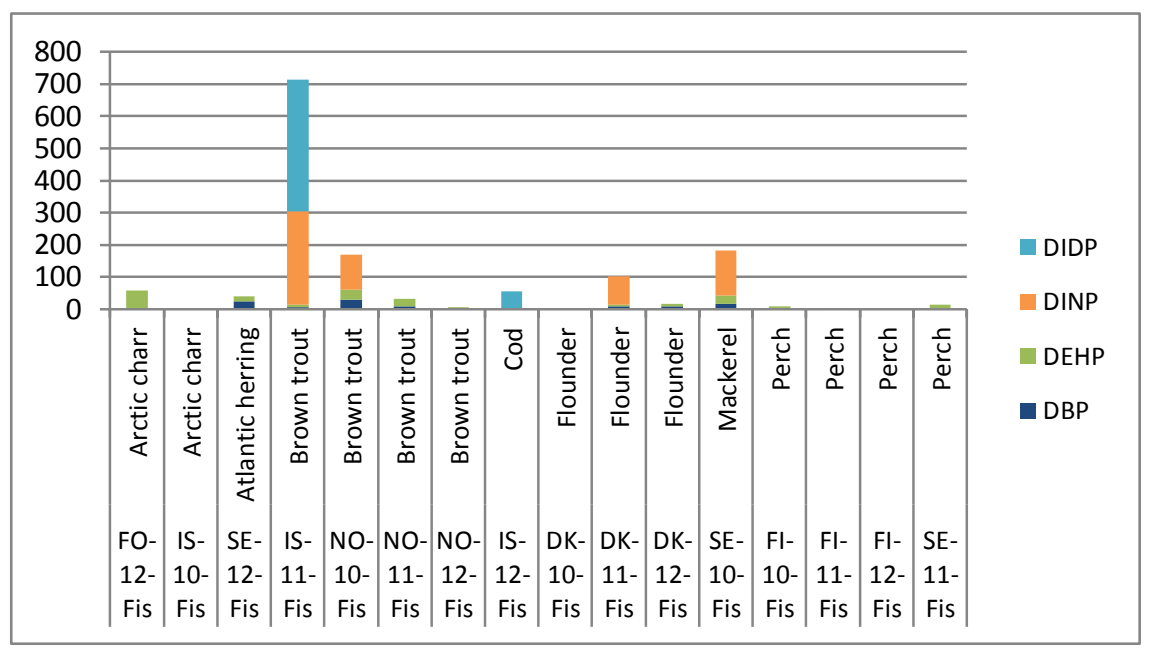

The samples FO-12-Fis, FI-11-Fis, IS-12-Fis and SE-11-Fis represents remote areas without direct influence from discharges.

One sample, IS-11-Fis (Brown trout), showed somewhat elevated concentrations of DINP and DIDP compared to IS-10-Fis (Arctic charr) which was caught in the same lake (Pingvallavatn). Sample IS-11-Fis was delivered in a glass jar with a lid containing a gasket that proved to contain DINP and DIDP (see text following Table 3.6), sample IS-10-Fis (Arctic char), was delivered as whole fish and prepared at the analytical laboratory and stored in heat cleaned glass jars closed with aluminium foil lined lids without gasket (prepared in the analytical laboratory) until analysis. One possible explanation for the difference in results may be contamination from the gasket.

The results for DEHP agree with Swedish measurements 2004. In that investigation DEHP (but no other plasticiser) was analysed in fish muscle, mostly from perch (Percha fluviatilis), collected from 15 reference lakes i 
Sweden. Most of the samples contained $<8 \mu \mathrm{g} / \mathrm{kg}$ ww of DEHP but in a few samples slightly higher concentrations were found (Sternbeck et al., 2004).

The low concentrations in fish muscle may be the result of the low water solubility of the plasticisers and the metabolism in fish (Albro et al., 1989; Barron et al., 1995; Silva et al., 2004).

\section{Fish liver}

Two out of 13 plasticisers, both phthalates (DBP and DEHP), were detected in fish liver. Five samples were analysed, DEHP was detected in all five, DBP i two (Table 4.8).

Table 4.8: Fish liver ( $n=5)$. Percentage of samples with a concentration above LOQ (DF), minimum, median and maximum concentration ( $\mu \mathrm{g} / \mathrm{kg} \mathrm{ww})$. Substances with $\mathrm{DF}=0$ are not shown

\begin{tabular}{lrrrr}
\hline & Det freq & Conc, $\min$ & Conc, median & Conc, max \\
\hline DBP & $40 \%$ & $<4$ & $<4$ & 130 \\
DEHP & $100 \%$ & 17 & 26 & 92 \\
\hline
\end{tabular}

The samples were all liver from cod caught $30 \mathrm{~km}$ off the Faroe Island coast (background area). Individual results are given in Table 4.9.

Table 4.9: Fish liver. Concentration ( $\mu \mathrm{g} / \mathrm{kg} \mathrm{ww})$ of plasticisers in individual samples of fish liver

\begin{tabular}{llcr}
\hline & Specie & DBP & DEHP \\
\hline FO-15-Fis & Cod, Gadus morhua & 130 & 92 \\
FO-16-Fis & Cod, Gadus morhua & 4.3 & 26 \\
FO-17-Fis & Cod, Gadus morhua & $<4$ & 40 \\
FO-18-Fis & Cod, Gadus morhua & $<4$ & 17 \\
FO-19-Fis & Cod, Gadus morhua & $<4$ & 26 \\
\hline
\end{tabular}

The concentrations of DEHP and DBP in liver were somewhat higher than in fish muscle (Table 4.7).

\section{Bird eggs}

Two out of 13 plasticisers, both phthalates (DBP and DINP) were detected in bird eggs. Four samples were analysed, DBP was detected in two, DINP in two (Table 4.10). The concentrations were close to LOQ making the quantification uncertain.

Table 4.10: Bird eggs ( $n=4)$. Percentage of samples with a concentration above LOQ (DF), minimum, median and maximum concentration $(\mu \mathrm{g} / \mathrm{kg} \mathrm{ww})$. Substances with $\mathrm{DF}=0$ are not shown

\begin{tabular}{lrrrr} 
& Det freq & Conc, $\min$ & Conc, median & Conc, $\max$ \\
\hline DBP & $50 \%$ & 4.2 & 4.8 & 5.3 \\
DINP & $50 \%$ & $<40$ & 40 & 160 \\
\hline
\end{tabular}

The investigation included four guillemot egg mixtures (mixture of five egg), two from Sweden (Uria aalge) and two from Faroe Islands (Cepphus grylle). Individual results are given in Table 4.11 and Figure 4.11. 
Table 4.11: Bird eggs. Concentration ( $\mu \mathrm{g} / \mathrm{kg} \mathrm{ww}$ ) of plasticisers in individual samples of bird eggs

\begin{tabular}{llrr}
\hline & Specie & DBP & DINP \\
\hline FO-13-Egg & Black guillemot Cepphus grylle & $<4$ & 160 \\
FO-14-Egg & Black guillemot Cepphus grylle & 5.3 & 120 \\
SE-13-Egg & Common Guillemot, Uria aalge & 4.2 & $<40$ \\
SE-14-Egg & Common Guillemot, Uria aalge & $<4$ & $<40$ \\
\hline
\end{tabular}

Figure 4.11 Concentration ( $\mu \mathrm{g} / \mathrm{kg} \mathrm{ww}$ ) of plasticisers in individual samples of bird eggs. Unfilled bars indicate that the substance was not found; the heights of the bars indicate LOQ

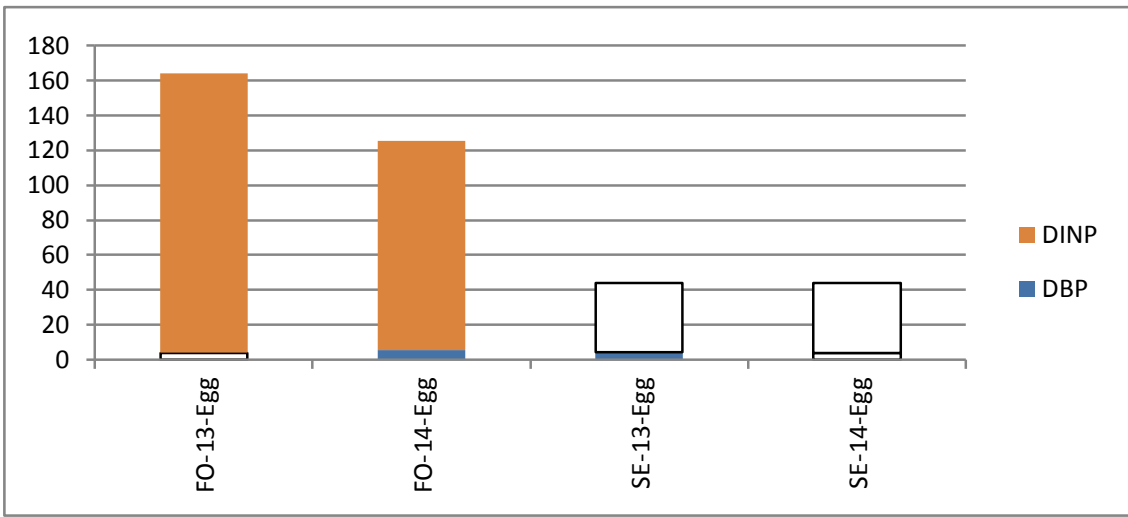

In the two samples from Stora Karlsö, Sweden, the only plasticiser found was DBP in one of the samples at a close to LOQ concentration. The eggs from Faroe Islands were collected at a remote area. The concentration of DBP was in the same range as in the Swedish eggs but also DINP was found. The samples from Faroe Islands were stored in the type of jars having a gasket potentially containing DINP and DIDP (see text following Table 3.6). Therefore, contamination from the sample container could not be ruled out.

\subsection{Initial ecotoxicological assessment}

As an initial ecotoxicological assessment the measured concentrations in effluents and sediment were compared with PNEC values. This was made for the substances frequently found in these matrices. In addition to the PNECs presented in Table 2. tentative PNECs were derived for DUP and DEHA based on the ecotoxicological data presented by Lambert et al. (2010) and the assessment factor methodology for the $\mathrm{PNEC}_{\text {water }}$ and the equilibrium partition methodology (EqP) for the $\mathrm{PNEC}_{\text {sediment }}$ (ECHA 2008; ECHA 2010), see Table 4.12. For DOP and L79P there were not sufficient data available for PNEC derivation. 
Table 4.12: Tentative predicted no effect concentrations (PNEC) estimated for DUP and DEHA, based on data presented in Lambert et al. (2010). No consideration was taken to potential differences between freshwater and marine water species. No in depth review of the data was possible within the scope of the present study, which means that the PNECs presented here are only rough estimations

\begin{tabular}{|c|c|c|}
\hline $\begin{array}{l}\text { Sub- } \\
\text { stance }\end{array}$ & PNEC & Comment \\
\hline \multirow[t]{2}{*}{ DUP } & $\mathrm{PNEC}_{\text {freshwater }} \approx 2 \mu \mathrm{g} / \mathrm{l}$ & $\begin{array}{l}\text { PNEC based on the acute NOEC ( } 96 \mathrm{~h} \text {, Cyprinodon varie- } \\
\text { gatus) } 0.22 \mathrm{mg} / \mathrm{l} \text { as it was lower than the chronic NOECs, and } \\
\text { AF } 100 \text { as data from two chronic studies was available but } \\
\text { not covering the potentially most sensitive species. }\end{array}$ \\
\hline & PNEC $_{\text {sediment }} \approx 3000 \mathrm{mg} / \mathrm{kg} \mathrm{dw}$ & $\begin{array}{l}\text { PNEC freshwater sediment derived with the EqP method and } \\
\text { a } K_{o c} \text { of } 14,110,000 \mathrm{l} / \mathrm{kg} \text { as predicted with the EPI Suite } 4.10 \\
\text { software. An AF of } 10 \text { may be added to consider ingestion as } \\
\text { an exposure route. }\end{array}$ \\
\hline \multirow[t]{2}{*}{ DEHA } & $\mathrm{PNEC}_{\text {freshwater }} \approx 0.5 \mu \mathrm{g} / \mathrm{l}$ & $\begin{array}{l}\text { PNEC based on MATC* }(21 \mathrm{~d}, \text { Daphnia magna })=0.024-0.052 \\
\mathrm{mg} / \mathrm{l} \text { and AF } 50 \text { as data from two chronic studies were } \\
\text { available. }\end{array}$ \\
\hline & $\mathrm{PNEC}_{\text {sediment }} \approx 0.7 \mathrm{mg} / \mathrm{kg} \mathrm{dw}$ & $\begin{array}{l}\text { PNEC derived with the EqP method and a } \mathrm{K}_{\mathrm{oc}} \text { of } 15,488 \mathrm{l} / \mathrm{kg} \\
\text { listed as an experimental value in the EPI Suite } 4.10 \text { soft- } \\
\text { ware. An AF of } 10 \text { may be added to consider ingestion as an } \\
\text { exposure route. }\end{array}$ \\
\hline
\end{tabular}

* MATC $=$ maximum acceptable concentration, i.e. an AF may already have been applied

DBP and BBP and DEHA were all found frequently in effluent waters. The maximum concentration of DEHA found in the effluent waters did exceed the PNEC. WWTP effluents will however be diluted after discharge. Also DEHP, DINP and DIDP were frequently detected but these substances are not expected to cause negative effects due to exposure via water (see Chapter 2). The DEHP environmental quality standard (AA-EQS) of $1.3 \mu \mathrm{g} / \mathrm{l}$ (EU Directive 2008/105/EC) was however exceeded in a number of samples, in one sample also after the dilution factor of 10 was applied. The EQS was set to prevent secondary poisoning of predators (DEHP Substance data sheet 2005), which makes this an indication of a risk for the aquatic ecosystem and not only the pelagic community. For DOP no assessment was possible due to lack of data but as the maximum concentration measured in the effluents ( $59 \mathrm{ng} / \mathrm{l})$ was not exceeding the concentrations measured for the other substances, there is thus no strong indication of risk but a substance specific PNEC is needed for a proper assessment.

All substances included in the screening, with the exception of BOA, DINA, DEHZ and DBEEA, were more or less frequently found in sediments. Comparisons of the maximum levels found with the PNEC for freshwater show that for DBP, DEHP, DUP, DEHA and BBP ${ }^{1}$ the measured concentration did not exceed the PNEC. Adding a safety factor of 10 
to the PNEC to also consider ingestion (for PNEC derived with EqP) showed that DBP and BBP occurred in concentrations above the PNEC. Adding further safety factors to consider the marine environment (ECHA 2008) showed that maximum concentrations of DBP, BBP and DEHA all exceeded the PNEC. It should also be noted that DEHP concentrations (maximum $9.5 \mathrm{mg} / \mathrm{kg} \mathrm{dw}$, median $1.0 \mathrm{mg} / \mathrm{kg} \mathrm{dw}$ ) were in levels which may affect microbial processes (see Chapter 2). DINP and DIDP were also frequently found in sediments but PNECs are not available and no negative effects are expected (see Chapter 2). For L79P and DOP no assessment is possible due to lack of data.

DBP, DEHP, DINP and DIDP were found in one or more biota sample. DBP and DEHP have been found to be toxic, DINP and DIDP to be potentially toxic, over prolonged exposure (Lambert et al. 2010). The fact that these substances were found in biota may thus be of concern but it is out of scope in the present study to assess whether the measured concentrations are in levels that can cause negative effects. 



\section{Conclusions, plasticisers}

The majority of plasticisers included in the screening were frequently found in effluents from WWTPs in all the Nordic countries. The phthalates DEHP, DINP and DIDP were quantitatively dominating. The individual concentrations were generally in the range up to $6,000 \mathrm{ng} / \mathrm{l}$, but in effluents from Faroe Islands concentrations up to $27,000 \mathrm{ng} / \mathrm{l}$ were measured.

The phthalates DBP and BBP and the adipate DEHA, were also frequently detected in effluents but in lower concentrations. This indicates that municipal sewage systems can be an important pathway for these substances to the environment

Almost all (11 of 13) plasticisers analysed for were found in WWTP sludge. The compounds which occurred in the highest concentrations were DINP, DEHP and DIDP. The individual compounds were found approximately in proportion to their current use and earlier use patterns.

Although the number of samples were too small to draw extensive conclusions on differences between the countries it is striking that the highest concentrations in effluents and sediments were found in samples from Faroe Islands, where also low concentrations in sludge could indicate an inefficient treatment plant process.

Many of the substances were found in sediments. Higher concentrations were generally found in samples from potentially affected areas compared to background areas. The relative concentration of substances in sediments showed a similar pattern to what was found for sludge.

The phthalates DBP, DEHP, DINP and DIDP were detected in one or more biological sample in concentrations close to LOQ. Adipates were not detected at all.

The low concentrations observed in fish may be a consequence of the low water solubility (low exposure) of the most common plasticisers (Table 2.2). Moreover, the ester bonds in the plasticisers are readily hydrolysed (Albro et al., 1989; Barron et al., 1995; Silva et al. 2004) by different enzymes (esterase and lipase) (Shintani 2000; Suzuki et al. 2001, Kato et al. 2003) which means that compounds containing ester bonds have short half-life in organisms.

Some of the substances included in the screening may be harmful to the environment. The fact that the concentrations found in effluents and sediments were close to or exceeded PNEC in several cases indicate the need for further studies to assess potential risks. Furthermore, some of the substances were also found in biota. 
As already mentioned, all stages of the determination process must be carefully checked for possible contamination. This is underlined by the discussion on possible contamination of liver and egg samples in this work. To avoid such a pitfall, blank controls of the sampling equipment must be performed before starting collection of samples for analysis, and this equipment only should be used for all sampling and sample storage. The sampling and preparation environment may be controlled by "sampling blanks" as was used in this study. Also, the analytical method was carefully checked for possible contamination. This implies control of equipment, solvents and procedure (analytical blank samples). 


\section{Results, sweeteners}

The measured concentrations of sweeteners in individual samples are tabulated in Appendix 6.

\section{Effluents}

An overview of the results for effluents, where detection frequencies, minimum, median and maximum concentration are shown, is given in Table 6.1.

Table 6.1: Effluents ( $n=14)$. Percentage of samples with a concentration above LOQ (DF), minimum, median and maximum concentration $(\mu \mathrm{g} / \mathrm{l})$

\begin{tabular}{lllll}
\hline & DF & Conc, $\min$ & Conc, median & Conc, max \\
\hline Aspartam & $0 \%$ & & $<0.08$ & \\
Cyclamate & $86 \%$ & $<0.01$ & 0.91 & 25 \\
Sucralose & $100 \%$ & 0.37 & 2.6 & 5 \\
\hline
\end{tabular}

Sucralose was most frequently detected followed by cyclamate, while the concentrations of aspartam were below the LOQ in all samples. The concentrations of cyclamate and sucralose in the individual effluents are shown inFigure 6.1 .

Figure 6.1 Concentration $(\mu \mathrm{g} / \mathrm{l})$ of cyclamate and sucralose in individual effluents

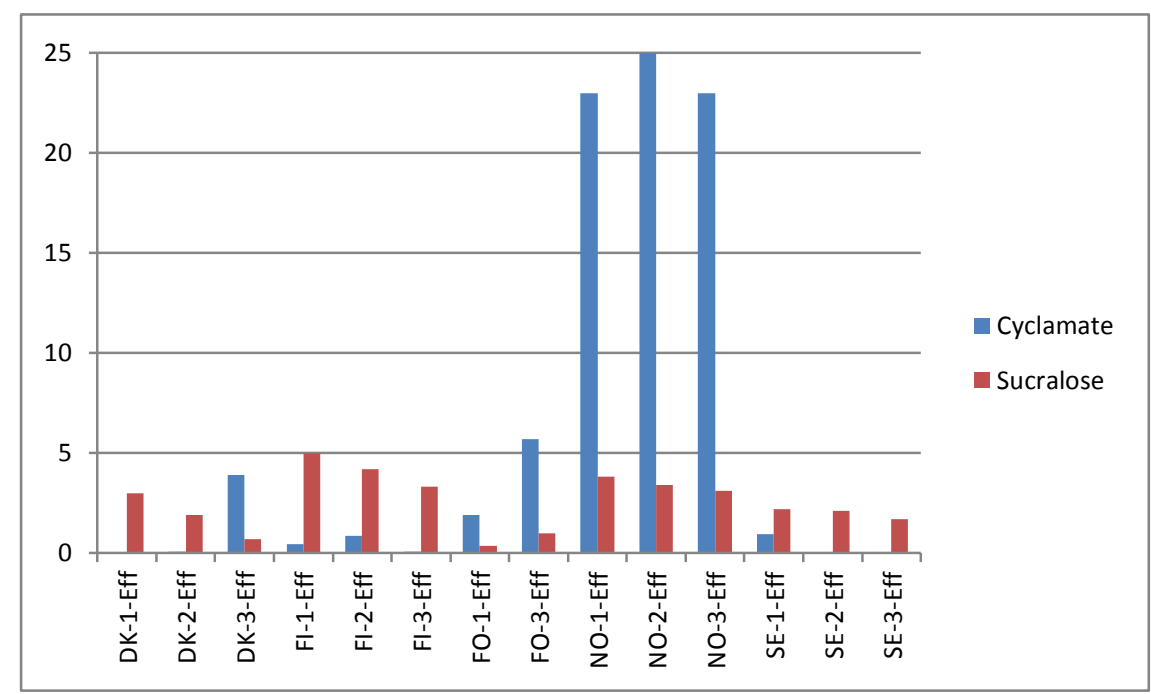

The highest effluent concentrations of cyclamate (23-25 $\mu \mathrm{g} / \mathrm{l})$ were measured in the Norwegian samples. They were however collected at the same WWTP and during the same day which explains the small variation in concentration among the those samples. The cyclamate concen- 
tration in the remaining samples were scattered in the range $<0.01-5.7$ $\mu \mathrm{g} / \mathrm{l}$. Sucralose spanned almost the same concentration range (0.37-5 $\mu \mathrm{g} / \mathrm{l})$ Ther was no apparent correlation between cyclamate and sucralose concentrations. The highest sucralose concentrations were measured in Finnish samples, the lowest in samples from Faroe Islands and Denmark.

Effluents from the three WWTPs representing Sweden in this investigation were also analysed for sucralose in 2007 (Brorström-Lundén 2008). The results were approximately equal or (in one case) somewhat lower in 2011 than in 2007 (Table 6.2).

Table 6.2: Sucralose in effluent waters ( $\mu \mathrm{g} / \mathrm{I})$ sampled in 2007 (Brorström-Lundén 2008) and 2011 (current investigation)

\begin{tabular}{llrr}
\hline & & $\mathbf{2 0 0 7}$ & $\mathbf{2 0 1 1}$ \\
\hline SE-1-Eff & Öhn WWTP, Umeå & 4.0 & 2.2 \\
SE-2-Eff & Ryaverken WWTP, Göteborg & 2.8 & 2.1 \\
SE-3-Eff & Gässlösa WWTP, Borås & 1.8 & 1.7 \\
\hline
\end{tabular}

\section{Sludge}

An overview of the results for sludge, where detection frequencies, minimum, median and maximum concentration are shown, is given in Table 6.3.

Table 6.3: Sludge ( $n=12)$. Percentage of samples with a concentration above LOQ (DF), minimum, median and maximum concentration $(\mu \mathrm{g} / \mathrm{kg} \mathrm{ww})$

\begin{tabular}{lrrrr}
\hline & DF & Conc, $\min$ & Conc, median & Conc, max \\
\hline Aspartam & $0 \%$ & & $<1$ & \\
Cyclamate & $62 \%$ & $<0.2$ & 0.33 & 55 \\
Sucralose & $92 \%$ & 2.1 & 3.9 & 12 \\
\hline
\end{tabular}

As was the case for effluents, sucralose was most frequently detected followed by cyclamate, while the concentrations of aspartam were below the LOQ in all samples.

The range of results for sludge (on a wet weight basis) do not differ much from the results for effluents (Table 6.1). This indicates that these substances are not preferentially adsorbed to sludge.

The concentrations of cyclamate and sucralose in individual sludge samples are shown in Figure 6.2. 
Figure 6.2 Concentration $(\mu \mathrm{g} / \mathrm{kg} \mathrm{ww}$ ) of cyklamate and sucralose in individual sludge samples

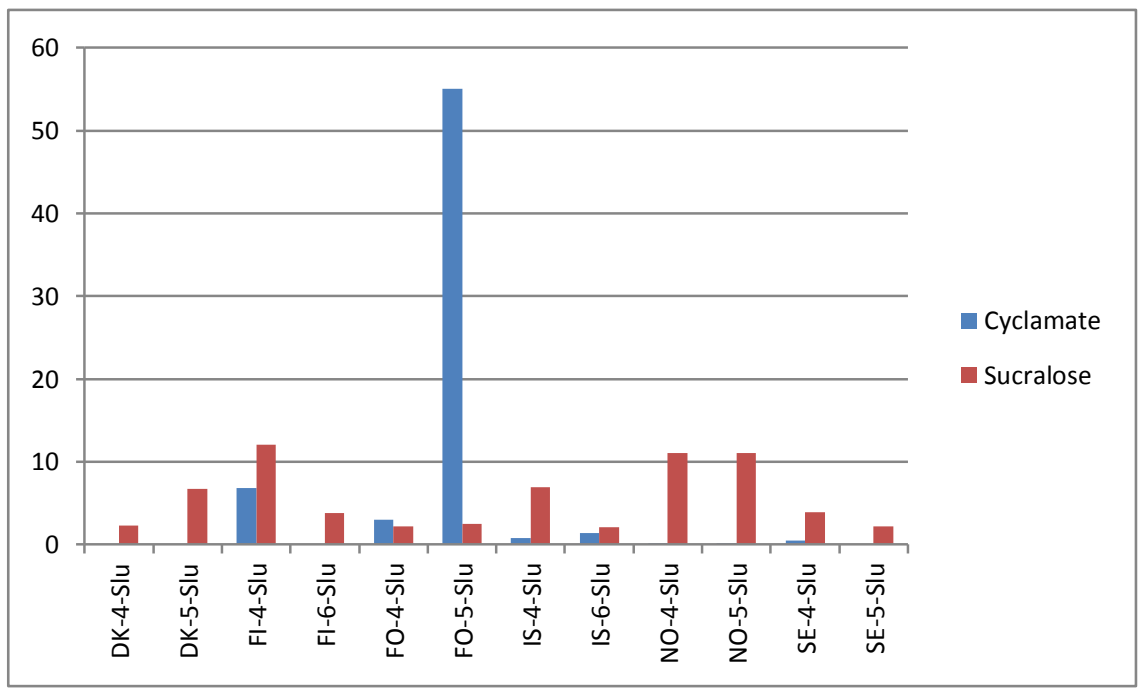

The sample F0-5-Slu showed the highest result for cyclamate. This was not a typical sludge; it was inhomogeneous and contained paper like residues which made it difficult to get representative subsamples which could have influenced the result.

The ratio concentration in sludge (on a wet weght basis) to concentration in effluent from the same WWTP ranged 0.01-16 (median 1.3) for cyclamate and 0.8-5.9 (median 2.4) for sucralose. This supports the conclusion that although there is variations in individual results the substances do not have a high affinity to sludge.

A compilation of previous measurements of sweeteners in the aquatic environment can be found in a recent review by Lange et al. (2012). 



\section{Acknowledgements}

\subsection{Denmark}

Thanks to Anna Gade Holm, John Dyrbye, Kirsten Johansen and Thoams K. Kjellerup, all Danish Nature Agency and Martin Larsen, Institute of Bioscience, Aarhus University for assistance during selection of sampling sites and providing samples for this project.

\subsection{Faroe Islands}

The assistance of a number of people who took part in the sampling for the present screening is gratefully acknowledged: Samples of marine sediments were taken by Gunnar Djurhuus, Regin Joensen and Kári Purkhuus. Black guillemot eggs were sampled by Bjørn Patursson and Jóannes Mikkelsen. Arctic charr was sampled by Kristian Martin Hansen and Jón í Haraldsstovu. Samples of cod were secured by Sámal Debes on fishing vessel "Gordrúgvin". Assistance in sampling and sample preparation otherwise was provided by Regin Olsen, Øssur Hentze, Katrin Hoydal and Rakul Mortsensen

\subsection{Finland}

Thanks to Kirsti Kalevi, Finnish Environment Institute (SYKE) and Markku Korhonen (SYKE) for assistance during selection of sampling sites and providing samples for this project.

\subsection{Iceland}

Experts of Innovation Center Iceland, Matis ohf, Environment Agency of Iceland, Natural History Museum of Kópavogur and Heilbrigðiseftirlit Suðurlands are acknowledged for sample collection and sample supply. 


\subsection{Norway}

Thanks to Kathrine Langford at NIVA who took care of the sampling on behalf of the the Climate and Pollution Agency in Norway.

\subsection{Sweden}

The collection of Swedish samples was coordinated by the Swedish Environmental Research Institute. Anette Johansson, GRYAB, Janet Albertsson, Gässlösa WWTP, Borås, Maria Nordström Öhn WWTP, Umeå, Marina Magnusson, Marine Monitoring, Lysekil, Elisabet Nyberg, Swedish Museum of Natural History and Ingemar Cato, Geological Survey of Sweden (SGU), are acknowledged for providing samples. 


\section{References}

Albro, P. W. and S. R. Lavenhar (1989). "Metabolism of di(2-ethyl-hexyl)phthalate." Drug metabolism reviews 21(1): 13-34.

Barron, M. G., P. W. Albro and W. L. Hayton (1995). "Biotransformation of di(2ethylhexyl)phthalate by rainbow trout." Environ. Toxicol. Chem. 14(5): 873-876.

Batterman, S. A., S. Chernyak, C. Jia, C. Godwin and S. Charles (2009). "Concentrations and Emissions of Polybrominated Diphenyl Ethers from U.S. Houses and Garages." Environmental Science \& Technology 43(8): 2693-2700.

Berset, J.-D. and N. Ochsenbein (2012). "Stability considerations of aspartame in the direct analysis of artificial sweeteners in water samples using high-performance liquid chromatography-tandem mass spectrometry (HPLC-MS/MS)." Chemosphere 88(5): 563-569.

Brorström-Lundén, E., A. Svenson, T. Viktor, A. Woldegiorgis, M. Remberger, L. Kaj, C. Dye A. Bjerke and M. Schlabach, (2008), Measurements of Sucralose in the Swedish Screening Program 2007, Part I: Sucralose in surface waters and STP samples. IVL Report B1769.

Cousins, I. and D. Mackay (2000). "Correlating the physical-chemical properties of phthalate esters using the 'three solubility' approach." Chemosphere 41(9): 1389-1399.

ChemIDplus Advanced. http://chem.sis.nlm.nih.gov/chemidplus/ search path: CAS no. 2012-04-11

CPSC (2010) CPSC Staff Toxicity Review of 17 Phthalates. United States Consumer Product Safety Commission. http://www.cpsc.gov/about/cpsia/ chap/toxreview.pdf

De Bruijn, J., F. Busser, et al. (1989). "Determination of octanol/water partition coefficients for hydrophobic organic chemicals with the "slow-stirring" method." Environ. Toxicol. Chem. 8: 499.

DEHP Substance Data Sheet 2005. Common Implementation Strategy for the Water Framework Directive Environmental Quality Standards (EQS) Substance Data Sheet Priority Substance No. 12 Diethylhexyl-phthalate (DEHP) CAS-No. 117-81-7 Final version Brussels, 31 July 2005

Ellington, J. J. (1999). Octanol/Water Partition Coefficients and Water Solubilities of Phthalate Esters J. Chem. Eng. Data 44: 1414-1418.

European Chemicals Agency (ECHA) 2010. Guidance on information requirements and chemical safety assessment Chapter R.16: Environmental Exposure Estimation. Version: 2 May 2010

European Chemicals Bureau (ECB) 2003 a. European Union Risk Assessment Report 1,2benzenedicarboxylic acid, di-C8-10-branched alkyl esters, C9-rich and di-"isononyl" phthalate (DINP). Volume 35. European Communities (EC). EUR 20784 EN.

European Chemicals Bureau (ECB) 2003 b. European Union Risk Assessment Report 1,2-benzenedicarboxylic acid, di-C9-11-branched alkyl esters, C10-rich and di"isodecyl" phthalate (DIDP).Volume 36. European Communities (EC). EUR 20785 EN.

European Chemicals Bureau (ECB) 2004. European Union Risk Assessment Report dibutyl phthalate, with addendum. Volume 29. European Communities (EC). EUR $19840 \mathrm{EN}$.

European Chemicals Bureau (ECB) 2007. European Union Risk Assessment Report benzyl butyl phthalate (BBP). Volume 76. European Communities (EC). EUR $22773 \mathrm{EN}$. 
European Chemicals Bureau (ECB) 2008. European Union Risk Assessment Report bis(2-ethylhexyl)-phthalate (DEHP). Volume 80. European Communities (EC). EUR 23384 EN.

European Chemicals Agency (ECHA) 2008. Guidance on information requirements and chemical safety assessment Chapter R.10: Characterisation of dose [concentration]-response for environment.

European Chemicals Agency (ECHA) 2010. Guidance on information requirements and chemical safety assessment Chapter R.16: Environmental Exposure Estimation.

ECOTOX database, homepage of US EPA (http://cfpub.epa.gov/ecotox/); the data search was made with CAS numbers as listed in Table 1, 2010.09.28

ECPI (2012) Plasticisers and Flexible PVC Information Centre. European Council for Plasticicers and Intermediates.http://www.plasticisers.org/plasticisers

Furtmann, K. (1995). "Phthalate analysis as a tool for environmental assessment." Analytical methods and Instrumentation 2(5): 254-265.

ISO, 1993, Guide to the expression of Uncertainty in Measurements.

Kaj, L (2009) Interlaboratory Comparison on Sucralose. Norman Bulletin Issue 1, 13-17

Kato, K., J. M. Silva, W. J. Brock, A. J. Reidy, A. N. Malek, C. C. Hodge, H. Nakazawa, L. K. Needham and B. D. Barr (2003). "Quantitative detection of nine phthalate metabolites in human serum using reversed-phas high-performance liquid chromatographyelectrospray ionization-tandem mass spectrometry." J. Anal. Toxicol. 27: 284-288.

Lambert, N., Rostock, C., Hetland, S (2010) Environmental risks associated to plasticizers and sweeteners in the Nordic countries. Bergfald miljørådgivere, Oslo. http://www.nordicscreening.org/index.php?module=Pagesetter\&func=viewpub\&t id=5\&pid=11

Lange, F. T, M. Scheurer, H. J. Brauch (2012) “Artificial sweeteners-a recently recognized class of emerging environmental contaminants: a review" Anal Bioanal Chem 403: 2503-2518

Letinksi, D. J., M. J. Connelly, et al. (1999). Slow-stir water solubility measurements for phthalate ester plasticicers. SETAC Europe, 9th_Annual meeting. Leipzig, Germany: 25-29.

Palm-Cousins, A., Remberger, M., Kaj, L., Ekheden, Y., Dusan, B., and Brorström-Lundén, E., (2007). Results from the Swedish national screening program 2006. Subreport 1: Phthalates. IVL Swedish Environmental Reserarchlinstitute, Report B 1750.

Parkman, H. and Remberger, M., (1994). Phthalates in Swedish Sediment. Stockholm, IVL Swedish Environmental Reseasch Institute, Report B 1167.

Remberger, M., Andersson, J., Palm-Cousins, A., Kaj, L., Ekheden, Y., Dusan, B., Brorström-Lundén, E., and Cato, I. (2005). Results from the national screening programme 2004. Subreport 1: Adipates. Stockholm, IVL Swedish environmental research institute Ltd, Report B1645.

Schlabach, M., Dye, C., Kaj, L., Klausen, S., Langford, K., Leknes, H., Moe, M. K., Remberger, M., Schøyer, M., Tomas, K., and Vogelsang, C. (2009). Environmental screening of selected organic compounds 2008. Human and hospital-use pharmaceuticals, aquaculture medicines and personal care products. NILU report OR 13/2009. SPFOrapport 1046/2009

Scheurer, M., H. J. Brauch, F.T. Lange (2009). "Analysis and occurrence of seven artificial sweeteners in German waste water and surface water and in soil aquifer treatment (SAT)." Analytical and Bioanalytical Chemistry 394(6): 1585-1594

Scheurer, M., A. Michel, H. J. Brauch, W. Ruck, F. Sacher (2012). "Occurrence and fate of the antidiabetic drug metformin and its metabolite guanylurea in the environment and during drinking water treatment." Water Research 46(15): 4790-4802.

Shintani, H. (2000). " Pretreatment and chromatographic analysis of phthalate esters, and their biochemical behavior in blood products." Chromatog. 52(11-12): 721-726. 
Silva, J. M., R. A. Slakman, A. J. Reidy, L. J. Pteau Jr, R. A. Herbert, E. Samander, L. L. Needham and M. A. Calafat (2004). "Analysis of human urine for fifteen phthalate metabolites using automated solid-phase extraction." J.Chromatigr. B. 805: 161-167.

SPIN (2012) Substances in Preparations in Nordic Countries, www.kemi.se Databases The SPIN database

Stales, C. A., D. R. Peterson, T F Parkerton, W J Adams (1997). "The environmental fate of phthalate esters: A literature review." Chemosphere 35(4): 667-749.

Sternbeck, J., Kaj, L., Remberger, M., Palm, A., Junedal, E., Bignert, A., Haglund, P., Lindkvist, K., Adolfsson-Erici, A., Nylund, K., and Asplund, L., (2004). "Organiska miljögifter i fisk från svenska bakgrundslokaler." IVL Report 1576.

Suzuki, T., K. Yaguchi and S. Suzuki (2001). "Monitoring of phthalic acid monoesters in river water by solid-phase extraction and GC-MS determination." Envirio. Sci. Technol. 35(18): 3757-3763.

Tienpont, B., F. David, et al. (2005). "Pitfalls and solutions for the trace determination of phthalates in water samples." CHROMATOGRAPHIA 61(7-8): 365-370.

US EPA 2012. Estimation Programs Interface Suite ${ }^{\mathrm{TM}}$ for Microsoft $\AA$ Windows, v 4.10 (EPI Suite). United States Environmental Protection Agency, Washington, DC, USA. 



\section{Sammanfattning}

Det övergripande syftet med föreliggande screeningstudie var att undersöka förekomsten av ett antal mjukgörare i miljörelaterade prover från de nordiska länderna. Proven analyserades på åtta ftalater, fyra adipater och en azelat. Provtyperna var utgående vatten och slam från kommunala reningsverk, sediment och fisk. Vanligtvis bidrog de deltagande länderna (Danmark, Finland, Färöarna, Island, Norge och Sverige) med tre prov av varje provtyp. Ett mindre antal fågelägg inkluderades också. Det relativt låga antalet prov och provtyper är avsedda att ge en ögonblicksbild av situationen.

För all provtyper detekterades ftalaterna DEHP, DINP och DIDP mest frekvent och i högst koncentrationer. DBP och BBP hittades också frekvent men i lägre koncentrationer. Detta gäller också för adipaterna DEHA och BOA, medan DINA och DBEEQ inte hittades alls. Azelaten DEHZ hittades enbart i ett slamprov.

I slam utgjorde DINP, DEHP och DIDP tillsammans $96-99.7 \%$ av den totalt uppmätta halten av mjukgörare. Den högsta sammanlagda koncentrationen var 260,000 $\mu \mathrm{g} / \mathrm{kg}$ TS. I avloppsvattnen hade DEHP nästan alltid den högsta koncentrationen, men alla slamprov dominerades av DINP.

Sediment från platser i närheten av reningsverk visade högre halter av mjukgörare än sediment från bakgrundsområden.

Koncentrationen i fiskmuskel var gener ellt låg, under eller nära kvantifieringsgränsen.

Mjukgörarna som ingick i screeningen kan vara skadliga för miljön. Att koncentrationer i effluenter och sediment var nära eller över PNECvärden indikerar ett behov av ytterligare studier för att utvärdera risken för negativa effekter. Vidare detekterades några av de screenade substanserna även i biota.

Avloppsvattnen och vissa av slamproven analyserades också på sötningsmedel. Resultaten visade att cyclamat och sucralos är vanligt förekommande i avloppsvatten från reningsverk i de nordiska länderna och att dessa substanser inte i någon stor utsträckning ackumuleras i slam. 



\section{Appendices}

\subsection{Analysis of selected plasticizers and additional sweeteners in a Nordic cooperation on screening}

\subsubsection{Sampling manual}

Each country are asked to contribute

- 3 WWTP effluent waters

- 3 WWTP sludges

- 3 sediments

- 3 fish samples

- 2 egg samples (only FO, IS, SE)

All samples will be analyzed for plasticizers. The effluent waters and 2 of the sludges will be analyzed for sweeteners.

\section{Equipment provided}

- $2.5 \mathrm{~L}$ glass bottles (effluent water samples).

- $120 \mathrm{ml}$ glass jars (sludge \& sediment for plasticizers)

- $250 \mathrm{ml}$ PE jars (sludge for sweeteners)

- Plastic bags for jars.

- Muffled Al-foil (packed in Al-foil).

- Labels.

- Plastic gloves.

- Sampling protocol.

\subsubsection{Planning the sampling}

Start by opening the provided "Sampling protocol" in excel format. Fill in data for each planned sample, one sample on each row. Use the suggested indication of matrix type or change among the possible choices on the list. This will give each sample a Sample identification in the format $\mathrm{CO}$ no-Mat where $\mathrm{CO}$ indicates country, no is a consecutive number and Mat indicates matrix. The samples should be labelled with their respective Sample identification.

Example: DK-3-Slu, the third Danish sample which is a sludge sample.

Use a printout of the sample list to record sample date and other relevant observations. The sheet Notes can also be used.

Please give coordinates as LAT and LONG in the WGS84 reference system expressed as degrees and decimal minutes. See example in the 
sampling protocol. We strongly suggest to cross-check the registered coordinates with an independent geographic tool like Google Earth or similar. Select all six Excel cells containing the coordinates, copy the content with Ctrl-C and paste it into the "fly to" window in the upper-left corner of Google Earth. By clicking onto the magnifier symbol Google Earth should show you the correct sample position.

\subsubsection{Precautions to be taken in advance of sampling to avoid contamination}

Cosmetic formulations contain various chemicals that potentially can contaminate the samples. Do not use products such as antiperspirant, eye shadow, hair spray, or skin lotions on the day of sampling. Only specially cleaned sampling containers provided by the laboratory should be used.

To check for contamination sampling blanks are used. The sampling blank to be used for water contains MilliQ-water, the sampling blank to be used for sludge and sediment sampling contains granulated diatomaceous earth containing $10 \%$ water. The sampling blanks should not be emptied or filled. They shall only be opened and closed at the time of sampling.

The number of sampling blanks is limited. Each country are assigned one water blank or one solid blank. The sites used for blank sampling should be selected at random before the start of sampling. Blank samples should be labelled BLW and BLS respectively.

\subsubsection{A. Sampling of water}

To minimize the contamination risk grab samples are preferred over composite samples.

- Arrange the sampling bottles to be used on a clean spot on the sampling site. Put on the supplied gloves.

- Immediately before sampling open the lid of the sampling container. Make sure that the white PTFE seal is not lost.

- Fill the sample container $(2.5 \mathrm{~L})$ and close the lid on the sample bottle.

- Mark bottles with Sample identification.

- Make notes on the sample protocol.

- Store the samples in a refrigerator $\left(5-10^{\circ} \mathrm{C}\right)$. (Both plasticizers and sweeteners will be analysed on the same sample). 


\section{B. Sampling of sludge}

- Put on the supplied gloves.

- Open the lid of the jar.

- Fill the jar with sludge and close the lid. If the Al-foil protecting the lid of the jar is ruptured replace it with new Al-foil.

- Mark the sample with Sample identification.

- If sweeteners are going to be analysed fill also a plastic jar.

- Put each sample in a plastic bag (2 L).

- Make notes on the sample protocol.

- Store the samples in a freezer $\left(-18^{\circ} \mathrm{C}\right)$ if the sample has low water content ( $30 \%$ or less). Sludges with high water content should not be frozen (risk of breaking the jar).

\section{Sampling of sediment}

- Put on the supplied gloves.

- Open the lid of the jar.

- Fill the jar with sediment and close the lid. If the Al-foil protecting the lid of the jar is ruptured replace it with new Al-foil.

- Mark the sample with Sample identification.

- Put each sample in a plastic bag (2 L).

- Make notes on the sample protocol.

- Store the samples in a freezer $\left(-18^{\circ} \mathrm{C}\right)$.

\section{Sampling of fish}

The number of fish per sample should be $5-10$ or more depending on weight.

The quantity should be sufficient to prepare a composite sample of at least $50 \mathrm{~g}$ fish muscle.

- Put on the supplied gloves.

- Wrap each fish individually in $\mathrm{Al}$-foil provided.

- Put the Al-foil packages making up one sample in one common plastic bag, or, if needed, mark additional bags accordingly.

- Mark the samples with Sample identification.

- Make notes on the sample protocol.

- Store the samples in a freezer $\left(-18^{\circ} \mathrm{C}\right)$.

\subsubsection{Storage and transport}

Send all samples to IVL in Stockholm as soon as possible in such a way that the samples will reach the laboratory within one day (DHL or equivalent courier service). Send samples in the same containers used for providing sampling material. Make sure to insulate glass bottles properly to avoid breakage during transport. Include a printout of the Sampling protocol. Send the samples to the address below. 
When sending the samples please send also an e-mail with the filled in Sample protocol attached to Lennart Kaj (lennar.kaj@ivl.se) and Mikael Remberger (mikael.remberger@ivl.se).

\section{Address}

IVL Swedish Environmental Research Institute Lennart Kaj

Valhallavägen 81

SE-114 27 Stockholm

Sweden.

Tel +46(0)8-59856300 


\subsection{Appendix 2 Sample list, plasticisers}

\begin{tabular}{|c|c|c|c|c|c|c|c|c|c|c|c|}
\hline \multirow{2}{*}{$\begin{array}{l}\text { MR\# } \\
9517\end{array}$} & \multirow{2}{*}{$\begin{array}{l}\begin{array}{l}\text { Sample } \\
\text { ident. }\end{array} \\
\text { DK-1-Eff }\end{array}$} & \multirow{2}{*}{$\begin{array}{l}\text { Location } \\
\text { Esbjerg }\end{array}$} & \multirow{2}{*}{$\begin{array}{l}\text { Site } \\
\text { Esbjerg central WWTP }\end{array}$} & \multirow[t]{2}{*}{ Species etc } & \multirow{2}{*}{\begin{tabular}{|l} 
Sampling date \\
$2011-11-02$
\end{tabular}} & \multicolumn{3}{|c|}{$\begin{array}{c}\text { LAT WGS84 } \\
\text { Deg., decimal min. }\end{array}$} & \multicolumn{3}{|c|}{$\begin{array}{l}\text { LONG WGS84 } \\
\text { Deg., decimal min }\end{array}$} \\
\hline & & & & & & 55 & 29.223 & $\mathrm{~N}$ & 8 & 25.491 & $\mathrm{E}$ \\
\hline 9492 & DK-2-Eff & Odense & Ejby Mølle WWTP & & 2011-10-24 & 55 & 23.576 & $\mathrm{~N}$ & 10 & 25.139 & $\mathrm{E}$ \\
\hline 9491 & DK-3-Eff & Vordingborg & Råbylille strand WWTP & & 2011-10-11 & 54 & 58.196 & $\mathrm{~N}$ & 12 & 23.697 & $\mathrm{E}$ \\
\hline 9518 & DK-4-Slu & Esbjerg & Esbjerg central WWTP & & 2011-11-02 & 55 & 29.223 & $\mathrm{~N}$ & 8 & 25.491 & $\mathrm{E}$ \\
\hline 9494 & DK-5-Slu & Odense & Ejby Mølle WWTP & & 2011-10-24 & 55 & 23.573 & $\mathrm{~N}$ & 10 & 24.499 & $\mathrm{E}$ \\
\hline 9728 & DK-7-Sed & $\varnothing$ resund & Vedbæk & & $2010-12-26$ & 55 & 48 & $\mathrm{~N}$ & 12 & 35.65 & $\mathrm{E}$ \\
\hline 9729 & DK-8-Sed & Kolding Fjord & & & 2011-11-09 & 55 & 30.11 & $\mathrm{~N}$ & 9 & 37.46 & $\mathrm{E}$ \\
\hline 9730 & DK-9-Sed & Limfjorden & & & 2011-11-16 & 56 & 39.4 & $\mathrm{~N}$ & 8 & 42.32 & $\mathrm{E}$ \\
\hline 9731 & DK-10-Fis & Ho bugt & Wadden Sea & Flounder, Platichthys flesus, muscle & 2011-09-19 & 55 & 35.16 & $\mathrm{~N}$ & 8 & 18.42 & $\mathrm{E}$ \\
\hline 9732 & DK-11-Fis & Hjelm bugt & Baltic Sea & Flounder, Platichthys flesus, muscle & 2011-11-15 & 54 & 56.36 & $\mathrm{~N}$ & 12 & 25.7 & $\mathrm{E}$ \\
\hline 9733 & DK-12-Fis & Agers $\varnothing$ & Great Belt & Flounder, Platichthys flesus, muscle & 2011-09-27 & 55 & 15.67 & $\mathrm{~N}$ & 11 & 10.36 & $\mathrm{E}$ \\
\hline 9544 & Fl-1-Eff & Turku & Kakolanmäki WWTP & & 2011-11-10 & 60 & 26.712 & $\mathrm{~N}$ & 22 & 14.204 & $\mathrm{E}$ \\
\hline 9545 & Fl-2-Eff & Helsinki & Viikki WWTP & & 2011-11-14 & 60 & 13.544 & $\mathrm{~N}$ & 24 & 59.612 & $\mathrm{E}$ \\
\hline 9546 & Fl-3-Eff & Tampere & Viinikanlahti WWTP & & 2011-11-14 & 61 & 29.319 & $\mathrm{~N}$ & 23 & 46.043 & $\mathrm{E}$ \\
\hline 9644 & FI-4-Slu & Turku & Kakolanmäki WWTP & & 2011-11-10 & 60 & 26.712 & $\mathrm{~N}$ & 22 & 14.204 & $\mathrm{E}$ \\
\hline 9645 & Fl-5-Slu & Helsinki & Viikki WWTP & & 2011-11-14 & 60 & 13.544 & $\mathrm{~N}$ & 24 & 59.612 & $\mathrm{E}$ \\
\hline 9646 & FI-6-Slu & Tampere & Viinikanlahti WWTP & & 2011-11-14 & 61 & 29.319 & $\mathrm{~N}$ & 23 & 46.043 & $\mathrm{E}$ \\
\hline 9647 & Fl-7-Sed & Turku & Turku harbour & & 2011-11-14 & 60 & 26.286 & $\mathrm{~N}$ & 22 & 13.050 & $\mathrm{E}$ \\
\hline 9648 & FI-8-Sed & Tampere & Viinikanlahti & & 2011-11-01 & 61 & 29.374 & $\mathrm{~N}$ & 23 & 45.808 & $\mathrm{E}$ \\
\hline 9649 & Fl-9-Sed & Helsinki & Vanhankaupunginlahti & & 2011-11-11 & 60 & 11.550 & $\mathrm{~N}$ & 24 & 59.575 & $\mathrm{E}$ \\
\hline 9650 & Fl-10-Fis & Tampere & Pirkkalan Pyhäjärvi & Perch, Perca fluviatilis, muscle & $2011-10-25$ & 61 & 28.943 & $\mathrm{~N}$ & 23 & 39.272 & $\mathrm{E}$ \\
\hline 9651 & Fl-11-Fis & Kuhmoinen & Päijänne Tehinselkä & Perch, Perca fluviatilis, muscle & $2011-10-28$ & 61 & 31.670 & $\mathrm{~N}$ & 25 & 21.900 & $\mathrm{E}$ \\
\hline 9652 & $\mathrm{Fl}-12$-Fis & Turku Archipelago & Airisto Seili & Perch, Perca fluviatilis, muscle & $2010-09-23$ & 60 & 13.783 & $\mathrm{~N}$ & 21 & 57.053 & $\mathrm{E}$ \\
\hline 9629 & FO-1-Eff & Torshavn & Sersjantvikin WWTP & Effluent & 2011-11-21 & 62 & 0.49 & $\mathrm{~N}$ & 6 & 45.717 & w \\
\hline 9630 & FO-2-Inf & Torshavn & Main Hospital WWTP & Influent! & 2011-11-21 & 62 & 0.098 & $\mathrm{~N}$ & 6 & 46.538 & w \\
\hline 9631 & FO-3-Eff & Klaksvik & Klaksvik Hospital WWTP & Effluent & 2011-11-21 & 62 & 13.5 & $\mathrm{~N}$ & 6 & 35.47 & w \\
\hline 9632 & FO-4-Slu & Torshavn & Sersjantvikin WWTP & sludge & 2011-11-21 & 62 & 0.49 & $\mathrm{~N}$ & 6 & 45.717 & w \\
\hline 9633 & FO-5-Slu & Torshavn & Main Hospital WWTP & sludge & $2011-11-21$ & 62 & 0.098 & $\mathrm{~N}$ & 6 & 46.538 & w \\
\hline 9634 & FO-6-Sed & Torshavn & Harbour, near shipyard, Stn BA & sediment, marine & $2011-11-21$ & 62 & 0.430 & $\mathrm{~N}$ & 6 & 46.439 & w \\
\hline 9635 & FO-7-Sed & Torshavn & Harbour, near marina & sediment, marine & $2011-11-21$ & 62 & 0.31 & $\mathrm{~N}$ & 6 & 46.220 & w \\
\hline 9636 & FO-8-Sed & Kollafjord & Station 6 & sediment, marine & 2011-11-11 & 62 & 6.064 & $\mathrm{~N}$ & 6 & 55.519 & w \\
\hline 9637 & FO-9-Sed & Klaksvik & Harbour, á Stongum & sediment, marine & 2011-11-19 & 62 & 13.835 & $\mathrm{~N}$ & 6 & 35.476 & w \\
\hline 9639 & FO-10-Fis & NW Faroe shelf & Mýlingsgrunnur, background area & Cod, Gadus morhua, liver & 2011-10-01 & 62 & 25 & $\mathrm{~N}$ & 7 & 25 & w \\
\hline 9640 & FO-11-Fis & NW Faroe shelf & Mýlingsgrunnur, background & Cod, Gadus morhua, liver & 2011-10-01 & 62 & 25 & $\mathrm{~N}$ & 7 & 25 & w \\
\hline 9641 & FO-12-Fis & Lake á Mýrunum & Freshwater lake, background & Arctic charr, Salvelinus alpinus, muscle & 2011 June/July & 62 & 9.83 & $\mathrm{~N}$ & 7 & 5.48 & w \\
\hline 9642 & FO-13-Egg & Skúvoy & Small island, background area & Black guillemot Cepphus grylle, eggs & 2010 June & 61 & 46.1 & $\mathrm{~N}$ & 6 & 48.1 & w \\
\hline 9643 & FO-14-Egg & Koltur & Small island, background area & Black guillemot Cepphus grylle, eggs & 2010-06-04 & 62 & 0.0 & $\mathrm{~N}$ & 7 & 0.0 & w \\
\hline 1384-1 & FO-15-Fis & NW on Faroe shelf & Mýlingsgrunnur, background area & Cod, Gadus morhua, liver & 2012-05-16 & 62 & 25 & $\mathrm{~N}$ & 7 & 25 & w \\
\hline 1384_2 & FO-16-Fis & NW on Faroe shelf & Mýlingsgrunnur, background area & Cod, Gadus morhua, liver & 2012-05-16 & 62 & 25 & $\mathrm{~N}$ & 7 & 25 & w \\
\hline $1384 \_3$ & FO-17-Fis & NW on Faroe shelf & Mýlingsgrunnur, background area & Cod, Gadus morhua, liver & 2012-05-16 & 62 & 25 & $\mathrm{~N}$ & 7 & 25 & w \\
\hline 1384_4 & FO-18-Fis & NW on Faroe shelf & Mýlingsgrunnur, background area & Cod, Gadus morhua, liver & 2012-05-16 & 62 & 25 & $\mathrm{~N}$ & 7 & 25 & w \\
\hline $1384 \_5$ & FO-19-Fis & NW on Faroe shelf & Mýlingsgrunnur, background area & Cod, Gadus morhua, liver & 2012-05-16 & 62 & 25 & $\mathrm{~N}$ & 7 & 25 & w \\
\hline $9533^{-}$ & IS-4-Slu & Hveragerði & WWTP & & $2011-10-24$ & 64 & 59.295 & $\mathrm{~N}$ & 21 & 10.638 & w \\
\hline
\end{tabular}




\begin{tabular}{|c|c|c|c|c|c|c|c|c|c|c|c|}
\hline \multirow{2}{*}{$\begin{array}{l}\text { MR\# } \\
9534\end{array}$} & \multirow{2}{*}{$\begin{array}{l}\begin{array}{l}\text { Sample } \\
\text { ident. }\end{array} \\
\text { IS-5-Slu }\end{array}$} & \multirow{2}{*}{$\begin{array}{l}\text { Location } \\
\text { Borg - Grímsnesi }\end{array}$} & \multirow{2}{*}{$\begin{array}{l}\text { Site } \\
\text { WWTP }\end{array}$} & \multirow[t]{2}{*}{ Species etc } & \multirow{2}{*}{$\begin{array}{r}\text { Sampling date } \\
2011-10-24\end{array}$} & \multicolumn{3}{|c|}{$\begin{array}{c}\text { LAT WGS84 } \\
\text { Deg., decimal min. }\end{array}$} & \multicolumn{3}{|c|}{$\begin{array}{l}\text { LONG WGS84 } \\
\text { Deg., decimal min }\end{array}$} \\
\hline & & & & & & 64 & 04.29 & $\mathrm{~N}$ & 20 & 46.09 & $\mathrm{w}$ \\
\hline 9535 & IS-6-Slu & Klettagarðar - Reyk. & WWTP & & 2011-11-02 & 64 & 9.324 & $\mathrm{~N}$ & 21 & 52.405 & w \\
\hline 9536 & IS-7-Sed & pingvallavatn & & & 2011-10-11 & 64 & 11.52 & $\mathrm{~N}$ & 21 & 8.6 & w \\
\hline 9537 & IS-8-Sed & Grafarvogur - Reyk. & Gullinbrú & & 2011-10-27 & 64 & 8.028 & $\mathrm{~N}$ & 21 & 48.879 & w \\
\hline 9538 & IS-9-Sed & Naustavogur - Reyk. & Háubakkar & & $2011-10-28$ & 64 & 7.814 & $\mathrm{~N}$ & 21 & 50.698 & w \\
\hline 9539 & IS-10-Fis & Pingvallavatn & & Arctic charr, Salvelinus alpinus, muscle & 2011-10-11 & 64 & 11.52 & $\mathrm{~N}$ & 21 & 8.6 & w \\
\hline 9540 & IS-11-Fis & pingvallavatn & & Brown trout, Salmo trutta, muscle & 2009, summer & 64 & 11.52 & $\mathrm{~N}$ & 21 & 8.6 & w \\
\hline 9541 & IS-12-Fis & Iceland Seas & NNV - mið & Cod, Gadus morhua, muscle & 2010-03-10 & 67 & 2.55 & $\mathrm{~N}$ & 23 & 29.93 & w \\
\hline 9495 & NO-1-Eff & Gjøvik & Rambekk WWTP & & $2011-10-25$ & 60 & 46.35 & $\mathrm{~N}$ & 10 & 42.21 & $\mathrm{E}$ \\
\hline 9496 & NO-2-Eff & Gjøvik & Rambekk WWTP & & $2011-10-25$ & 60 & 46.35 & $\mathrm{~N}$ & 10 & 42.21 & $\mathrm{E}$ \\
\hline 9497 & NO-3-Eff & Gjøvik & Rambekk WWTP & & $2011-10-25$ & 60 & 46.35 & $\mathrm{~N}$ & 10 & 42.21 & $\mathrm{E}$ \\
\hline 9499 & NO-4-Slu & Gjøvik & Rambekk WWTP & & $2011-10-25$ & 60 & 46.35 & $\mathrm{~N}$ & 10 & 42.21 & $\mathrm{E}$ \\
\hline 9500 & NO-5-Slu & Gjøvik & Rambekk WWTP & & $2011-10-25$ & 60 & 46.35 & $\mathrm{~N}$ & 10 & 42.21 & $\mathrm{E}$ \\
\hline 9501 & NO-6-Slu & Gjøvik & Rambekk WWTP & & $2011-10-25$ & 60 & 46.35 & $\mathrm{~N}$ & 10 & 42.21 & $\mathrm{E}$ \\
\hline 9604 & NO-7-Sed & Bergen & Kviturspollen & depth: $13.1 \mathrm{~m}$ & 2002-11-11 & 60 & 15.773 & $\mathrm{~N}$ & 5 & 15.223 & $\mathrm{E}$ \\
\hline 9605 & NO-8-Sed & Bergen & Puddefjorden & depth: $26 \mathrm{~m}$ & 2005-10-11 & 60 & 23.267 & $\mathrm{~N}$ & 5 & 18.473 & $\mathrm{E}$ \\
\hline 9606 & NO-9-Sed & Bergen & Puddefjorden & depth: $79 \mathrm{~m}$ & 2005-10-11 & 60 & 23.725 & $\mathrm{~N}$ & 5 & 17.079 & $\mathrm{E}$ \\
\hline 9657 & NO-10-Fis & Vingrom & Mjøsa & Brown trout, Salmo trutta, muscle & 2011-08-01 & 61 & 2.67 & $\mathrm{~N}$ & 10 & 27.1 & $\mathrm{E}$ \\
\hline 9658 & NO-11-Fis & Vingrom & Mjøsa & Brown trout, salmo trutta, muscle & 2011-08-01 & 61 & 2.67 & $\mathrm{~N}$ & 10 & 27.1 & $\mathrm{E}$ \\
\hline 9659 & NO-12-Fis & Vingrom & Mjøsa & Brown trout, salmo trutta, muscle & 2011-08-01 & 61 & 2.67 & $\mathrm{~N}$ & 10 & 27.1 & $\mathrm{E}$ \\
\hline 9628 & SE-1-Eff & Umeå & Öhn WWTP & & 2011-11-21 & 63 & 48.25 & $\mathrm{~N}$ & 20 & 17.5 & $\mathrm{E}$ \\
\hline 9597 & SE-2-Eff & Göteborg & Ryaverken WWTP & & 2011-11-10 & 57 & 41.83 & $\mathrm{~N}$ & 11 & 53.5 & $\mathrm{E}$ \\
\hline 9598 & SE-3-Eff & Borås & Gässlösa WWTP & & 2011-11-16 & 57 & 42.3 & $\mathrm{~N}$ & 12 & 55.5 & $\mathrm{E}$ \\
\hline 9532 & SE-4-Slu & Umeå & Öhn WWTP & & 2011-11-08 & 63 & 48.25 & $\mathrm{~N}$ & 20 & 17.5 & $\mathrm{E}$ \\
\hline 9599 & SE-5-Slu & Göteborg & Ryaverken WWTP & & 2011-11-10 & 57 & 41.83 & $\mathrm{~N}$ & 11 & 53.5 & $\mathrm{E}$ \\
\hline 9600 & SE-6-Slu & Borås & Gässlösa WWTP & & 2011-11-16 & 57 & 42.3 & $\mathrm{~N}$ & 12 & 55.5 & $\mathrm{E}$ \\
\hline 9601 & SE-7-Sed & Göteborg & Stockholmen & & 2011-10-17 & 57 & 40.426 & $\mathrm{~N}$ & 11 & 49.531 & $\mathrm{E}$ \\
\hline 9602 & SE-8-Sed & Göteborg & Björkö & & $2011-10-20$ & 57 & 43.469 & $\mathrm{~N}$ & 11 & 41.407 & $\mathrm{E}$ \\
\hline 9593 & SE-9-Sed & Strömstad & Kosterfjorden & depth: $95 \mathrm{~m}$ & 2011-05-11 & 58 & 52.069 & $\mathrm{~N}$ & 11 & 6.649 & $\mathrm{E}$ \\
\hline 9614 & SE-10-Fis & Göteborg & Hakefjorden & Mackerel, Scomber scombrus, muscle & 2011-10-26 & 57 & 40 & $\mathrm{~N}$ & 11 & 45 & $\mathrm{E}$ \\
\hline 1108 & SE-11-Fis & Holmöarna & Golf of Bothnia & Perch, Perca fluviatilis, muscle & 2011-08-16 & 63 & 40.834 & $\mathrm{~N}$ & 20 & 52.618 & $\mathrm{E}$ \\
\hline 1109 & SE-12-Fis & Kullen & Kattegat & $\begin{array}{l}\text { Atlantic herring, Clupea harengus, } \\
\text { muscle }\end{array}$ & 2011-10-06 & 56 & 19.497 & $\mathrm{~N}$ & 12 & 22.855 & $\mathrm{E}$ \\
\hline 1112 & SE-13-Egg & St.Karlsö & Baltic Sea & Common Guillemot, Uria aalge, egg & 2011-05-06 & 57 & 16.975 & $\mathrm{~N}$ & 17 & 58.462 & E \\
\hline 1113 & SE-14-Egg & St.Karlsö & Baltic Sea & Common Guillemot, Uria aalge, egg & 2011-05-06 & 57 & 16.975 & $\mathrm{~N}$ & 17 & 58.462 & $\mathrm{E}$ \\
\hline
\end{tabular}

Sample ident. suffix: Eff=Effluent, Inf=influent, Slu=Sludge, Sed=Sediment, Fis=Fish, Egg=Eggs 
10.3 Appendix 3 Individual results, plasticisers

\begin{tabular}{|c|c|c|c|c|c|c|c|c|c|c|c|c|c|c|c|c|}
\hline MR\# & Sample ident. & Location & Unit & DBP & BBP & DEHP & L79P & DOP & DINP & DIDP & DUP & DEHA & DINA & BOA & DBEEA & DEHZ \\
\hline 9517 & DK-1-Eff & Esbjerg & $\mathrm{ng} / \mathrm{l}$ & 110 & 110 & 1,100 & 270 & $<20$ & 160 & $<100$ & $<20$ & 39 & $<20$ & $<130$ & $<150$ & $<15$ \\
\hline 9492 & DK-2-Eff & Odense & $\mathrm{ng} / \mathrm{l}$ & 140 & 29 & 800 & $<50$ & $<20$ & $<80$ & $<100$ & $<20$ & $<25$ & $<20$ & $<130$ & $<150$ & $<15$ \\
\hline 9491 & DK-3-Eff & Vordingborg & $\mathrm{ng} / \mathrm{l}$ & $<50$ & 20 & $<200$ & $<50$ & $<20$ & $<80$ & $<100$ & $<20$ & $<25$ & $<20$ & $<130$ & $<150$ & $<15$ \\
\hline 9518 & DK-4-Slu & Esbjerg & $\mu g / \mathrm{kg} d w$ & 35 & 160 & 18,000 & $<8$ & 23 & 50,000 & 9,900 & $<20$ & 19 & $<8$ & $<200$ & $<100$ & $<10$ \\
\hline 9494 & DK-5-Slu & Odense & $\mu g / \mathrm{kg} \mathrm{dw}$ & 80 & 190 & 17,000 & 68 & 59 & 49,000 & 14,000 & $<20$ & 30 & $<8$ & $<200$ & $<100$ & $<10$ \\
\hline 9728 & DK-7-Sed & Øresund & $\mu g / \mathrm{kg} \mathrm{dw}$ & 8.6 & $<4$ & $<80$ & $<8$ & $<5$ & 92 & $<20$ & $<10$ & $<1$ & $<10$ & $<50$ & $<50$ & $<5$ \\
\hline 9729 & DK-8-Sed & Kolding Fjord & $\mu g / \mathrm{kg} \mathrm{dw}$ & 41 & 12 & 300 & $<8$ & $<5$ & 490 & 63 & $<10$ & 3 & $<10$ & $<50$ & $<50$ & $<5$ \\
\hline 9730 & DK-9-Sed & Limfjorden & $\mu g / \mathrm{kg} \mathrm{dw}$ & $<8$ & $<4$ & 110 & $<8$ & $<5$ & 59 & $<20$ & $<10$ & $<1$ & $<10$ & $<50$ & $<50$ & $<5$ \\
\hline 9731 & DK-10-Fis & Ho bugt & $\mu g / \mathrm{kg} \mathrm{ww}$ & $<4$ & $<2$ & $<4$ & $<2$ & $<2$ & $<40$ & $<40$ & $<6$ & $<30$ & $<8$ & $<40$ & $<5$ & $<2$ \\
\hline 9732 & DK-11-Fis & Hjelm bugt & $\mu g / \mathrm{kg} \mathrm{ww}$ & 9.3 & $<2$ & 5.5 & $<2$ & $<2$ & 87 & $<40$ & $<6$ & $<30$ & $<8$ & $<40$ & $<5$ & $<2$ \\
\hline 9733 & DK-12-Fis & Agers $\varnothing$ & $\mu g / \mathrm{kg} \mathrm{ww}$ & 7.4 & $<2$ & 9.2 & $<2$ & $<2$ & $<40$ & $<40$ & $<6$ & $<30$ & $<8$ & $<40$ & $<5$ & $<2$ \\
\hline 9544 & Fl-1-Eff & Turku & $\mathrm{ng} / \mathrm{l}$ & 74 & 64 & 720 & $<50$ & 22 & 120 & $<100$ & $<20$ & 54 & $<20$ & $<130$ & $<150$ & $<15$ \\
\hline 9545 & FI-2-Eff & Helsinki & $\mathrm{ng} / \mathrm{l}$ & 300 & 170 & 2200 & $<50$ & 26 & 450 & 220 & $<20$ & 43 & $<20$ & $<130$ & $<150$ & $<15$ \\
\hline 9546 & FI-3-Eff & Tampere & $\mathrm{ng} / \mathrm{l}$ & 79 & 90 & 2400 & $<50$ & 22 & 350 & 110 & $<20$ & 120 & $<20$ & $<130$ & $<150$ & $<15$ \\
\hline 9644 & FI-4-Slu & Turku & $\mu g / k g d w$ & 330 & 1,100 & 67,000 & 370 & 220 & 160,000 & 32,000 & $<20$ & 27 & $<8$ & $<200$ & $<100$ & $<10$ \\
\hline 9645 & Fl-5-Slu & Helsinki & $\mu g / k g d w$ & 140 & 190 & 33,000 & 210 & 150 & 97,000 & 25,000 & $<20$ & $<10$ & $<8$ & $<200$ & $<100$ & $<10$ \\
\hline 9646 & Fl-6-Slu & Tampere & $\mu g / k g d w$ & 86 & 610 & 36,000 & $<8$ & 53 & 52,000 & 4,900 & $<20$ & 180 & $<8$ & $<200$ & $<100$ & $<10$ \\
\hline 9647 & Fl-7-Sed & Turku & $\mu g / k g d w$ & 110 & 7.6 & 1300 & 15 & 8.2 & 3500 & 510 & $<10$ & 1.8 & $<10$ & $<50$ & $<50$ & $<5$ \\
\hline 9648 & Fl-8-Sed & Tampere & $\mu g / k g d w$ & 54 & 17 & 3700 & $<8$ & 12 & 3800 & 660 & $<10$ & 5 & $<10$ & $<50$ & $<50$ & $<5$ \\
\hline 9649 & Fl-9-Sed & Helsinki & $\mu g / k g d w$ & 15 & 16 & 1300 & $<8$ & $<5$ & 3200 & 940 & $<10$ & 2.6 & $<10$ & $<50$ & $<50$ & $<5$ \\
\hline 9650 & Fl-10-Fis & Tampere & $\mu g / \mathrm{kg} \mathrm{ww}$ & $<4$ & $<2$ & 7.4 & $<2$ & $<2$ & $<40$ & $<40$ & $<6$ & $<30$ & $<8$ & $<40$ & $<5$ & $<2$ \\
\hline 9651 & Fl-11-Fis & Kuhmoinen & $\mu g / \mathrm{kg} \mathrm{ww}$ & $<4$ & $<2$ & 4.1 & $<2$ & $<2$ & $<40$ & $<40$ & $<6$ & $<30$ & $<8$ & $<40$ & $<5$ & $<2$ \\
\hline 9652 & Fl-12-Fis & Turku Archipelago & $\mu g / \mathrm{kg} \mathrm{ww}$ & $<4$ & $<2$ & $<4$ & $<2$ & $<2$ & $<40$ & $<40$ & $<6$ & $<30$ & $<8$ & $<40$ & $<5$ & $<2$ \\
\hline 9629 & FO-1-Eff & Torshavn & $\mathrm{ng} / \mathrm{l}$ & 140 & 140 & 12,000 & $<50$ & 41 & 27,000 & 4,000 & $<20$ & 49 & 120 & $<130$ & $<150$ & $<15$ \\
\hline 9630 & FO-2- Inf & Torshavn & $\mathrm{ng} / \mathrm{l}$ & 180 & 130 & 62,000 & $<50$ & $<20$ & 3100 & 1,500 & $<20$ & $<25$ & $<20$ & $<130$ & $<150$ & $<15$ \\
\hline 9631 & FO-3-Eff & Klaksvik & $\mathrm{ng} / \mathrm{l}$ & 200 & 99 & 15,000 & $<50$ & 39 & 8100 & 1,400 & $<20$ & 44 & 270 & $<130$ & $<150$ & $<15$ \\
\hline 9632 & FO-4-Slu & Torshavn & $\mu g / k g d w$ & 130 & 270 & 14,000 & $<8$ & 62 & 96,000 & 8,600 & $<20$ & 64 & $<8$ & $<200$ & $<100$ & $<10$ \\
\hline 9633 & FO-5-Slu & Torshavn & $\mu g / k g d w$ & 110 & 160 & 12,000 & $<8$ & $<10$ & 17,000 & 1,800 & $<20$ & 28 & $<8$ & $<200$ & $<100$ & $<10$ \\
\hline 9634 & FO-6-Sed & Torshavn & $\mu g / k g ~ d w$ & 120 & 670 & 3,700 & $<8$ & $<5$ & 5200 & 20,000 & $<10$ & 11 & $<10$ & $<50$ & $<50$ & $<5$ \\
\hline 9635 & FO-7-Sed & Torshavn & $\mu g / k g d w$ & 410 & 3,000 & 9,500 & $<8$ & 11 & 17,000 & 36,000 & $<10$ & 26 & $<10$ & $<50$ & $<50$ & $<5$ \\
\hline 9636 & FO-8-Sed & Kollafjord & $\mu g / \mathrm{kg} \mathrm{dw}$ & 40 & 17 & 320 & $<8$ & $<5$ & 590 & 110 & $<10$ & $<1$ & $<10$ & $<50$ & $<50$ & $<5$ \\
\hline 9637 & FO-9-Sed & Klaksvik & $\mu g / \mathrm{kg} \mathrm{dw}$ & 31 & 410 & 1,000 & $<8$ & $<5$ & 1300 & 1,200 & $<10$ & 13 & $<10$ & $<50$ & $<50$ & $<5$ \\
\hline 9641 & FO-12-Fis & Lake á Mýrunum & $\mu g / \mathrm{kg} \mathrm{ww}$ & 4.2 & $<2$ & 53 & $<2$ & $<2$ & $<40$ & $<40$ & $<6$ & $<30$ & $<8$ & $<40$ & $<5$ & $<2$ \\
\hline 9642 & FO-13-Egg & Skúvoy & $\mu g / \mathrm{kg} \mathrm{ww}$ & $<4$ & $<2$ & $<4$ & $<2$ & $<2$ & 160 & $<40$ & $<6$ & $<30$ & $<8$ & $<40$ & $<5$ & $<2$ \\
\hline 9643 & FO-14-Egg & Koltur & $\mu g / \mathrm{kg} \mathrm{ww}$ & 5.3 & $<2$ & $<4$ & $<2$ & $<2$ & 120 & $<40$ & $<6$ & $<30$ & $<8$ & $<40$ & $<5$ & $<2$ \\
\hline 1384:1 & FO-15-Fis & NW on Faroe shelf & $\mu g / k g ~ w w$ & 130 & $<2$ & 92 & $<2$ & $<2$ & $<40$ & $<40$ & $<6$ & $<30$ & $<8$ & $<10$ & $<5$ & $<2$ \\
\hline 1384:2 & FO-16-Fis & NW on Faroe shelf & $\mu g / \mathrm{kg} \mathrm{ww}$ & 4.3 & $<2$ & 26 & $<2$ & $<2$ & $<40$ & $<40$ & $<6$ & $<30$ & $<8$ & $<10$ & $<5$ & $<2$ \\
\hline 1384:3 & FO-17-Fis & NW on Faroe shelf & $\mu g / \mathrm{kg} \mathrm{ww}$ & $<4$ & $<2$ & 40 & $<2$ & $<2$ & $<40$ & $<40$ & $<6$ & $<30$ & $<8$ & $<10$ & $<5$ & $<2$ \\
\hline 1384:4 & FO-18-Fis & NW on Faroe shelf & $\mu g / \mathrm{kg} \mathrm{ww}$ & $<4$ & $<2$ & 17 & $<2$ & $<2$ & $<40$ & $<40$ & $<6$ & $<30$ & $<8$ & $<10$ & $<5$ & $<2$ \\
\hline 1384:5 & FO-19-Fis & NW on Faroe shelf & $\mu g / \mathrm{kg} \mathrm{ww}$ & $<4$ & $<2$ & 26 & $<2$ & $<2$ & $<40$ & $<40$ & $<6$ & $<30$ & $<8$ & $<10$ & $<5$ & $<2$ \\
\hline 9533 & IS-4-Slu & Hveragerđi & $\mu g / \mathrm{kg} \mathrm{dw}$ & 84 & 210 & 21,000 & 130 & 60 & 98,000 & 19,000 & $<20$ & 31 & 400 & $<200$ & $<100$ & $<10$ \\
\hline 9534 & IS-5-Slu & Borg - Grímsnesi & $\mu g / k g d w$ & 280 & 340 & 16,000 & $<8$ & $<10$ & 130,000 & 12,000 & $<20$ & 180 & $<8$ & $<200$ & $<100$ & $<10$ \\
\hline 9535 & IS-6-Slu & Klettagarðar - Reyk. & $\mu g / \mathrm{kg} \mathrm{dw}$ & 610 & 630 & 16,000 & $<8$ & 48 & 69,000 & 6,700 & 230 & 970 & 1,100 & $<200$ & $<100$ & 32 \\
\hline 9536 & IS-7-Sed & pingvallavatn & $\mu g / \mathrm{kg} \mathrm{dw}$ & $<8$ & $<4$ & $<80$ & $<8$ & $<5$ & $<30$ & $<20$ & $<10$ & $<1$ & $<10$ & $<50$ & $<50$ & $<5$ \\
\hline
\end{tabular}




\begin{tabular}{|c|c|c|c|c|c|c|c|c|c|c|c|c|c|c|c|c|}
\hline MR\# & Sample ident. & Location & Unit & DBP & BBP & DEHP & L79P & DOP & DINP & DIDP & DUP & DEHA & DINA & BOA & DBEEA & DEHZ \\
\hline 9537 & IS-8-Sed & Grafarvogur - Reyk. & $\mu g / k g d w$ & 110 & 25 & 1,100 & $<8$ & $<5$ & 5,200 & 880 & $<10$ & 1.8 & $<10$ & $<50$ & $<50$ & $<5$ \\
\hline 9538 & IS-9-Sed & Naustavogur - Reyk. & $\mu g / k g d w$ & 400 & 56 & 2,100 & $<8$ & $<5$ & 5,000 & 1,300 & $<10$ & 4.5 & $<10$ & $<50$ & $<50$ & $<5$ \\
\hline 9539 & IS-10-Fis & Pingvallavatn & $\mu g / k g$ ww & $<4$ & $<2$ & $<4$ & $<2$ & $<2$ & $<40$ & $<40$ & $<6$ & $<30$ & $<8$ & $<40$ & $<5$ & $<2$ \\
\hline 9540 & IS-11-Fis & Pingvallavatn & $\mu g / \mathrm{kg} w w$ & 6.3 & $<2$ & 7.9 & $<2$ & $<2$ & 290 & 410 & $<6$ & $<30$ & $<8$ & $<40$ & $<5$ & $<2$ \\
\hline 9541 & IS-12-Fis & Iceland Seas & $\mu \mathrm{g} / \mathrm{kg}$ ww & $<4$ & $<2$ & $<4$ & $<2$ & $<2$ & $<40$ & 55 & $<6$ & $<30$ & $<8$ & $<40$ & $<5$ & $<2$ \\
\hline 9495 & NO-1-Eff & Gjøvik & $\mathrm{ng} / \mathrm{l}$ & 500 & 600 & 1,600 & $<50$ & $<20$ & 610 & 180 & $<20$ & $<25$ & $<20$ & $<130$ & $<150$ & $<15$ \\
\hline 9496 & NO-2-Eff & Gjøvik & $\mathrm{ng} / \mathrm{l}$ & 490 & 570 & 970 & $<50$ & 23 & 620 & 200 & $<20$ & $<25$ & $<20$ & $<130$ & $<150$ & $<15$ \\
\hline 9497 & NO-3-Eff & Gjøvik & $\mathrm{ng} / \mathrm{l}$ & 510 & 610 & 1,300 & $<50$ & $<20$ & 620 & 170 & $<20$ & 61 & $<20$ & $<130$ & $<150$ & $<15$ \\
\hline 9499 & NO-4-Slu & Gjøvik & $\mu g / k g d w$ & 28 & 81 & 24,000 & $<8$ & 74 & 74,000 & 14,000 & 1,200 & 21 & $<8$ & $<200$ & $<100$ & $<10$ \\
\hline 9500 & NO-5-Slu & Gjøvik & $\mu g / k g d w$ & 43 & 82 & 24,000 & $<8$ & 78 & 77,000 & 15,000 & 1,400 & 36 & $<8$ & $<200$ & $<100$ & $<10$ \\
\hline 9501 & NO-6-Slu & Gjøvik & $\mu g / k g d w$ & 27 & 88 & 23,000 & $<8$ & 81 & 68,000 & 14,000 & 1,400 & 13 & $<8$ & $<200$ & $<100$ & $<10$ \\
\hline 9604 & NO-7-Sed & Bergen & $\mu g / k g d w$ & 95 & $<4$ & 1,300 & 29 & 5.6 & 2,300 & 370 & $<10$ & 5.1 & $<10$ & $<50$ & $<50$ & $<5$ \\
\hline 9605 & NO-8-Sed & Bergen & $\mu g / k g d w$ & 98 & 230 & 2,900 & $<8$ & 10 & 2,300 & 850 & 58 & 27 & $<10$ & $<50$ & $<50$ & $<5$ \\
\hline 9606 & NO-9-Sed & Bergen & $\mu g / k g d w$ & 99 & 25 & 480 & $<8$ & $<5$ & 400 & 77 & $<10$ & 4 & $<10$ & $<50$ & $<50$ & $<5$ \\
\hline 9657 & NO-10-Fis & Vingrom & $\mu g / \mathrm{kg} w w$ & 30 & $<2$ & 30 & $<2$ & $<2$ & 110 & $<40$ & $<6$ & $<30$ & $<8$ & $<40$ & $<5$ & $<2$ \\
\hline 9658 & NO-11-Fis & Vingrom & $\mu g / k g$ ww & 8.9 & $<2$ & 22 & $<2$ & $<2$ & $<40$ & $<40$ & $<6$ & $<30$ & $<8$ & $<40$ & $<5$ & $<2$ \\
\hline 9659 & NO-12-Fis & Vingrom & $\mu g / \mathrm{kg} w w$ & $<4$ & $<2$ & 7.3 & $<2$ & $<2$ & $<40$ & $<40$ & $<6$ & $<30$ & $<8$ & $<40$ & $<5$ & $<2$ \\
\hline 9628 & SE-1-Eff & Umeå & $\mathrm{ng} / \mathrm{l}$ & 90 & 170 & 5,300 & $<50$ & 46 & 490 & 200 & $<20$ & 97 & $<20$ & $<130$ & $<150$ & $<15$ \\
\hline 9597 & SE-2-Eff & Göteborg & $\mathrm{ng} / \mathrm{l}$ & $<50$ & 62 & 1,500 & $<50$ & 59 & 170 & $<100$ & $<20$ & 1,300 & $<20$ & $<130$ & $<150$ & $<15$ \\
\hline 9598 & SE-3-Eff & Borås & $\mathrm{ng} / \mathrm{l}$ & $<50$ & 130 & 2,300 & $<50$ & 21 & 530 & 370 & $<20$ & 59 & $<20$ & $<130$ & $<150$ & $<15$ \\
\hline 9532 & SE-4-Slu & Umeå & $\mu \mathrm{g} / \mathrm{kg} \mathrm{dw}$ & 51 & 380 & 45,000 & $<8$ & 110 & 74,000 & 19,000 & 870 & 48 & 620 & $<200$ & $<100$ & $<10$ \\
\hline 9599 & SE-5-Slu & Göteborg & $\mu g / k g d w$ & 42 & 84 & 27,000 & 390 & 190 & 71,000 & 20,000 & $<20$ & 21 & $<8$ & $<200$ & $<100$ & $<10$ \\
\hline 9600 & SE-6-Slu & Borås & $\mu g / k g d w$ & 110 & 460 & 28,000 & $<8$ & 110 & 71,000 & 42,000 & $<20$ & 14 & 430 & $<200$ & $<100$ & $<10$ \\
\hline 9601 & SE-7-Sed & Göteborg & $\mu g / k g d w$ & 8.3 & $<4$ & 800 & 15 & $<5$ & 1,900 & 510 & 21 & 3.8 & $<10$ & $<50$ & $<50$ & $<5$ \\
\hline 9602 & SE-8-Sed & Göteborg & $\mu g / k g d w$ & $<8$ & $<4$ & 170 & $<8$ & $<5$ & 320 & 55 & $<10$ & $<1$ & $<10$ & $<50$ & $<50$ & $<5$ \\
\hline 9593 & SE-9-Sed & Strömstad & $\mu g / k g d w$ & 45 & $<4$ & $<80$ & $<8$ & $<5$ & 39 & 25 & $<10$ & $<1$ & $<10$ & $<50$ & $<50$ & $<5$ \\
\hline 9614 & SE-10-Fis & Göteborg & $\mu g / \mathrm{kg} w w$ & 16 & $<2$ & 27 & $<2$ & $<2$ & 140 & $<40$ & $<6$ & $<30$ & $<8$ & $<40$ & $<5$ & $<2$ \\
\hline 1108 & SE-11-Fis & Holmöarna & $\mu g / \mathrm{kg} w w$ & $<4$ & $<2$ & 13 & $<2$ & $<2$ & $<40$ & $<40$ & $<6$ & $<30$ & $<8$ & $<40$ & $<5$ & $<2$ \\
\hline 1109 & SE-12-Fis & Kullen & $\mu g / k g$ ww & 23 & $<2$ & 16 & $<2$ & $<2$ & $<40$ & $<40$ & $<6$ & $<30$ & $<8$ & $<40$ & $<5$ & $<2$ \\
\hline 1112 & SE-13-Egg & St. Karlsö & $\mu g / \mathrm{kg} w w$ & 4.2 & $<2$ & $<4$ & $<2$ & $<2$ & $<40$ & $<40$ & $<6$ & $<30$ & $<8$ & $<40$ & $<5$ & $<2$ \\
\hline 1113 & SE-14-Egg & St. Karlsö & $\mu g / k g$ ww & $<4$ & $<2$ & $<4$ & $<2$ & $<2$ & $<40$ & $<40$ & $<6$ & $<30$ & $<8$ & $<40$ & $<5$ & $<2$ \\
\hline
\end{tabular}




\subsection{Appendix 4 Individual results, optional plasticisers}

\begin{tabular}{|c|c|c|c|c|c|c|}
\hline MR\# & Sample ident. & Location & Unit & DIBP & DPHP & DIDP \\
\hline 9517 & DK-1-Eff & Esbjerg & $\mathrm{ng} / \mathrm{l}$ & $<130$ & $<20$ & $<130$ \\
\hline 9492 & DK-2-Eff & Odense & $\mathrm{ng} / \mathrm{l}$ & $<130$ & $<20$ & $<130$ \\
\hline 9491 & DK-3-Eff & Vordingborg & $\mathrm{ng} / \mathrm{l}$ & $<130$ & $<20$ & $<130$ \\
\hline 9518 & DK-4-Slu & Esbjerg & $\mu \mathrm{g} / \mathrm{kg} \mathrm{dw}$ & $<200$ & 1,000 & $<200$ \\
\hline 9494 & DK-5-Slu & Odense & $\mu \mathrm{g} / \mathrm{kg} \mathrm{dw}$ & $<200$ & 1,600 & $<200$ \\
\hline 9728 & DK-7-Sed & $\varnothing$ resund & $\mu \mathrm{g} / \mathrm{kg} \mathrm{dw}$ & $<50$ & $<10$ & $<50$ \\
\hline 9729 & DK-8-Sed & Kolding Fjord & $\mu \mathrm{g} / \mathrm{kg} \mathrm{dw}$ & $<50$ & $<10$ & $<50$ \\
\hline 9730 & DK-9-Sed & Limfjorden & $\mu \mathrm{g} / \mathrm{kg} \mathrm{dw}$ & $<50$ & $<10$ & $<50$ \\
\hline 9731 & DK-10-Fis & Ho bugt & $\mu g / k g$ ww & $<40$ & $<5$ & $<40$ \\
\hline 9732 & DK-11-Fis & Hjelm bugt & $\mu \mathrm{g} / \mathrm{kg} w \mathrm{w}$ & $<40$ & $<5$ & $<40$ \\
\hline 9733 & DK-12-Fis & Agers $\varnothing$ & $\mu \mathrm{g} / \mathrm{kg} w \mathrm{w}$ & $<40$ & $<5$ & $<40$ \\
\hline 9544 & Fl-1-Eff & Turku & $\mathrm{ng} / \mathrm{l}$ & $<130$ & $<20$ & $<130$ \\
\hline 9545 & Fl-2-Eff & Helsinki & $\mathrm{ng} / \mathrm{l}$ & $<130$ & $<20$ & $<130$ \\
\hline 9546 & Fl-3-Eff & Tampere & $\mathrm{ng} / \mathrm{l}$ & $<130$ & $<20$ & $<130$ \\
\hline 9644 & Fl-4-Slu & Turku & $\mu \mathrm{g} / \mathrm{kg} \mathrm{dw}$ & $<200$ & 2,200 & $<200$ \\
\hline 9645 & FI-5-Slu & Helsinki & $\mu \mathrm{g} / \mathrm{kg} \mathrm{dw}$ & $<200$ & 3,500 & $<200$ \\
\hline 9646 & FI-6-Slu & Tampere & $\mu \mathrm{g} / \mathrm{kg} \mathrm{dw}$ & $<200$ & 390 & $<200$ \\
\hline 9647 & Fl-7-Sed & Turku & $\mu \mathrm{g} / \mathrm{kg} \mathrm{dw}$ & $<50$ & $<10$ & $<50$ \\
\hline 9648 & FI-8-Sed & Tampere & $\mu \mathrm{g} / \mathrm{kg} \mathrm{dw}$ & $<50$ & $<10$ & $<50$ \\
\hline 9649 & Fl-9-Sed & Helsinki & $\mu \mathrm{g} / \mathrm{kg} \mathrm{dw}$ & $<50$ & $<10$ & $<50$ \\
\hline 9650 & Fl-10-Fis & Tampere & $\mu \mathrm{g} / \mathrm{kg} w \mathrm{w}$ & $<40$ & $<5$ & $<40$ \\
\hline 9651 & FI-11-Fis & Kuhmoinen & $\mu \mathrm{g} / \mathrm{kg} w \mathrm{w}$ & $<40$ & $<5$ & $<40$ \\
\hline 9652 & $\mathrm{FI}-12-\mathrm{Fis}$ & Turku Archipelago & $\mu \mathrm{g} / \mathrm{kg} \mathrm{ww}$ & $<40$ & $<5$ & $<40$ \\
\hline 9629 & FO-1-Eff & Torshavn & $\mathrm{ng} / \mathrm{l}$ & $<130$ & 210 & $<130$ \\
\hline 9630 & FO-2- Inf & Torshavn & $\mathrm{ng} / \mathrm{l}$ & $<130$ & 93 & $<130$ \\
\hline 9631 & FO-3-Eff & Klaksvik & $\mathrm{ng} / \mathrm{l}$ & $<130$ & 88 & $<130$ \\
\hline 9632 & FO-4-Slu & Torshavn & $\mu \mathrm{g} / \mathrm{kg} \mathrm{dw}$ & $<200$ & 650 & $<200$ \\
\hline 9633 & FO-5-Slu & Torshavn & $\mu \mathrm{g} / \mathrm{kg} \mathrm{dw}$ & $<200$ & 93 & $<200$ \\
\hline 9634 & FO-6-Sed & Torshavn & $\mu \mathrm{g} / \mathrm{kg} \mathrm{dw}$ & $<50$ & 27 & $<50$ \\
\hline 9635 & FO-7-Sed & Torshavn & $\mu \mathrm{g} / \mathrm{kg} \mathrm{dw}$ & $<50$ & 250 & $<50$ \\
\hline 9636 & FO-8-Sed & Kollafjord & $\mu \mathrm{g} / \mathrm{kg} \mathrm{dw}$ & $<50$ & $<10$ & $<50$ \\
\hline 9637 & FO-9-Sed & Klaksvik & $\mu \mathrm{g} / \mathrm{kg} \mathrm{dw}$ & $<50$ & 108 & $<50$ \\
\hline 9641 & FO-12-Fis & Lake á Mýrunum & $\mu \mathrm{g} / \mathrm{kg} w \mathrm{w}$ & $<40$ & $<5$ & $<40$ \\
\hline 9642 & FO-13-Egg & Skúvoy & $\mu \mathrm{g} / \mathrm{kg} \mathrm{ww}$ & $<40$ & $<5$ & $<40$ \\
\hline 9643 & FO-14-Egg & Koltur & $\mu \mathrm{g} / \mathrm{kg} w \mathrm{w}$ & $<40$ & $<5$ & $<40$ \\
\hline $1384: 1$ & FO-15-Fis & North-West on the Faroe shelf & $\mu \mathrm{g} / \mathrm{kg} \mathrm{ww}$ & $<40$ & $<5$ & $<40$ \\
\hline $1384: 2$ & FO-16-Fis & North-West on the Faroe shelf & $\mu \mathrm{g} / \mathrm{kg} \mathrm{ww}$ & $<40$ & $<5$ & $<40$ \\
\hline $1384: 3$ & FO-17-Fis & North-West on the Faroe shelf & $\mu \mathrm{g} / \mathrm{kg} w \mathrm{w}$ & $<40$ & $<5$ & $<40$ \\
\hline $1384: 4$ & FO-18-Fis & North-West on the Faroe shelf & $\mu \mathrm{g} / \mathrm{kg} \mathrm{ww}$ & $<40$ & $<5$ & $<40$ \\
\hline $1384: 5$ & FO-19-Fis & North-West on the Faroe shelf & $\mu \mathrm{g} / \mathrm{kg}$ ww & $<40$ & $<5$ & $<40$ \\
\hline 9533 & IS-4-Slu & Hveragerði & $\mu \mathrm{g} / \mathrm{kg} \mathrm{dw}$ & $<200$ & 600 & $<200$ \\
\hline 9534 & IS-5-Slu & Borg - Grímsnesi & $\mu \mathrm{g} / \mathrm{kg} \mathrm{dw}$ & $<200$ & 370 & $<200$ \\
\hline 9535 & IS-6-Slu & Klettagarđar - Reyk. & $\mu \mathrm{g} / \mathrm{kg} \mathrm{dw}$ & $<200$ & 380 & $<200$ \\
\hline 9536 & IS-7-Sed & Pingvallavatn & $\mu \mathrm{g} / \mathrm{kg} \mathrm{dw}$ & $<50$ & $<10$ & $<50$ \\
\hline 9537 & IS-8-Sed & Grafarvogur - Reyk. & $\mu \mathrm{g} / \mathrm{kg} \mathrm{dw}$ & $<50$ & 47 & $<50$ \\
\hline 9538 & IS-9-Sed & Naustavogur - Reyk. & $\mu \mathrm{g} / \mathrm{kg} \mathrm{dw}$ & $<50$ & 140 & $<50$ \\
\hline 9539 & IS-10-Fis & Pingvallavatn & $\mu \mathrm{g} / \mathrm{kg} w \mathrm{w}$ & $<40$ & $<5$ & $<40$ \\
\hline 9540 & IS-11-Fis & Pingvallavatn & $\mu \mathrm{g} / \mathrm{kg} w \mathrm{w}$ & $<40$ & $<5$ & $<40$ \\
\hline 9541 & IS-12-Fis & Iceland Seas & $\mu \mathrm{g} / \mathrm{kg} w \mathrm{w}$ & $<40$ & $<5$ & $<40$ \\
\hline 9495 & NO-1-Eff & Gjøvik & $\mathrm{ng} / \mathrm{l}$ & $<130$ & 24 & $<130$ \\
\hline 9496 & NO-2-Eff & Gjøvik & $\mathrm{ng} / \mathrm{l}$ & $<130$ & 36 & $<130$ \\
\hline 9497 & NO-3-Eff & Gjøvik & $\mathrm{ng} / \mathrm{l}$ & $<130$ & 31 & $<130$ \\
\hline 9499 & NO-4-Slu & Gjøvik & $\mu \mathrm{g} / \mathrm{kg} \mathrm{dw}$ & $<200$ & 1,400 & $<200$ \\
\hline 9500 & NO-5-Slu & Gjøvik & $\mu \mathrm{g} / \mathrm{kg} \mathrm{dw}$ & $<200$ & 1,400 & $<200$ \\
\hline 9501 & NO-6-Slu & Gjøvik & $\mu \mathrm{g} / \mathrm{kg} \mathrm{dw}$ & $<200$ & 1,400 & $<200$ \\
\hline 9604 & NO-7-Sed & Bergen & $\mu \mathrm{g} / \mathrm{kg} \mathrm{dw}$ & $<50$ & $<10$ & $<50$ \\
\hline 9605 & NO-8-Sed & Bergen & $\mu \mathrm{g} / \mathrm{kg} \mathrm{dw}$ & $<50$ & 21 & $<50$ \\
\hline 9606 & NO-9-Sed & Bergen & $\mu \mathrm{g} / \mathrm{kg} \mathrm{dw}$ & $<50$ & $<10$ & $<50$ \\
\hline 9657 & NO-10-Fis & Vingrom & $\mu \mathrm{g} / \mathrm{kg} w \mathrm{w}$ & $<40$ & $<5$ & $<40$ \\
\hline 9658 & NO-11-Fis & Vingrom & $\mu \mathrm{g} / \mathrm{kg} w \mathrm{w}$ & $<40$ & $<5$ & $<40$ \\
\hline 9659 & NO-12-Fis & Vingrom & $\mu \mathrm{g} / \mathrm{kg} \mathrm{ww}$ & $<40$ & $<5$ & $<40$ \\
\hline
\end{tabular}




\begin{tabular}{llllrrr}
\hline MR\# & Sample ident. & Location & Unit & DIBP & DPHP & DIDP \\
\hline 9628 & SE-1-Eff & Umeå & $\mathrm{ng} / \mathrm{l}$ & $<130$ & $<20$ & $<130$ \\
9597 & SE-2-Eff & Göteborg & $\mathrm{ng} / \mathrm{l}$ & $<130$ & $<20$ & $<130$ \\
9598 & SE-3-Eff & Borås & $\mathrm{ng} / \mathrm{l}$ & $<130$ & $<20$ & $<130$ \\
9532 & SE-4-Slu & Umeå & $\mu \mathrm{g} / \mathrm{kg} \mathrm{dw}$ & $<200$ & 1,700 & $<200$ \\
9599 & SE-5-Slu & Göteborg & $\mu \mathrm{g} / \mathrm{kg} \mathrm{dw}$ & $<200$ & 2,100 & $<200$ \\
9600 & SE-6-Slu & Borås & $\mu \mathrm{g} / \mathrm{kg} \mathrm{dw}$ & $<200$ & 2,400 & $<200$ \\
9601 & SE-7-Sed & Göteborg & $\mu \mathrm{g} / \mathrm{kg} \mathrm{dw}$ & $<50$ & 21 & $<50$ \\
9602 & SE-8-Sed & Göteborg & $\mu \mathrm{g} / \mathrm{kg} \mathrm{dw}$ & $<50$ & $<10$ & $<50$ \\
9593 & SE-9-Sed & Strömstad & $\mu \mathrm{g} / \mathrm{kg} \mathrm{dw}$ & $<50$ & $<10$ & $<50$ \\
9614 & SE-10-Fis & Göteborg & $\mu \mathrm{g} / \mathrm{kg} \mathrm{ww}$ & $<40$ & $<5$ & $<40$ \\
1108 & SE-11-Fis & Holmöarna & $\mu \mathrm{g} / \mathrm{kg} \mathrm{ww}$ & $<40$ & $<5$ & $<40$ \\
1109 & SE-12-Fis & Kullen & $\mu \mathrm{g} / \mathrm{kg} \mathrm{ww}$ & $<40$ & $<5$ & $<40$ \\
1112 & SE-13-Egg & St. Karlsö & $\mu \mathrm{g} / \mathrm{kg} \mathrm{ww}$ & $<40$ & $<5$ & $<40$ \\
1113 & SE-14-Egg & St. Karlsö & $\mu \mathrm{g} / \mathrm{kg} \mathrm{ww}$ & $<40$ & $<5$ & $<40$ \\
\hline
\end{tabular}




\subsection{Appendix 5 Sample list, sweeteners}

\begin{tabular}{|c|c|c|c|c|c|c|c|c|c|c|}
\hline \multirow{2}{*}{$\begin{array}{l}\text { MR\# } \\
9517\end{array}$} & \multirow{2}{*}{$\begin{array}{l}\text { Sample } \\
\text { ident. } \\
\text { DK-1-Eff }\end{array}$} & \multirow{2}{*}{$\begin{array}{l}\text { Location } \\
\text { Esbjerg }\end{array}$} & \multirow{2}{*}{$\begin{array}{l}\text { Site } \\
\text { Esbjerg central WWTP }\end{array}$} & \multirow{2}{*}{$\begin{array}{r}\text { Sampling date } \\
2.11 .2011\end{array}$} & \multicolumn{4}{|c|}{$\begin{array}{r}\text { LAT WGS84 } \\
\text { Deg., decimal min. }\end{array}$} & \multicolumn{2}{|c|}{$\begin{array}{r}\text { LONG WGS84 } \\
\text { Deg., decimal min }\end{array}$} \\
\hline & & & & & 55 & 29.223 & $\mathrm{~N}$ & 8 & 25.491 & $\mathrm{E}$ \\
\hline 9492 & DK-2-Eff & Odense & Ejby Mølle WWTP & 24.10.2011 & 55 & 23.576 & $\mathrm{~N}$ & 10 & 25.139 & $\mathrm{E}$ \\
\hline 9491 & DK-3-Eff & Vordingborg & Råbylille strand WWTP & 11.10 .2011 & 54 & 58.196 & $\mathrm{~N}$ & 12 & 23.697 & $\mathrm{E}$ \\
\hline 9518 & DK-4-Slu & Esbjerg & Esbjerg central WWTP & 2.11 .2011 & 55 & 29.223 & $\mathrm{~N}$ & 8 & 25.491 & $\mathrm{E}$ \\
\hline 9494 & DK-5-Slu & Odense & Ejby Mølle WWTP & 24.10 .2011 & 55 & 23.573 & $\mathrm{~N}$ & 10 & 24.499 & $\mathrm{E}$ \\
\hline 9544 & Fl-1-Eff & Turku & Kakolanmäki WWTP & 10.11.2011 & 60 & 26.712 & $\mathrm{~N}$ & 22 & 14.204 & $\mathrm{E}$ \\
\hline 9545 & FI-2-Eff & Helsinki & Viikki WWTP & 14.11.2011 & 60 & 13.544 & $\mathrm{~N}$ & 24 & 59.612 & $\mathrm{E}$ \\
\hline 9546 & Fl-3-Eff & Tampere & Viinikanlahti WWTP & 14.11.2011 & 61 & 29.319 & $\mathrm{~N}$ & 23 & 46.043 & $\mathrm{E}$ \\
\hline 9644 & $\mathrm{Fl}-4-\mathrm{Slu}$ & Turku & Kakolanmäki WWTP & 10.11.2011 & 60 & 26.712 & $\mathrm{~N}$ & 22 & 14.204 & $\mathrm{E}$ \\
\hline 9646 & $\mathrm{FI}-6-\mathrm{Slu}$ & Tampere & Viinikanlahti WWTP & 14.11.2011 & 61 & 29.319 & $\mathrm{~N}$ & 23 & 46.043 & $\mathrm{E}$ \\
\hline 9629 & FO-1-Eff & Torshavn & Sersjantvikin WWTP & 21.11.2011 & 62 & 0.49 & $\mathrm{~N}$ & 6 & 45.717 & w \\
\hline 9630 & FO-2-- $\ln$ & Torshavn & Main Hospital WWTP,INFLUENT! & 21.11.2011 & 62 & 0.098 & $\mathrm{~N}$ & 6 & 46.538 & w \\
\hline 9631 & FO-3-Eff & Klaksvik & Klaksvik Hospital WWTP & 21.11.2011 & 62 & 13.5 & $\mathrm{~N}$ & 6 & 35.47 & w \\
\hline 9632 & FO-4-Slu & Torshavn & Sersjantvikin WWTP & 21.11.2011 & 62 & 0.49 & $\mathrm{~N}$ & 6 & 45.717 & w \\
\hline 9633 & FO-5-Slu & Torshavn & Main Hospital WWTP & 21.11.2011 & 62 & 0.098 & $\mathrm{~N}$ & 6 & 46.538 & w \\
\hline 9533 & IS-4-Slu & Hveragerði & WWTP & 24.10 .2011 & 64 & 59.295 & $\mathrm{~N}$ & 21 & 10.638 & w \\
\hline 9535 & IS-6-Slu & Klettagarđar Reyk. & WWTP & 2.11 .2011 & 64 & 9.324 & $\mathrm{~N}$ & 21 & 52.405 & w \\
\hline 9495 & NO-1-Eff & Gjøvik & Rambekk WWTP & 25.10 .2011 & 60 & 46.35 & $\mathrm{~N}$ & 10 & 42.21 & $\mathrm{E}$ \\
\hline 9496 & NO-2-Eff & Gjøvik & Rambekk WWTP & 25.10 .2011 & 60 & 46.35 & $\mathrm{~N}$ & 10 & 42.21 & $\mathrm{E}$ \\
\hline 9497 & NO-3-Eff & Gjøvik & Rambekk WWTP & 25.10 .2011 & 60 & 46.35 & $\mathrm{~N}$ & 10 & 42.21 & $\mathrm{E}$ \\
\hline 9499 & NO-4-Slu & Gjøvik & Rambekk WWTP & 25.10 .2011 & 60 & 46.35 & $\mathrm{~N}$ & 10 & 42.21 & $\mathrm{E}$ \\
\hline 9500 & NO-5-Slu & Gjøvik & Rambekk WWTP & 25.10 .2011 & 60 & 46.35 & $\mathrm{~N}$ & 10 & 42.21 & $\mathrm{E}$ \\
\hline 9628 & SE-1-Eff & Umeå & Öhn WWTP & 21.11.2011 & 63 & 48.25 & $\mathrm{~N}$ & 20 & 17.5 & $\mathrm{E}$ \\
\hline 9597 & SE-2-Eff & Göteborg & Ryaverken WWTP & 10.11.2011 & 57 & 41.83 & $\mathrm{~N}$ & 11 & 53.5 & $\mathrm{E}$ \\
\hline 9598 & SE-3-Eff & Borås & Gässlösa WWTP & 16.11.2011 & 57 & 42.3 & $\mathrm{~N}$ & 12 & 55.5 & $\mathrm{E}$ \\
\hline 9532 & SE-4-Slu & Umeå & Öhn WWTP & 8.11 .2011 & 63 & 48.25 & $\mathrm{~N}$ & 20 & 17.5 & $\mathrm{E}$ \\
\hline 9599 & SE-5-Slu & Göteborg & Ryaverken WWTP & 10.11.2011 & 57 & 41.83 & $\mathrm{~N}$ & 11 & 53.5 & $\mathrm{E}$ \\
\hline
\end{tabular}

Sample ident. suffix: Eff=Effluent, Slu=Sludge 


\subsection{Appendix 6 Individual results, sweeteners}

\begin{tabular}{|c|c|c|c|c|c|c|c|c|}
\hline MR\# & $\begin{array}{l}\text { Sample } \\
\text { ident. }\end{array}$ & Location & Site & Unit & Aspartam & Cyclamate & Sucralose & Dry weight \\
\hline 9517 & DK-1-Eff & Esbjerg & Esbjerg central WWTP & $\mu \mathrm{g} / \mathrm{l}$ & $<0.06$ & 0.02 & 3.0 & \\
\hline 9492 & DK-2-Eff & Odense & Ejby Mølle WWTP & $\mu \mathrm{g} / \mathrm{l}$ & $<0.05$ & 0.07 & 1.9 & \\
\hline 9491 & DK-3-Eff & Vordingborg & Råbylille strand WWTP & $\mu \mathrm{g} / \mathrm{l}$ & $<0.08$ & 3.9 & 0.69 & \\
\hline 9518 & DK-4-Slu & Esbjerg & Esbjerg central WWTP & $\mu g / k g w ~ w$ & $<1$ & $<0.2$ & 2.3 & $22 \%$ \\
\hline 9494 & DK-5-Slu & Odense & Ejby Mølle WWTP & $\mu \mathrm{g} / \mathrm{kg} \mathrm{w} \mathrm{w}$ & $<1$ & $<0.2$ & 6.7 & $31 \%$ \\
\hline 9544 & Fl-1-Eff & Turku & Kakolanmäki WWTP & $\mu \mathrm{g} / \mathrm{l}$ & $<0.13$ & 0.43 & 5.0 & \\
\hline 9545 & FI-2-Eff & Helsinki & Viikki WWTP & $\mu \mathrm{g} / \mathrm{l}$ & $<0.07$ & 0.87 & 4.2 & \\
\hline 9546 & Fl-3-Eff & Tampere & Vinikanlahti WWTP & $\mu \mathrm{g} / \mathrm{l}$ & $<0.08$ & 0.08 & 3.3 & \\
\hline 9644 & Fl-4-Slu & Turku & Kakolanmäki WWTP & $\mu \mathrm{g} / \mathrm{kg} \mathrm{w} \mathrm{w}$ & $<1$ & 6.8 & 12 & $23 \%$ \\
\hline 9646 & FI-6-Slu & Tampere & Viinikanlahti WWTP & $\mu \mathrm{g} / \mathrm{kg} \mathrm{w} \mathrm{w}$ & $<1$ & $<0.2$ & 3.8 & $30 \%$ \\
\hline 9629 & FO-1-Eff & Torshavn & Sersjantvikin WWTP & $\mu \mathrm{g} / \mathrm{l}$ & $<0.03$ & 1.9 & 0.37 & \\
\hline 9630 & FO-2-Inf & Torshavn & Main Hospital WWTP, INFLUENT! & $\mu \mathrm{g} / \mathrm{l}$ & $<0.23$ & 8.0 & 0.34 & \\
\hline 9631 & FO-3-Eff & Klaksvik & Klaksvik Hospital WWTP & $\mu \mathrm{g} / \mathrm{l}$ & $<0.05$ & 5.7 & 1.0 & \\
\hline 9632 & FO-4-Slu & Torshavn & Sersjantvikin WWTP & $\mu \mathrm{g} / \mathrm{kg} \mathrm{w} \mathrm{w}$ & $<1$ & 3.0 & 2.2 & $19 \%$ \\
\hline 9633 & FO-5-Slu & Torshavn & Main Hospital WWTP & $\mu \mathrm{g} / \mathrm{kg} \mathrm{w} \mathrm{w}$ & $<1$ & 55 & 2.5 & $7 \%$ \\
\hline 9533 & IS-4-Slu & Hveragerði & WWTP & $\mu \mathrm{g} / \mathrm{kg} \mathrm{w} \mathrm{w}$ & $<1$ & 0.80 & 6.9 & $11 \%$ \\
\hline 9535 & IS-6-Slu & Klettagarđar - Reyk. & WWTP & $\mu \mathrm{g} / \mathrm{kg} \mathrm{w} \mathrm{w}$ & $<1$ & 1.4 & 2.1 & $83 \%$ \\
\hline 9495 & NO-1-Eff & Gjøvik & Rambekk WWTP & $\mu \mathrm{g} / \mathrm{l}$ & $<0.18$ & 23 & 3.8 & \\
\hline 9496 & NO-2-Eff & Gjøvik & Rambekk WWTP & $\mu \mathrm{g} / \mathrm{l}$ & $<0.17$ & 25 & 3.4 & \\
\hline 9497 & NO-3-Eff & Gjøvik & Rambekk WWTP & $\mu \mathrm{g} / \mathrm{l}$ & $<0.17$ & 23 & 3.1 & \\
\hline 9499 & NO-4-Slu & Gjøvik & Rambekk WWTP & $\mu \mathrm{g} / \mathrm{kg} \mathrm{w} \mathrm{w}$ & $<1$ & 0.20 & 11 & $25 \%$ \\
\hline 9500 & NO-5-Slu & Gjøvik & Rambekk WWTP & $\mu \mathrm{g} / \mathrm{kg} \mathrm{w} \mathrm{w}$ & $<1$ & 0.20 & 11 & $25 \%$ \\
\hline 9628 & SE-1-Eff & Umeå & Öhn WWTP & $\mu \mathrm{g} / \mathrm{l}$ & $<0.08$ & 0.94 & 2.2 & \\
\hline 9597 & SE-2-Eff & Göteborg & Ryaverken WWTP & $\mu \mathrm{g} / \mathrm{l}$ & $<0.08$ & $<0.01$ & 2.1 & \\
\hline 9598 & SE-3-Eff & Borås & Gässlösa WWTP & $\mu \mathrm{g} / \mathrm{l}$ & $<0.10$ & $<0.01$ & 1.7 & \\
\hline 9532 & SE-4-Slu & Umeå & Öhn WWTP & $\mu \mathrm{g} / \mathrm{kg} \mathrm{w} \mathrm{w}$ & $<1$ & 0.46 & 3.9 & $34 \%$ \\
\hline 9599 & SE-5-Slu & Göteborg & Ryaverken WWTP & $\mu \mathrm{g} / \mathrm{kg} \mathrm{w} \mathrm{w}$ & $<1$ & $<0.2$ & 2.2 & $30 \%$ \\
\hline
\end{tabular}

Sample ident. suffix: Eff=Effluent, Slu=Sludg 


\section{Selected Plasticisers and Additional Sweeteners in the Nordic Environment}

The report Selected plasticisers and additional sweeteners in the Nordic Environment describes the findings of a Nordic environmental study. The study has been done as a screening, that is, it provides a snapshot of the occurrence of selected plasticisers and sweeteners, both in regions most likely to be polluted as well as in some very pristine environments. The plasticisers analysed were long chained phthalates and adipates, and the sweeteners analysed were aspartame, cyclamate and sucralose. The purpose of the screening was to elucidate levels and pathways of hitherto unrecognized pollutants. Thus the samples analysed were taken mainly from sewage lines, but also in recipients and biota, both in assumed hot-spot areas and in background areas. 